$I_{1} B L--29445$

DE9 1000226

Transuranium Elements: A Half Century

\author{
Glenn T. Seaborg \\ Nuclear Science Division \\ Lawrence Berkeley Laboratory \\ University of California \\ Berkeley, California 94720
}

\begin{abstract}
August 1990
Presented at the 200th ACS Meeting, Washington, D.C.

Symposium to Commemorate

the 50th Arniversary of Transuranium Elements
\end{abstract}

This work was supported by the Director, Office of Energy Research, Office of High Energy and Nuclear Physics, Nuclear Physics Division of the U.S. Department of Energy under Contract DEAC03-76SFODO98. 


\title{
Transuranium Elements: A Half Century
}

\author{
Remarks by Glenn T. Seaborg \\ at ACS Symposiuin to Commemorate \\ the 50th Anniversary of Transiranium Elements
}

\author{
Washington, D.C. \\ August 27, 1990
}

We have reached the 50th anniversary of the synthesis and identification (i.e., the "discovery") of the first transuranium elements, neptunium and plutonium. The intervening years have seen the addition of 15 more transuranium elements with the result that this group now consists of 17 known elements, extending from neptunium (atomic number 93) through the unnamed element with atomic number 109.

Thus the addition of the transuranium elements to mankind's natural heritage of elements has led to an expansion of nearly $20 \%$ in the fundamental building blocks of nature. Investigation of these manmade elements beyond uranium has led to a tremendous expansion of our knowledge of atomic and nuclear structure. Each of these elements has a number of known isotopes, all radioactive, the overall total being about 200. Predictions indicate an additional 500 should have half-lives sufficiently long to allow identification (greater than $10^{-6}$ seconds). Synthetic in origin, they are produced in a variety of transmutation reactions by neutrons or charged particles, including heavy ions. (Neptunium and plutonium are, in addition, present in nature in very small concentrations.) There is a total of some 30 isotopes with half-lives long enough to be available in macroscopic (weighable) quantities.

Many of the transuranium elements are produced and isolated in large quantities through the use of neutrons furnished by nuclear fission reactions: plutonium (atomic number 94) in ton quantities; neptunium (93), americium (95), and curium (96) in kilogram quantities; berkelium (97) in 100 milligram quantities; californium (98) in gram quantities; and einsteinium (99) in milligram quantities. Transuranium isotopes have found many practical applications--as nuclear fuel for the large-scale generaticn of electricity, as compact, long-lived power sources for use in space exploration, as means for diagnosis and treatment in the medical area, and as fools in numerous industrial processes. Of particular interest is the unusual chemistry and impact of these heaviest elements on the periodic table. 


\section{Prefission and Fission}

Our initiation into the realm of the transuranium elements came in the spring of 1940, when Edwin M. McMillan and Philip H. Abelson (1) proved that the radioactive product of their fission experiments was actually a new element--the first identifiable member of the transuranium family. In the 50 years following that discovery, teams of scientists have tried to increase our knowledge of nature by expanding the periodic table of the elements. Looking at the events since late 1938 when fission was discovered not only illustrates how much more has been learned, it also helps dispel the idea that good scientists--even top scientists working together--don't miss the obvious answer on occasions.

To really appreciate the number of false starts--the erroneous paths we took toward the discovery of the new elements--we need to go back to the beginning. And the beginning was in 1869, when Dmitri Ivanovich Mendeleev, a Russian chemist, proposed an arrangement of chemical elements that not only took into account similarities among known elements but also provided the framework for predicting thenunknown entries.

Using the periodic table (Figure 1) of the 1930s, Enrico Fermi, the great Italian physicist, thought that if he could operate on uranium some way--transmute it--why couldn't he produce element 93, and maybe element 94? According to this periodic table, elements 93 and 94 would have chemical properties similar to those of rt nium and osmium, respectively. Fermi and coworkers (Emilio Segrè, Edoardo Amaldi, Franco Rasseti and O. D'Agostino) planned to start with the heaviest element, actually bombarding it with neutrons, and then hoped that after it captured a neutron it would emit an electron (that is the same thing as increasing its charge by one), losing a negative charge, and that way go up to element 93 . So they bombarded uranium with neutrons, forming a number of radioactive isotopes. It was, of course, expected that these isotopes would be radioactive because they do not exist on Earth; they had decayed away.

Fermi and his coworkers in 1934 thought that they chemically proved that one of the isotopes, with a half-life of 13 minutes, had chemical properties like those expected for element 93, i.e., chemical properties like those of rhenium (2).

For several years the so-called transuranium elements were the subject of much experimental work and discussion. Experiments in Germany by Otto Hahn, Lise Meitner, and Fritz Strassmann seemed to confirm Fermi's view (3). A series of papers published between 1935 and 1938 reported not only eka-rhenium--that which resembles rhenium--but also eka-osmium, eka-iridium, and eka-platinum (atomic numbers 93, 94, 95 and 96). 
There was, however, one person who didn't believe that these discoveries were transuranium elements. In 1934, Ida Noddack wrote a paper asking if these observations could not be due to isotopes in the middle of the periodic table (4). Fermi had not proved that the decay products were transuranium elements. Even then, however, we didn't see the light. This paper was in the literature from the beginning, and was ignored.

Early in 1939, Hahn and Strassmann described experiments that confirmed that they had observed radioactive barium and lanthanum isotopes as a result of the bombardment of uranium with neutrons (5). Hahn and Strassmann were absolutely nonplussed by their results, and the tone of that 1939 paper was more or less along the lines of: "You're not going to believe this, but this is what we found--actually, when you bombard uranium with neutrons, you get barium." Subsequent work showed that the other radioactivities previously ascribed to transuranium elements are actually also due to uranium fission products.

I remember when this news came to Berkeley. It was reported at what was called the Journal Club in the Physics Department; a meeting I attended every Monday night. Somebody got up and said, "You know, all of these transuranium elements that Hahn and Strassmann have been finding are due to the splitting of uranium in half. .." Before he had finished the sentence, I said to myself, "My God, how stupid we have been! Obviously, that should be the explanation."

\section{First Transuranium Elernents. Neptunium (23) and Plutonium (24)}

With those radioactivities identified as fission products, there were no longer any transuranium elements left. However, in later investigations by Edwin M. McMillan (6) at Berkeley and others elsewhere, one of the radioactivities behaved differently from the others. The beta radioactivity with a half-life of about 2 days did not separate by recoil from thin layers of uranium, as did the energetic fission products, when uranium was bombarded with slow neutrons. Along toward the spring of 1940, McMillan began to come to the conclusion that the 2.3-day activity might actually be due to the daughter of the 23-minute uranium-239 and thus might indeed be an isotope of element 93 with the mass number 239 (93-239). Phil Abelson joined him in this work in the spring of 1940, and together they were able to chemically separate and identify and thus discover (1) element 93 (Figure 2) formed in the following reaction sequences:

$$
{ }_{92}^{239} U \frac{{ }_{92}^{238} U+{ }_{0}^{1} \rightarrow+{ }_{92}^{239} U+\gamma}{t_{1 / 2}=23.5 \mathrm{~min}}{ }^{23993_{t_{1 / 2}}=2.36 d}
$$


They showed that element 93 has chemical properties similar to those of uranium and not similar to those of rhenium as suggested by the periodic table of that time (Figure 1).

Immediately thereafter, during the summer and fall of 1940, McMillan started looking for the daughter product of the 2.3-day activity, which obviously would be the isotope of element 94 with mass number 239 (94-239). Not finding anything he could positively identify as such, he began to bombard uranium with deuterons in the 60-Inch Cyclotron in the hope that he might find a shorter-lived isotope--one of a higher intensity of radioactivity that would be easier to identify as an isotope of element 94 . Before he could finish this project, he was called away to work on radar at M.I.T.

During this time my interest in the tiansuranium elements continued. Since McMillan and I lived only a few rooms apart in the Faculty Club, we saw each other quite often, and, as I recall, much of our conversation, whether in the laboratory, at meals, in the hallway, or even going in and out of the shower, had something to do with element 93 and the search for element 94 . I must say, therefore, that his sudden departure for M.I.T. came as something of a surprise to me--especially since I did not even know when he had gone.

In the meantime, I had asked Arthur Wahl, one of my two graduate students, to begin studying the tracer chemical properties of element 93 with the idea that this might be a good subject for his thesis. My other coworker was Joe Kennedy, fellow instructor at the University and also very interested in the general transuranium problem.

I quote from my diary of Friday, August 30, 1940 (note that in three days we will reach the 50th Anniversary of this date):

"This afternoon Wahl, Kennedy, and I irradiated our first sample of uranium with neutrons to produce the recently discovered isotope $93^{239}$ in order to begin a program of study, by tracer technique, of the chemical properties of element 93. This research and its possible expansion into the search for the next transuranium element, element 94 , may provide a suitable subject for Wahl's Ph.D. thesis. Today's bombardmeint used $5.5 \mathrm{~g}$ uranyl nitrate hexahydrate $\left[\mathrm{UO}_{2}\left(\mathrm{NO}_{3}\right)_{2} 6 \mathrm{H}_{2} \mathrm{O}\right.$ or $\left.\mathrm{UNH}\right]$ placed directly behind a beryllium target bombarded with $16 \mathrm{Mev}$ deuterons in the 60-inch cyclotron. This UNH sample was dissalved in water, and the oxidation-reduction cycle was performed by Wahl in order to isolate the $93^{239}$ from uranium and fission products in order to characterize its radiation and follow its decay to see if it displays the known half-life of $93^{239}, 2.3$ days. Absorption measurements of the radiations in aluminum will be made.

In order to distinguish between this and subsequent bombardments, we intend to use the following nomenclature. Since our primary product of interest is element 93 , our designation in each case will start with 93 followed in turn by a 
number designating the bombardment and a second designating the chemical fraction within that bombardment. Thus, this first bombardment is designated 93 1; the chemical fractions separated are designated 93-1-1, 93-1-2, and so forth. Today the purified element 93 fraction upon which the decay and radiation measurements are being made is being designated 93-1-3."

When I learned that McMillan had gone, I wrote to him asking whether it might not be a good idea if we carried on the work he had started, especially the deuteron bombardment of uranium. He readily assented.

Our first deuteron bombardment of uranium was conducted on December 14, 1940. What we bombarded was a form of uranium oxide, $\mathrm{U}_{3} \mathrm{O}_{8}$, which was literally plastered onto a copper backing plate. From this bombarded material Wahl isolated a chemical fraction of element 93. The radioactivity of this fraction was measured and studied. We observed that it had different characteristics than the radiation from a sample of pure 93-239. The beta-particles, which in this case were due to a mixture of 93-239 and the new isotope of element 93 with mass number 238 (93-238), had a somewhat higher energy than the radiation from pure 93-239 and there was more gamma radiation. But the composite half-life was about the same, namely, 2 days. However, the sample also differed in another very important way from a sample of pure 93-239. Into this sample there grew an alpha-particle-emitting radioactivity. A proportional counter was used to count the alpha-particles to the exclusion of the betaparticles. This work led us to the conclusion that we had a daughter of the new isotope 93-238--a daughter with a half-life of about 50 years and with the atomic number 94 . This is much shorter-lived thar the now known half-life of $94-239$, which is about 24,000 years. The shorter half-life means a higher intensity of alpha-particle emission, which explains why it was so much easier to identify what proved to be the isotope of element 94 with the mass number 238 (94-238). The reactions are:

$$
\begin{gathered}
{ }_{92}^{238} \mathrm{U}+{ }_{1}^{2} \mathrm{H} \rightarrow{ }^{23893}+{ }_{2}^{1} \mathrm{n} \\
23893 \frac{\beta-}{\mathrm{T}_{1 / 2}=2 \mathrm{~d}}{ }^{23894\left(\mathrm{t}_{1 / 2}=50 \mathrm{y}\right)}
\end{gathered}
$$

On January 28,1941 , we sent a short note to Washington describing our initial studies on element 94; this communication also served for later publication in The Physical Review under the names of Seaborg, McMillan, Kennedy, and Wahl(Z). We did not consider, however, that we had sufficient proof at that time to say we had discovered a new element and felt that we had to have chemical proof to be positive. So, during the rest of January, and into February, we attempted to identify this alpha activity chemically.

Our attempts pro ed unsuccessful for some time. We did not find it possible to oxidize the isotope responsible for this alpha radioactivity. I recall that we then asked 
Professor Wendell Latimer, whose office was on the first floor of Gilman Hall, to suggest the strongest oxidizing agent he knew for use in aqueous solution. At his suggestion we used peroxydisulphate with argentic ion as catalyst.

On the stormy night of February 23, 1941, in an experiment that ran well into the next morning, Wahl performed the oxidation which gave us proof that what we had made was chemically different from all other known elements. That experiment, and hence the first chemical identification of element 94, took place in Room 307 of Gilman Hall, the room that was dedicated as a National Historic Landmark, 25 years later. Thus, we showed that the chemical properties of element 94 were similar to those of uranium and not like osmium (as suggested by Figure 1).

The communication to Washington describing this oxidation experiment, which was critical to the discovery of element 94 , was sent on March 7, 1941, and this served for later publication in The Physical Review under the authorship of Seaborg, Wahl, and Kennedy (8) (Figure 3).

How element 94 eventually got the name plutonium is an interesting story and one worth telling. This work was carried on under self-imposed secrecy in view of its potential implications for national security. Following the discovery in February 1941 and well into 1942, we used only the name "element 94" among ourselves and the few other people who knew of the element's existence. But we needed a code name to be used when we might be overheard. Someone suggested "silver" as a code name for element 93, and we decided to use "copper" for element 94. This worked fine until, for some reason I cannot recall now, it became necessary to use real copper in our work. Since we continued to call element 94 "copper" on occasion we had to refer to the real thing as 'honest-to-God-copper."

The first time a true name for element 94 seemed necessary was in writing the report to the Uranium Committee in Washington in March of 1942, which was published later under the authorship of Seaborg and Wahl (2). I remember very clearly the debates within our small group as to what the name should be. It eventually became obvious to us that we should follow the lead of Ed McMillan, who had named element 93 neptunium because Neptune is the next planet after Uranus, which had served as the basis for the naming of uranium 150 years earlier. Thus we should name element 94 for Pluto, the next planet beyond Neptune. But, and this is a little-known story, it seemed to us that one way of using the base name Pluto was to name the element "plutium." We debated the question of whether the name should be "plutium" or "plutonium," the sound of which we liked much better. We finally decided to take the name that sounded better. I think we made a wise choice, and I believe it also etymologically correct.

There was also the matter of the need for a symbol. Here, too, a great deal of debate was engendered because, although the symbol might have been "PI," we liked 
the sound of "Pu"--for the reason you might suspect. We decided on "Pu," and, I might add, we expected a much greater reaction after it was declassified than we ever received.

\section{Fission of Plutonium}

Almost concurrent with this work was the search for, and the demonstration of the fission of, the isotope of major importance--94-239, the radioactive daughter of 93-239. Emilio Segrè (Figure 4) played a major role in this work together with Kennedy, Wahl and me. The importance of element 94 stems from its fission properties and its capability of production in large quantities. This work involved, the 60-Inch Cyclotron, the Old Chemistry Building, the Crocker Laboratory, and the 37-Inch Cyclotron, all of which have by now been removed from the Berkeley campus (Figure 5). The 0.5microgram sample on which the fission of 94-239 was first demonstrated was produced by transmutation of uranium with neutrons from the 60-Inch Cyclotron; it was chemically isolated in rooms in Old Chemistry Building and Crocker Laboratory and in Room 307 Gilman; and the fission counting was done using the neutrons from the $37-$ Inch Cyclotron.

A sampie of uranyl nitrate weighing 1.2 kilograms was distributed in a large paraffin block (neutron-slowing material) placed directly behind the beryllium target of the 60-Inch Cyclotron in the Crocker Laboratory and was bombarded for two days with neutrons produced by the impact of the full $16 \mathrm{Mev}$ deuteron beam on beryllium. The irradiated uranyl nitrate was placed in a continuously-operating glass extraction apparatus, and the uranyl nitrate was extracted into diethyl ether.' Neptunium-239 was isolated from the aqueous layer by use of the oxidation-reduction principle (described in the next section) with lanthanum and cerium fluoride carrier and was reprecipitated six times in order to remove all uranium impurity. Measurement of the radiation from the neptunium-239 made it possible to calculate that 0.5 microgram was present to yield plutonium-239 decay. The resulting alpha activity corresponded to a half-life of 30,000 years for the daughter plutonium-239, in demonstrable agreement with the present best value for the half-life of 24,110 years.

The group first demonstrated, on March 28, 1941, with the sample containing 0.5 microgram of plutonium-239, that this isotope undergoes slow neutron-induced fission with a probability of reaction comparable to that of uranium-235. The sample was placed near the screened window of an ionization chamber that could detect the fissions of plutonium-239. Neutrons were then produced near the sample by bombarding a beryllium target with deuterons in the 37-Inch Cyclotron of Berkeley's "Old Radiation Laboratory" (the name applied to the original wooden building, since torn down to make way for modern buildings). Paraffin around the sample slowed the neutrons down so they would be captured more readily by the plutonium. This experiment gave a small but detectable fission rate when a six microampere beam of deuterons ivas used. To 
increase the accuracy of the measurement of the fission cross section, this sample, which had about five milligrams of rare-earth carrier materials, was subjected to an oxidation-reduction chemical procedure that reduced the amount of carrier to a few tenths of a milligram. A fission cross section for plutonium-239, some 50 percent greater than that for uranium-235, was found, agreeing remarkably with the accurate values that were determined laier. This result was communciated to Washington on May 29, 1941, and this served as the basis for the later publication of an expurgated version by Kennedy, Segrè, Wahl and me (10).

\section{Eirst Isolation of Plutonium}

The observation that plutonium-239 is fissionable with slow neutrons provided the information that formed the basis for the U.S. wartime Plutonium Project of the Manhattan Engineer District (MED) centered at the Metallurgical Laboratory of the University of Chicago. Given impetus by the entry of the United States into the war in December 1941, I and some of my colleagues moved to Chicago in the spring of 1942. The mission of the Met Lab was to develop (1) a method for the production of plutonium in quantity, and (2) a method for its chemical separation on a large scale.

The key to solving the first problem was the demonstration by Enrico Fermi and his colleagues of the first sustained nuclear chain reaction in uranium on December 2 , 1941.

Important to the solution of the second problem was the determination of the chemical properties of plutonium, an element so new that little was known of its characteristics, and the application of these to the design of a chemical separation process to separate the plutonium from the enormous quantity of fission products and the uranium. I served as leader of the large group of chemists who worked in collaboration with the chemical engineers to solve this problem.

The earlier tracer chemical investigations at Berkelsy, continued at Chicago, served to outline the nature of the chemical separation process. The key was the oxidation-reduction cycle in which plutonium is carried in its lower oxidation state(s) by certain precipitates and not carried by these same precipitates when it is present in its higher oxidation state. Thus, it is separated from the fission products, which do not exhibit this difference in carrying behavior from oxidizing and reducing solutions. However, the carrying properties of plutonium at tracer (extremely small) concentrations might be different at the macroscopic concentrations that would exist under actual operating conditions in the chemical separation plant.

It occurred to me that central to the achievement of such a separation process would be chemical work on concentrations that would exist in the chemical separation plant. This seemed a very far-out lidea, and I can remember a number of people telling 
me that they thought it was essentially impossible bocause we had no large source of plutonium. But I thought we could irradiate large amounts of uranium with the neutrons from cyclotrois since the indications were that we probably could produce sufficient plutonium, if we could learn to work on the microgram or smaller-than-microgram scale. That way we could get concentrations as large as those that would exist in the chemical separation plant.

I knew rather vaguely about two schools of ultramicrochemistry--the School of Anton Benedetti-Pichler at Queens College in New York and the School of Paul Kirk in the Department of Blochemistry at the University of California at Berkeley.

I went to New York in May 1942, looked up Benedetti-Pichler, and told him that I needed a good ultramichrochemist. He introduced me to Michael Cefola, and I offered him a job, which he accepted immediately. That he was on the job about three weeks later illustrates the pace at which things moved in those days.

Then, early in June, I took a trip to Berkeley, where I looked up my friend Paul Kirk and put the same problem to him. I could not tell any of these people why we wanted to work with microgram amounts or what the material was, but this did not seem to deter their willingness to accept. Paul Kirk introduced me to Burris Cunningham. When I asked him if he would come to Chicago, he accepted and was in town by the end of the month. He told me as soon as he arrived that he had a fine student, Louis Werner, he would like to invite, and I was, of course, delighted. Werner came along in a few weeks.

These, then, are the people who began the task of isolating plutonium from large amounts of uranium. We brought from Berkeley a little cyclotron-produced sample prepared by Wahl. It contained a microgram or so of plutonium mixed with several milligrams of rare earths. Using that sample, the ultramicrochemists Cunningham, Cefola, and Werner, isolated the first visible amount--about a microgram--of pure plutonium in the form of the fluoride. It was not weighed, but it could be seen! We were all very excited when we were the first to see a man-made element on August 20, 1942 (Figure 6).

In the meantime, hundreds of pounds of uranium were being bornbarded with neutrons produced by the cyclotron at Washington University, under the leadership of Alex Langsdorf, and at the 60-Inch Cyclotron at Berkeley, under the leadership of Joe Hamilton. This highly radioactive material was then shipped to Chicago. Art Jaffey, Truman Kohman, and Isadore Periman led a team of chemists who put this material through the ether extraction process and the oxidation and reduction cycles to bring it down to a few milligrams of rare earths containing perhaps 100 micrograms of plutonium. This was turned over to Cunningham, Werner and Cefola. These men 
prepared the first sample in pure form by going through the plutonium lodate and the hydroxide, etc., on to the oxide.

This 2.77-microgram sample was weighed on September 10, 1942 (Figure 7). The first aim was to weigh it with a so-called Emich balance, which was somewhat complicated and had electromagnetic compensation features. As it turned out, owing to the heavy load in the shops, this weighing balance would have taken perhaps six months to build.

Cunningham then had the idea of using a simple device consisting of a quartz fiber about 12 centimeters long and $1 / 10$ of a millimeter in diameter suspended at one end with a veighing pan hung on the other end. Then the depression of that end of the fiber with the pan containing the sample would relate to the weight of the sample. Cunningham measured the depression of the quartz fiber with a telescope. He built this balance himself, although iie found out later that an Italian named Salvioni invented it earlier, and so it became known as the Salvioni balance. A description of this first isolation and first weighing of plutonium was published by Cunningham and Werner (11) after World War II.

The chemical separation (extraction) process that finally evolved had three stages: (1) the separation from uranium (extraction) and from the fission products (decontamination) used oxidation-reduction cycles with bismuth phosphate as the carrier precipitate; (2) the concentration (volume reduction) step used an oxidationreduction cycle with rare earth fluoride as the carrier precipitate; (3) the isolation step consisted of the precipitation of pure (carrier-free) plutonium peroxide from acid solution. There was widespread concern that bismuth (IIi) phosphate would not carry plutonium (IV) quantitatively at the concentrations that would exist in the chemical separation plant. The critical experiments on the ultramicro-chemical scale showed that plutonium (IV) phosphate is carried completely ( $>95 \%$ ) at these concentrations. The so-called Bismuth Phosphate Process operated very successfully in both the plutonium pilot plant at Oak Ridge, Tennessee, and the production plant at Hanford, Washington.

\section{The Revised Periodic Table}

At this time we thought that the transuranium elemerits had the same kind of relationship as the rare earths--a new group of rare earths--and there should be 14 of them, with uranium as the prototype. This we would call the uranide series, just like the lanthanide series. It was on this basis that we predicted that element 95 and element 96 would be chemically like plutonium, neptunium and uranium--a little different, but more or less the same. Wrong again! We were just slow learners; we had to proceed by making mistakes. When we tried by transmutation reactions to produce elements 95 and 96 by this method and to identify them chemically, we could not do it. 
In 1944, I got the idea that maybe these elements were misplaced in the periodic table. Perhaps the new heavy rare earth series should start back at thorium (Figure 8) with actinium as its prototype--thus dubbing the collection the actinide series. With such an arrangement the position of elements 95 and 96 would suggest that they be chemically similar to europium and gadolinium. When we tried this idea, we found that it was right. We identified elements 95 and 96. A year later, I published the rearrangement of the periodic table in Chemical and Engineering News (12). I remember at the time that when I showed this table to a number of my friends and said that I was contemplating publishing it in Chemical and Engineering News, they said, "Don't do it, you'll ruin your scientific reputation." I had a great advantage--I didn't have any scientific reputation at the time--so I went ahead and published it.

This concept had great predictive value, and its success led to tha discovery of the remainder of the actinide elements and its acceptance by the scientific community. The modern periodic table contains not only a full lanthanide series, but a full actinide series and transactinide elements as well.

\section{Americium and curium ( 95 and 36 )}

At the wartime Metallurgical Laboratory, after the completion of the most essential part of the chemical investigations involved in the production of plutonium, attention was turned to the synthesis and identification of the next transuranium elements. R. A. James, L. O. Morgan, A. Ghiorso and I were collaborators in this endeavor (Figure 9).

As indicated above, the first attempts to produce these elements ended in failure. Small amounts of ${ }_{94}^{239} \mathrm{Pu}$ were irradiated with neutrons and deuterons but no new $\alpha$ emitting products were found due to the use of insensitive detection techniques and because the experiments were based upon the premise that these elements should behave chemically like plutonium, i.e., they could be oxidized to the Vi oxidation state and chemically isolated. It was not until the summer of 1944, when it was first recognized that these elements were a part of an actinide transition series (with stable +3 oxidation states) that any progress was made. Success in their identification followed quickly.

Once it was realized that these elements could be oxidized above the III state only with difficulty, the use of a proper chemical procedure led quickly to the identification of an isotope of a transplutonium element. Thus, a new $\alpha$-emitting nuclide, now known to be ${ }_{96}^{242} \mathrm{Cm}$ (half-life $162.9 \mathrm{~d}$ ), was produced in the summer of 1944 (12) by the bombardment of ${ }_{94}^{239} \mathrm{Pu}$ with $32-\mathrm{MeV}$ helium ions:

$$
{ }_{94}^{239} \mathrm{Pu}+{ }_{2}^{4} \mathrm{He} \rightarrow{ }_{96}^{242} \mathrm{Cm}+{ }_{0}^{1} \mathrm{n}
$$


The bombardment took place in the Berkeley 60 -inch cyclotron after which the material was shipped to the Metallurgical Laboratory at Chicago for chemical separation and identification. The crucial step in the identification of the $\alpha$-emitting nuclide as an isotope of elernent $96,{ }_{96}^{242} \mathrm{Cm}$, was the identification of the known ${ }_{94}^{238} \mathrm{Pu}$ as the $\alpha$-decay daughter cif the new nuclide.

The identification of an isotope of element 95 , in late 1944 and early 1945 , followed after the identification of this isotope of element $96\left({ }^{242} \mathrm{Cm}\right)$ as a result of the bombardment of ${ }_{94}^{239} \mathrm{Pu}$ with neutrons in a nuclear reactor(13). The production reactions, involving multiple neutron capture by plutonium are:

$$
\begin{gathered}
{ }_{94}^{239} \mathrm{Pu}+{ }_{0}^{1} \mathrm{n} \rightarrow{ }_{94}^{240} \mathrm{Pu}+\gamma \\
{ }_{94}^{240} \mathrm{Pu}+{ }_{0}^{1} \mathrm{n} \rightarrow{ }_{94}^{241} \mathrm{Pu}+\gamma \\
{ }_{94}^{241} \mathrm{Pu} \frac{\mathrm{B}^{-}}{\mathrm{t}_{1 / 2}=14.4 \mathrm{y}}{ }_{95}^{241} \mathrm{Am}\left(\mathrm{t}_{\mathrm{\gamma} / 2}=432.7 \mathrm{y}\right) \\
241 \\
{ }_{95} \mathrm{Am}+{ }_{0}^{1} \rightarrow{ }_{95}^{242} \mathrm{Am}+\gamma \\
{ }_{95}^{242} \mathrm{Am} \underset{\mathrm{t}_{1 / 2}=16.0 \mathrm{~B}}{\vec{B}}{ }_{96}^{242} \mathrm{Cm}
\end{gathered}
$$

A confirmation of the identification of the nuclide $2419 \mathrm{Am}$ involved the physical separation (based L, on volatility) of ${ }_{95}^{241} \mathrm{Am}$ from its parent ${ }_{94}^{24} \mathrm{Pu}$ in a separated mass 241 sample.

Some comments should be made, at this point, concerning the similarity of these two elements to the rare-earth elements. The hypothesis that elements 95 and 96 should have a stable III oxidation state and greatly resemble the rare-earth elements in their chemical properties proved to be true. In fact, the near identity of their properties greatly hindered the efforts of the discovery team. The better part of a year was spent in trying, without success, to separate chemically the two elements from each other and from the fission product and carrier rare-earth elements. Although the discovery team was confident on the basis of their chemical and radioactive properties and the methods of production, that isot ipes of elements 95 and 96 had been produced, the complete chemical proof still was lacking. The elements remained unnamed during this period of futile attempt at separation (although one of the group referred to them as "pandemcnium" and "delirium" in recognition of their difficulties). The key to their chemical separation, which occurred later at Berkeley, and the technique which made feasible the separation and identification of subsequent transuranium elements was the ion-exchange technique.

The present names of these new elements were proposed on the basis of their chemical properties. The name "americium" was suggested for element 95, after the Americas, by analogy with the naming of its rare-earth counterpart or homologue, 
europium, after Europe; and the name "curium" was suggested for element 96, after Pierre and Marie Curie, by analogy with the naming of its homologue, gadolinium, after the Finnish rare-earth chemist J. Gadolin.

By chance, the discovery of these elements was revealed informally on a nationally-broadcast radio program, the Quiz Kids, on which one author appeared as a guest on November 11, 1945 (Figure 10). The discovery information had already been declassified (i.e., removed from the "Secret" category) for presentation at an American Chemical Society symposium at Northwestern University in Chicago the following Friday. Therefore, when one of the youngsters asked--during a session in which one of the authors was trying to answer their questions--if any additional new elements had been discovered in the course of research on nuclear weapons during the war, he was able to reveal the existence of the elements 95 and 96 . Apparently many children in America told their teachers about it the next day, and, judging from some of the letters which the author subsequently received from such yourigsters, they were not entirely successful in convincing their teachers. The formal announcement of the discoveries was, of course, made later in the week, as planned.

\section{Berkelium and californium (97 and 98)}

The story of the discovery of berkelium and californium began shortly after the end of Woild War II. I recall that we began planning for the possible synthesis and identification of transuranium elements as soon as, or even before, we returned to Berkeley from the Chicago Metallurgical Laboratory; i.e., in late 1945 and in 1946. I thought that this would be a good Ph.D. thesis problem for Stan Thompson and it was, of course, natural that Al Ghiorso would participate on the radiation detection end of the problem as he had in the discovery of americium and curium in Chicago a year or two earlier.

On the basis of our confidence in the actinide concept we felt we could make the chemical identification, although we knew we would have to develop better chemical separation methods than were then available to us. And it seemed clear that we would use helium ion bombardments of americium and curium for our production reactions once these elements became available in sufficient quantify through production by prolonged neutron bombardment of plutonium, and we learned how to handle safely their intense radioactivity.

We knew these things, but we didn't anticipate how long it would take to solve these simple problems. Actually, three years went by before we found ourselves ready to make our first realistic experiment.

The most important prerequisite to the process for making the transcurium elements was the manufacture of sufficiently large amounts of americium and curium to 
serve as target material. Because of the intense radioactivity of americium and curium, even in milligram or submilligram amounts, it was necessary to develop extremely efficient chemical separation methods to isolate the new elements from the target materials. This large degree of separation was necessary to detect the very small amounts of radioactivity due to the new elements produced in the presence of the highly radioactive starting materials. The dangerous radioactivity of the source material also made it necessary to institute complicated remote control methods of operation to keep health hazards at a minimum.

These problems were solved after three years work. Americium for target material was prepared in milligram amounts by intense neutron bombardment of plutonium over a long period of time, and curium target materials were prepared in microgram amounts as the result of the intense neutron bombardment of some of this americium. Both of these neutron bombardments took place in high-flux reactors (i.e., reactors that deliver large concentrations of neutrons that can be used for transmutation purposes).

Element 97 was discovered by S. G. Thompson, Ghiorso, and me in December 1949 as the result of the bombardment of milligram quantities of ${ }_{95}^{241} \mathrm{Am}$ with $35 \mathrm{MeV}$ helium ions accelerated in the 60-inch cyclotron at Berkeley (14). The nuclear reaction was

$$
{ }_{95}^{241} \mathrm{Am}+{ }_{2}^{4} \mathrm{He} \rightarrow{ }_{97}^{243} \mathrm{Bk}+2{ }_{1}^{0} \mathrm{n}
$$

The new nuclide was expected to have a short half-life and thus relatively rapid chemical separation techniques had to be employed. For this purpose cation-exchange was used.

The actual discovery experiments were not as simple as this description would indicate. During the fall of 1949 we made a number of bombardments of americium with helium ions in the 60-inch cyclotron, with emphasis on looking for alpha-particle emitting isotopes of element 97 , all with negative results. It was becoming clear that we should look for electron capture decay by detecting the accompanying conversion electrons and $\mathrm{X}$-rays so Ghiorso worked to improve the detection efficiency for such radiations.

The first successful experiment was performed on Monday, December 19, 1949. A target containing 7 milligrams of $241 \mathrm{Am}$ was bombarded with helium ions in the 60 inch cyclotron, after which the chemical separation was started at 10:00 a.m. After the rem.oval of the bulk of the americium by two oxidation cycles (utilizing oxidation to the hexapositive, fluoride-soluble, oxidation state of americium, which had just been discovered by Asprey, Stephanou and Penneman at Los Alamos), the 97, Cm and renlaining Am were carried on lanthanum fluoride, dissolved and subjected to a group separation from fission product lanthanide elements (using a method of elution with 
concentrated $\mathrm{HC} 1$, just discovered by Ken Street), after wihich the actinide fraction was put through a cation exchange adsorption-elution procedure; this entire process was completed in seven hours. The prediction that element 97 would elute ahead of $\mathrm{Cm}$ and $\mathrm{Am}$, in sequence, was of course the key to its successful chemical identification. In this case, and especially in considering the data from following elution experiments, we were somewhat surprised to see the rather large gap between 97 and curium; we shouldn't have been surprised because there is a notably large gap between the elution peaks of the homologous lanthanide elements terbium and gadoliniurn.

Detected in the samples that eluted at the peak corresponding to element 97 were conversion electrons, $X$-rays of energy corresponding to decay by electron capture, and alpha particles at very low relative intensity (iess than $1 \%$ ). These radiations were found to decay with a half-life of about 4.5 hours, and it was immediately assumed that the isotope was 24497 produced by the reaction: ${ }^{241} \mathrm{Am}(\alpha, n)^{24497}$. Soon thereafter it was correctly surmised that the main isotope, that giving rise to the observed alpha particles, was actually $2.43 \mathrm{Bk}$ produced by the reaction ${ }^{241} \mathrm{Am}(\alpha, 2 n)$ $243 \mathrm{BK}$.

It is interesting to note that experiments as early as the first day, i.e., Monday night, indicated that element 97 has two oxidation states, III and IV. The actinide concept provided the guidance to look for these two oxidation states, by analogy with the homologous element, terbium. In fact, the chemical identification procedure had been devised to accommodate either oxidation state and the large gap in the elution positions of element 97 and the curium was at first erroneously thought to be due to the fact that element 97 was in the IV oxidation state at that stage.

Element 98 was first produced and identified similarly by Thompson, K. Street, Jr., Ghiorso, and me (Figure 11), soon afterward in February of 1950, again at Berkeley (15). The first isotope produced is now assigned the mass riumber 245 and decays by alpha-particle emission and orbital electron capture with a half-life of 44 minutes. This isotope was produced by the bombardment of microgram amounts of ${ }_{96}^{242} \mathrm{Cm}$ with 35 . $\mathrm{MeV}$ helium ions accelerated in the 60-inch cyclotron:

$$
{ }_{96}^{242} \mathrm{Cm}+{ }_{2}^{4} \mathrm{He} \rightarrow{ }_{98}^{245} \mathrm{Cf}\left(\mathrm{t}_{1 / 2}=44 \mathrm{~m}\right)+{ }_{0}^{1} \mathrm{n}
$$

It is interesting to note that this identification of element 98 was accomplished with a total of only some 5,000 atoms; someone remarked at the time that this number was substantially smaller than the number of students attending the University of California.

The key to the discovery of element 98 was once again the use of ion-exchange techniques. On the basis of column calibration experiments, elemient 98 was expected to elute onto collection plate \#13 in the 26th and 27 th drops of eluant and this is exactly 
where it was found after a total elapsed chemical separation time of two hours. The half-life and alpha particle energy were also in agreement with predictions.

Element 97 was called berkelium after the city of Berkeley, California, where it was discovered, just as its rare-earth analogue, terbium, was given a name derived from Ytterby, Sweden, where so many of the early rare-earth minerals were found. Element 98 was named californium, after the university and state where the work was done. This latter name, chosen for the reason given, does not reflect the observed chemical analogy of element 98 to dysprosium, as "americium," "curium," and "berkelium" signify that these elements are the chemical analogues of europium, gadolinium, and terbium, respectively. In their announcement of the discovery of element 98 in Physical Review, thre authors commented, "The best we can do is point out, in recognition of the fact that dysprosium is named on the basis of a Greek word meaning 'difficult to gei at:' that the searchers for another element (Au) a century ago found it difficult to get to California."

Upon learning about the naming of these elements, the "Talk of the Town" section of the New Yorker magazine had the following to say:

New atoms are turning up with spectacular, if not downright alarming frequency nowadays, and the University of California at Berkeley, whose scientists have discovered elements 97 and 98 , has christened them berkelium and californium, respectively. While unarguably suited to their place of birth, these names strike us as indicating a surprising lack of public relations foresight on the part of the university, located, as it is, in a state where publicity has flourished to a degree matched perhaps only by evangelism. California's busy scientists will undoubtedly come up with another atom or two one of these days, and the university might well have anticipated that. Now it has lost forever the chance of immortalizing itself in the atomic tables with some such sequence as universitium (97), offium (98), californium (99), berkelium (100).

The discoverers sent the following reply:

"Talk of the Town" has missed the point in their comments on naming of the elements 97 and 98 . We may have shown lack of confidence but no lack of foresight in naming these elements "berkelium" and "californium." By using these names first, we have forestalled the appalling possibility that after naming 97 and 98 "universitium" and "offium," some New Yorker might follow with the discovery of 99 and 100 and apply the names "newium" and "yorkium." 
The answer from the New Yorker staff was brief:

We are already at work in our office laboratories on "newium" and "yorkium"! So far we have just the names.

\section{Einsteinium and fermium (99 and 100)}

The discoveries of many of the transuranium elements were the result of careful planning, taking into account predictions of chemical and physical properties.

Elements 99 and 100 , however, were unexpectedly discovered in debris from the "Mike" thermonuclear explosion which took place in the Pacific on November 1, 1952. This was the first large test of a thermonuclear device. Debris from the explosion was collected, first on filter papers attached to airplanes which flew through the clouds (this sampling effort cost the life of First Lieutenant Jimmy Robinson who waited too long before returning to his base, tried to land on Eniwetok and ditched about a mile short of the runway) and, later in more substantial quantify, gathered up as fall-out material from the surface of a neighboring atoll. This debris was brought to the United States for chemical investigation in a number of laboratories to establish the properties of the explosion.

Early analysis of the "Mike" debris by scientists at the Argonne National Laboratory near Chicago and the Los Alamos Scientific Laboratory in New Mexico showed the unexpected presence of new isotopes of plutonium, ${ }_{94}^{244} \mathrm{Pu}$ and ${ }_{94}^{246} \mathrm{Pu}$. (At the time the heaviest known isotope of plutonium was ${ }_{94}^{243} \mathrm{Pu}$.) This observation led to the conclusion that the ${ }_{92}^{238} \mathrm{U}$ in the device had been subjected to an enormous neutron flux and had successively captured numerous neutrons. (Later calculations showed an integrated neutron fluence of $1-4 \times 10^{24}$ neutrons was delivered in a few nanoseconds-a few moles of neutrons!l)

Armed with the knowledge of the multineutron capture by $238 \mathrm{U}$, we at the University of California immediately began a search for transcalifornium isotopes in the bomb debris. Ion-exchange experiments of the type previously mentioned in the case of berkelium and californium immediately demonstrated the existence of a new element and within a few weeks, of a second new element. The first identification of element 100 was made with only about 200 atoms. To secure a larger amount of source material, it was necessary later to process many hundreds of pounds of coral from orie of the atolls adjoining the explosion area. Eventually, such coral was processed by the ton, using bismuth phosphate as the carrier for the tripositive actinide elements, in a pilot-plant operation which went under the name of "Paydirt."

Without going into the details, it may be pointed out that such experiments involving the groups at the three laboratories led to the positive identification of isotopes 
of elements 99 and 100. A twenty-day activity amitting alpha particles of 6.6-MeV energy was identifled as an isotope of element 99 (with the mass number 253), and a $7.1 \mathrm{MeV}$ alpha activity with a half-life of 22 hours was identified as an isotope of elemeri 100 (with the mass riumber 255).

The path of successive neutron captures by ${ }_{92}^{238} U$ and subsequent $B$ - decay $O^{\prime}$ the capture products is shown in Figure 12. The B-decay chains for each $A$ value ond in the first $B$ stable nuclide. Thus the first isotopes of elements 99 and 100 prodiced in such a device are those with $A=253$ and 255 , respectively.

The large group of scientists who contributed to the discovery of eiorients 99 and 100 included A. Ghiorso, S. G. Thompson, G. H. Higgins, and me from the Riadiation Laboratory and Department of Chemistry of the University of California; M. H. Studier, P. R. Fields, S. M. Fried, H. Diamond, J. F. Mech, G. L. Pyle, J. R. Huizenga, A. Hirsch, and W. M. Manning of the Argonne National Laboratory; and C. I. Browne, H. L. Smith, and R. W. Spence of the Los Alamos Scientific Laboratory (16) (Figure 13). These researchers suggested the name einsteiniurn (symbol E) for element 99 in honor of the great physicist Albert Einstein; , nd for element 100, the name fermium (symbol Fm) in honor of the father of the atomic age, Enrico Fermi, making these the first in a series of elements named after eminent scientists. The chemical symbols Es and Fm, were adopted subsequently for these elements. The choice of name of fermiurn for element 100 has proven to be prescient since it is the last element to be synthesized using neutron capture reactions (which were extensively studied by Fermi).

Before removal of the "secret" label from this information and the subsequent announcement of the original discovery experiments could be accomplished, isotopes of elements 99 and 100 were produced by other, more conventional methods. Chief among these was that of successive neutron capture as the result of intense neutron irradiation of plutonium in the high-flux Materials Testing Reactor (MTR) at the National Reactor Testing Station in Idaho (Figure 14). The difference between this method of production and that of the "Mike" thermonuclear explosion is one of time as well as of starting material. In a reactor, it is necessary to bombard gram quantities of plutonium for two or three years; thus, the short-lived, intermediate isotopes of the various elements have an opportunity to decay. The path of element production proceeds up the valley of $B$ - stability. In the thermonuclear device larger amounts of uranium were subjected to an extremely high neutron flux for a period of nanoseconds; the subsequent beta decay of the ultraheavy isotopes of uranium led to the nuclides found in the debris. 


\section{Mendelevium (101)}

The discovery of mendelevium was one of the most dramatic in the sequence of transuranium element syntheses. It marked the first time in which a new element was produced and identified one atom at a time.

By 1.955 we at Berkeley had prepared an equilibrium amount of $\sim 10^{9}$ atoms of ${ }_{99}^{253}$ Es by neutron irradiation of plutonium in the Materials Testing Reactor. As the result of a "back of the envelope" calculation done by Ghiorso during an airplane flight, we thought it might be possible to prepare element 101 using the reaction

$$
{ }_{99}^{253} \mathrm{Es}+{ }_{2}^{4} \mathrm{He} \rightarrow{ }_{101}^{256}+{ }_{0}^{1} \mathrm{n}
$$

The amount of element 101 expected to be produced in an experiment can be calculated using the formula

$$
N_{101}=\frac{N_{E S} \sigma \phi\left(1-\theta^{-\lambda t}\right)}{\lambda}
$$

where $N_{101}$ and $N_{E s}$ are the number of element 101 atoms produced and the number of ${ }_{99}^{253}$ Es target atoms, respectively, $\sigma$ is the reaction cross section (estimated to be $\sim 10^{-27}$ $\left.\mathrm{cm}^{2}\right), \phi$ the helium ion flux ( $10^{14}$ particles/sec), $\lambda$ the decay constant of ${ }_{101}^{256} \mathrm{Md}$ (estimated to be $\sim 10^{-4} \mathrm{sec}^{-1}$ ) and the length of each bombardment $\left(\sim 10^{4} \mathrm{sec}\right.$ ).

$$
N_{101} \approx \frac{\left(10^{9}\right)\left(10^{-27}\right)\left(10^{14}\right)\left(1-e^{\left.-\left(10^{-4}\right)\left(10^{+4}\right)\right)}\right.}{\left(10^{-4}\right)} \approx 1 \text { atom }
$$

Thus the production of only one atom of element 101 per experiment could be expected!

Adding immeasurably to the complexity of the experiment was the absolute necessity for the chemical separation of the one atom of element 101 from the $10^{9}$ atoms of einsteinium in the target and its ultimate, complete chemical identification by separation with the ion-exchange method. This separation and identification would presumably have to take place in a period of hours, or perhaps even one hour or less, because the expected half-life was of this order of magnitude or less. Furthermore the target material had a 20-day half-life and one needed a non-destructive technique of using the target material over and over again.

These requirements indicated the desperate need for new techniques, together with some luck. Fortunately, both were forthcoming. The first new technique involved separation of the element 101 by the recoil method from the einsteinium in the target. The einsteinium was placed on a gold foil in an invisibly thin layer. The helium-ion beam was sent through the back of the foil so that the atoms of element 101 , recoiling through 
a vacuum due to the momentum of the impinging hellum lons, could be caught on a second thin gold catcher foll. This second gold foil, which contained recoil atoms and was relatively free of the einsteinium target material, was dissolved and was used for later chemical c perations.

The preparation of the $253 \mathrm{Es}$ target for this recoll experiment was another technical tour-de-force. After approximately five failures to prepare the target by vaporization of ${ }^{253} \mathrm{Es}$ from a hot filament, the essentially weightless deposit of ${ }^{253} \mathrm{Es}$ was electroplated onto the Au foil within a very small area.

An extremely reliable ion exchange separation scheme had to be developed to unambiguously chemically identify atoms of a new element that were made. It took several months, involving hundreds of column elutions to develop the appropriate procedure. The final choice was the use of a Dowex 50 lon exchange column run at an elevated temperature $\left(87^{\circ} \mathrm{C}\right)$ with an alpha-hydroxyisobutyrate eluant. The procedure was so well developed that the discovery team could tell exactly in which drops of eluant the interesting activities would appear. Finally the 60 -inch cyclotron ${ }^{4} \mathrm{He}^{2}+$ beam was increased by an order of magnitude in intensity to 100 microamperes per $\mathrm{cm}^{2}$.

The earliest experiments were confined to a search for short-lived, alpha-emitting isotopes that might be due to element 101. For this purpose it was sufficient to look quickly at the actinide chemical fraction as separated by the ion-exchange method. No alpha activity was observed that could be attributed to element 101, even when the time between the end of bombardment and the beginning of the alpha particle analyses had been reduced to five minutes. The experiments were continued and, in one of the subsequent overnight bombardments, two large pulses in the electronic detection apparatus due to spontaneous fission were observed. With probably unjustified selfconfidence, it was thought that this might be a significant result. Although such an attitude might ordinarily have been considered foollsh, it must be recalled that rapid decay by spontaneous fission was--up until that time-..confined to only a few nuclides, none of which should have been introduced spuriously into the experiment. In addition, background counts due to this mode of decay should be zero in proper equipment.

The major question, of course, was whether the experiment could be repeated. In a number of subsequent bombardments, one or two spontaneous fission events were observed in some, while none was observed in other experiments. This, of course, was to be expected, because of the statistical fluctuation inherent in the production of the order of one atom per bombardment. Furthermore, more advanced chemical experiments seemed to indicate that spontaneous fission counts, when they did appear, came in about the element 100 or 101 chemical fractions.

The definitive experiments were performed in a memorable, all-night session, February 18,1955 . To increase the number of events that might be observed at one 
time, three successive three-hour bombardments were made, and, in turn, their transmutation products were quickly and completely separated by the ion-exchange method. Some of the nuclide is $(253,99)$ Es was present in each case so that, together with the ${ }_{98}^{246} \mathrm{Cf}$ produced from ${ }_{96}^{244} \mathrm{Cm}$ also present in the target (via the ${ }^{244} \mathrm{Cm}\left({ }^{4} \mathrm{He}, 2 \mathrm{n}\right)$ reaction), it was possible to define the positions in which the element came off the column used to contain the ion-exchange resin. Five spontaneous fission counters then were used to count simultaneously the corresponding drops of solution from the three runs.

A total of five sporitaneous fission counts were observed in the element 101 position, while a total of eight spontaneous fission counts were also observed in the element 100 position. No such counts were observed in any other position.

The rate of spontaneous fission in both the element 101 and 100 fractions decayed with a half-life of about three hours (later determined to be 160 minutes). This and other evidence led to the hypothesis that this isotope of alement 101 has the mass number 256 and decays, by electron capture (designated by the symbol EC), with a half-life of the order of one-and-one-half hours, to the isotope ${ }_{100}^{2.56} \mathrm{Fm}$, which is responsible for the spontaneous fission decay. The discovery reactions were:

$$
\begin{gathered}
{ }_{99}^{253} \mathrm{Es}+{ }_{2}^{4} \mathrm{He} \rightarrow{ }_{101}^{256} \mathrm{Md}+{ }_{0^{n}} \mathrm{n} \\
{ }_{101}^{256} \mathrm{Md} \frac{{ }_{\mathrm{t}_{1 / 2}}=1.3 \mathrm{~h}}{{ }_{100}^{256} \mathrm{Fm}} \frac{{ }_{100} 56}{\mathrm{t}_{1 / 2}=2.63 \mathrm{~h}} \text { spontaneous fission }
\end{gathered}
$$

On the basis of this evidence and the experiments which led to the production of 17 atoms of element 101, Ghiorso, Harvey, Choppin, Thompson, and I (Figure 15) announced the discovery of element 101 (17). The name mendelevium (symbol Mv) was suggested for the element, in recognition of the role of the great Russian chernist, Dmitri Mendeleev, who was the first to lise the periodic system of the elements to predict the chemical properties of undiscovered elements, a principle which was used in nearly all the transuranium element discovery experiments. The chemical symbol, Md, was later adopted for this element.

It is comforting to be able to record that subsequent experiments using larger amounts of einsteinium in the target led to the production of thousands of atoms of mendelevium, lending confirmation to the sparse evidence on which the original conclusions were made. The indications are clear that, as expected, mendelevium is a typical tripositive actinide element. 


\section{Nobellum (102)}

In 1957 a team of scientists from the Argonne National Laboratory in the United States, the Atomic Energy Research Establishment at Harwell in England and the Nobel Institute of Physics in Stockholm announced the discovery of element 102 based upon work done at the Nobel institute (18). The group reported that in irradlations of ${ }_{96}^{244} \mathrm{Cm}$ with ${ }^{13} \mathrm{C}$, lons accelerated at the Nobel Institute Cyclotron; they found an $8.5 \mathrm{MeV} \alpha$ emitter with a half-life of about 10 minutes, presumably due to the $\mathrm{ls}(244,96) \mathrm{Cm}$ (is $(13$, 6) C, $4 n)$ or ${ }_{96}^{244} \mathrm{Cm}\left({ }_{6}^{13} \mathrm{C}, 6 \mathrm{n}\right)$ reactions. They claimed that this activity had been identified as a new element on the basis of lon-exchange chromatography in which the $8.5 \mathrm{MeV}$ actlvity appeared in the "expected "element 102 position when eluted from a cation exchange column with alpha-hydroxylsobutyrate. The name of nobelium (chemical symbol No) was suggested for the new element in recognition of Alfred Nobel's contributlons to the advancernent of science.

How'ever, neither experiments at Berkeley (19) nor related experiments at the Kurchatov Institute in Moscow, USSR (20) confirmed this Stockholm work. In fact, subsequent experiments done in Berkeley have shown that the most stable oxidation state of element 102 in solution is +2 ; ihus it would not appear in the "expected" element 102 tripositive position in a cation-exchange column.

In 1958 Ghiorso, T Sikkeland, J. R. Walton, and I (21) (Figure 16) announced the positive identiflcation of 102 No produced using the Berkeley heavy lon linear accelerator (HILAC) which they attributed to the reactions

$$
\begin{aligned}
& { }_{96}^{246} \mathrm{Cm}+{ }_{6}^{12} \mathrm{C} \rightarrow{ }_{102}^{254} \mathrm{No}+4{ }_{0}^{1} \mathrm{n} \\
& { }_{102}^{254} \mathrm{No} \underset{\mathrm{t}_{1 / 2} \sim 3 \mathrm{sec}}{\longrightarrow}{ }_{100}^{250} \mathrm{Fm}+{ }_{2}^{4} \mathrm{He}
\end{aligned}
$$

The ${ }_{100}^{250} \mathrm{Fm}$ daughter of the new element was collected using recoll techniques, one atom at a time. Eleven atoms of the $\theta_{100}^{250} \mathrm{Fm}$ daughter were ideritifled by their position in a cation exchange elution curve. A half-lle of $\sim 3$ sec was assigned to 254 No on the basis of many recoil experiments in which an apparent $\alpha$-emitting daughter of ${ }_{102}^{254} \mathrm{No}$ was produced and direct counting of an $8.3 \mathrm{MeV} \alpha$-emitting nuclide with a 3-second half-life. The $8.3 \mathrm{MeV} \alpha$-emitter was found also to decay by spontaneous fission in $30 \%$ of its decays. It is now know that the 3-second activity originally assigned to ${ }_{102}^{254} \mathrm{No}$ in the direct counting experiments was, in fact, ${ }_{102}^{252} \mathrm{No}\left(\mathrm{t}_{1 / 2}=2.3 \mathrm{sec}, \mathrm{E} \alpha=8.4 \mathrm{MeV}\right.$ ) produced by a ${ }_{96}^{244} \mathrm{Cm}\left({ }^{12} \mathrm{C}, 4 \mathrm{n}\right)$ reaction in that the $1246 \mathrm{Cm}$ target" used by Ghiorso et al. had $20 \mathrm{x}$ more ${ }^{244} \mathrm{Cm}$ than $246 \mathrm{Cm}$ in it. ${ }_{102}^{254} \mathrm{No}$ is now known to have a $55 \mathrm{sec}$ half-life.

The experimental claim for discovery of a new element, element 102, however, must be judged upon the observation of the ${ }_{100}^{250} \mathrm{Fm}$ daughter of ${ }_{102}^{254}$ No because this is the only evidence that establishes the atomic number of the new element. The recoil 
studies which assigned a 3-sec half-life to ${ }_{102}^{254} \mathrm{No}$ by observation of what was thought to be ${ }_{100}^{250} \mathrm{Fm}$ were probably erroneous. What was probably being observed was the sequence

$$
{ }_{102}^{252} \mathrm{No}_{\mathrm{t}_{1 / 2}=2.3 \mathrm{s \theta C}}{ }_{100}^{248} \mathrm{Fm}_{\mathrm{t}_{1 / 2}=36 \mathrm{sec}} \frac{\alpha}{98}{ }_{98}^{244} \mathrm{Ct}_{\mathrm{t}_{1 / 2}=19 \mathrm{~min}}
$$

In which the $19 \mathrm{mln} .{ }_{98}^{244} \mathrm{Cf}$ granddaughter $\left(E_{\alpha}=7.21 \mathrm{MeV}\right)$ was mistaken for the $30 \mathrm{~min}$. ${ }_{100}^{250} \mathrm{Fm}(7.43 \mathrm{MeV})$. The lon exchange elution curve showing 11 atoms of ${ }_{100}^{250} \mathrm{Fm}$ to appear in the proper position remains as the first definitive evidence for the production of element 102. The errors in this experiment indicate the difficulties associated with "one-atom-at-a-time" studies.

A parallel lina of research on element 102 was carried out by G. N. Flerov and co-workers in the Kurchatov Institute in the USSR. In an experiment reported in 1958 Flerov et al. studied the reaction of ${ }_{94}^{239}$ Pu with ${ }_{8}^{16} \mathrm{O}$ lons, reporting an alpha-emitter. with $E_{\alpha}=8.9 \mathrm{MeV}$ and $2<t_{1 / 2}<40 \mathrm{sec}$. (22). In $1964 \mathrm{E}$. D. Donets, V. A. Schegolev, and $\checkmark$ A. Ermakov (23) of the Dubna laboratory reported the production of the new isotope ${ }_{2102}^{256}$ No using recoil techniques with chemical ldentlfication of the alpha-emitting daughter ${ }_{100}^{2} \mathrm{Fm}$. The first correct identification of the half-life of ${ }_{102}^{254} \mathrm{No}$ was in $1966-67$ by groups working at Dubna.

In summary one can say that the Berkeley group was the first group to clearly Identify the atomic number of element 102 (l.e., to "discover" it) but important contributions to the definitive establishment of the existence of element 102 were made by the Soviet research scientists. Since the name nobellum and symbol (No) for this element are in common use, the Berkeley sclentists have suggested retention of the name suggested in the original, incorrect Stockholm experiment, and this name and symbol have been accepted by the IUPAC.

\section{Lawrencium (103)--the last actinide element}

The first identification of an isotope of element 103 was by Ghiorso, Sikkeland, A. E. Larsh, and R. M. Latimer in 1961 (24) (Figure 17). Three micrograms of a mixture of callfornium isotopes $(A=249,250,251,252)$ were bombarded with heavy lon beams of ${ }^{10} \mathrm{~B}$ and ${ }^{11} \mathrm{~B}$ at the Berkeley HILAC. Atoms recoilling from the target were caught by a long metallized mylar tape which was moved past a series of $\alpha$-particle detectors. A new $\alpha$-emitting nuclide with $E \alpha=8.6 \mathrm{MeV}$ and $t_{1 / 2} \sim 8 \mathrm{sec}$. was observed and assigned to ${ }_{103}^{257} \mathrm{Lr}$. Later experiments indicated that this activity was due to ${ }_{103}^{258} \mathrm{Lr}(E \alpha=8.6 \mathrm{MeV}$, $t_{1 / 2}=4$. $:$ sec.). 
A subsequent identification of the atomic number of element 103 was made by Donets, Schegolev, and Ermakov at Dubna in 1965 (25). The nuclear reaction used was

$$
{ }_{95}^{243} \mathrm{Am}+{ }_{8}^{18} \mathrm{O} \rightarrow{ }_{103}^{256} \mathrm{Lr}+5_{0}^{1} \mathrm{n}
$$

Using a double recoll technique, they identifled the $\alpha$-emitter ${ }_{103}^{256} \mathrm{Lr}\left(\mathrm{T}_{1 / 2} \sim 45 \mathrm{sec}\right.$.) and linked it genetically to its granddaughter, the known ${ }_{100}^{252} \mathrm{Fm}$ via the decay sequence:

$$
{ }_{103}^{256} \mathrm{Lr} \stackrel{\alpha}{\rightarrow}{ }_{101}^{252} \mathrm{Md} \stackrel{\mathrm{EC}}{\longrightarrow}{ }_{100}^{252} \mathrm{Fm} \stackrel{\alpha}{\stackrel{\alpha}{\longrightarrow}}
$$

The relatively long half-life of ${ }_{103}^{256} \mathrm{Lr}$ (now known to be $\sim 30$ sec.) enabled Silva, Sikkeland, Nurmia, and Ghiorso (26) to establish in 1970 that element 103 exhibits a stable +3 oxidation state in solution, as expected by the actinide concept.

In the report of the original experiments of Ghiorso et al. (24) they suggested the name lawrenclum (subsequently accepted by the IUPAC) and the chemical symbol LW for element 103 in honor of E. O. Lawrence, the inventor of the cyclotron and founder of the Radiation Laboratory at Berkeley where so much of the transuranium research has been carried out. The finally accepted chemical symbol is $L r$.

\section{Rutherfordium and Hahnium (104 and 105)}

There is considerable controversy over the discovery of the elements beyond lawrenclum (103). Flerov and co-workers (27) bombarded ${ }_{94}^{242} \mathrm{Pu}$ with ${ }_{10}^{22} \mathrm{Ne}$ from the Dubna cyclotron and reported finding a nuclide that decayed by spontaneous fission with $t_{1 / 2} \sim 0.3 \mathrm{sec}$. This nuclide was assigned to be 260104 on the basis of nuclear reaction systematics. The name of kurchatovium $(\mathrm{Ku})$ in honor of the Soviet nuclear physicist Igor Kurchatov was suggested later for element 104. Subsequently this group suggested that the half-life of this nuclide was $0.1 \mathrm{sec}$., then $80 \mathrm{~ms}$ and most recently 28 msec. The identification of the atomic number of the new species on the basis of thermochromatography of the chlorides of this element (in a glass column without packing material) was claimed by I. Zvara, K. T. Chuburkov, R. Tsaletka, T. S. Zvarova, M. R. Shalaevskil, and B. V. Shilov in 1966 (28). However, if the half-life of the 260104 nuclide was $28 \mathrm{msec}$, it is impossible that it could have survived passage through the apparatus of Zvara gt al. which involved a $1.2 \mathrm{sec}$. transit time for the volatile chlorides. Furthermore, an important part of the interpretation of the thermochromatography experiment was the assumption of a $0.3 \mathrm{sec}$. half-life for the species being detected. Much later Zvara and co-workers have claimed, in retrospect, that their original experiment probably measured the chemical behavior of 3 sec. ${ }^{259104}$ which would have survived transit through their apparatus. However, in the description of the original thermochromatography experiments, Zvara et al. stated "positively that the half-life could not be 3.7 sec." Because of questions about these thermochromatography 
experiments, many (in particular, see the work of Hyde et al. (29), have regarded these experiments as not providing a definitive characterization of the atomic number of the new specles.

There is little doubt that Ghiorso, M. Nurmia, J. Harris, K. Eskola, and P. Eskola (Figure 18) did definitely produce isotopes of element 104 and identify their atomic number in experiments at Berkeley in 1969 (30). The nuclear reactions involved were

$$
\begin{aligned}
& { }_{98}^{249} \mathrm{Cf}+{ }_{6}^{12} \mathrm{C} \rightarrow{ }_{104}^{257} \mathrm{Rf}\left(\mathrm{t}_{1 / 2} \sim 3.8 \text { sec }\right)+{ }_{0}^{1} \mathrm{n} \\
& { }_{98}^{249} \mathrm{Cf}+{ }_{6}^{13} \mathrm{C} \rightarrow{ }_{104}^{259} \mathrm{Rf}\left(\mathrm{t}_{1 / 2} \sim 3.4 \text { sec. }\right)+3{ }_{0}^{1} n
\end{aligned}
$$

The atomic numbers of the isotopes of element 104 were identified by detecting the known daughters of ${ }_{104}^{257} \mathrm{Rf}$ and ${ }_{104}^{259} \mathrm{Rf},{ }_{102}^{253} \mathrm{No}$ and ${ }_{102}^{255} \mathrm{No}$. This group later suggested the name of rutherfordium (chemical symbol $\mathrm{Rf}$ ) for element 104 in honor of Lord Ernest Rutherford. These results were ronfirmed in subsequent work by E. E. Bemis et al. at Oak Ridge National Laboratory (31).

Studies at Berkeley (by R. Silva, J. Harris, M. Nurmia, K. Eskola, and A. Ghiorso) of the aqueous chemistry of rutherfordium have shown it to behave differently than the heavy actinides. Its solution chemistry resembles that of hafnium and zirconium, in agreement with the idea that rutherfordium is not an actinide but a Group IV slement (32).

Controversy also exists over the discovery of element 105. In 1968 Flerov and co-workers (33) in Dubna reported production of two new alpha-emitters, assigned to be 260105 and 261105 , in the reaction of ${ }_{95}^{243} \mathrm{AnI}$ with ${ }_{10}^{22} \mathrm{Ne}$ ions. The element 105 radioactivities were claimed to be identified by detection of events in which the initial $\alpha$ particles (9.7 and $9.4 \mathrm{MeV}$ ) emitted by the element 105 activities were said to be correlated in time with the $\alpha$-particles emitted by the daughter (element 103) nuclides. A small number of such events ( 10) was observed and the two element 105 nuclides were said to have half-lives in the range $0.1-3$ and $>0.01$ seconds, respectively. The international groups who compile and certify nuclear data have generally considered this work to be inconclusive or possibly wrong because of the small number of observed events and the discrepancy between the reported element 105 alpha-particle energies of 9.7 and $9.4 \mathrm{MeV}$ and those now known to be correct, i.e., 9.1 and $8.9 \mathrm{MeV}$, respectively.

In 1970 A. Ghiorso, M. Nurmia, K. Eskola, J. Harris, and P. Eskola (34) reported the observation of an isotope of element 105 with mass number 260 produced in the following reaction:

$$
{ }_{98}^{249} \mathrm{Cf}+{ }_{7}^{15} \mathrm{~N} \rightarrow{ }_{105}^{260} \mathrm{Ha}\left(\mathrm{t}_{1 / 2}=1.5 \mathrm{sec} .\right)+4_{0}^{1} \mathrm{n}
$$


The $Z$ and $A$ of the element 105 nuclide were unambiguously identified in a manner similar to that used in the discoviary of rutherfordium by observing the time correlation between $\alpha$-particles emitted by the parent (element 105) and those of the known daughter (256Lr). The Berkeley grcup's data combined more than ten times more events than were reported by Flerov et al. Their $\alpha$-particle energies are in agreement with what is currently known about ${ }_{105}^{260} \mathrm{Ha}$. In honor of the German radiochemist Otto Hahn who discovered fission and developed many experimental techniques, the Berkeley group suggested the name of hafnium (symbol $\mathrm{Ha}$ ) for this element. This work was subsequently confirmed by Bemis et al. (35).

At about the same time as the Berkeley work, Flerov, Y. T. Oganessian, Y. V. Lobanov, Y. A. Lasarev, S. P. Tretyakova, I. V. Kolesov, and V. M. Plotko (36) reported the otiservation of a nuclicie with a half-life of $1.8 \pm 0.6 \mathrm{sec}$. (which decayed by spontatineous fission) produced in the reaction ${ }_{95}^{243} \mathrm{Am}$ with ${ }_{10}^{22} \mathrm{Ne}$. On the basis of nuclear reaction systematics and the angular distribution of the observed reaction products, those workers assigned this nuclide to 261105 . This spontaneous fission activity was reported (3Z) to behave as if it were due to a group $V$ element in a thermochromatography experiment although this conclusion has been criticized (29). The Soviet group has suggested the name of nielsbohrium (symbol Ns) for element 105 in honor of the Danish physicist Niels Bohr.

K. E. Gregorich, R. A. Henderson, D. M. Lee, M. J. Nurmia, R. M. Chasteler, H. L. Hall, D. A. Bennett, C. M. Gannett, R. B. Chadwick, J. D. Leyba, D. C. Hoffman and G. Herrmann (38) have shown that hahnium behaves chemicaily much like tantalum and iobium, in agreement with the actinide concept. J. V. Kratz, H. P. Zimmerman, U. W. Scherer, M. Schädel, W. Brüchle, K. E. Gregorich, C. M. Gannett, H. L. Hall, R. A. Henderson, D. M. Lee, J. D. Leyba, M. J. Nurmia, H. Gäggeler, D. Jost, U. Baliensperger, Ya Nai-Qi, A. Türler, and Ch. Lienert (39) later showed, in anion exchange experiments, that anionic halide complexes of hahnium are different from those of tantalum and are more like those of niobium and protactinium.

\section{Element 106}

Experiments leading to competing claims for the discovery of element 106 were performed essentially simultaneously at Berkeley and Dubna in 1974. Ghiorso, J. M. Nitschke, J. R. Alonso, C. T. Alonso, M. Nurmia, E. K. Hulet, R. W. Lougheed and I (40) (Figure 19) reported the observation of 263106 by the reaction

$$
{ }_{98}^{249} \mathrm{Cf}+{ }_{8}^{18} \mathrm{O} \rightarrow 263106+4{ }_{0}^{1} \mathrm{n}
$$

The new nuclide was shown to decay by $\alpha$-emission with a half-life of $0.9 \pm 0.2 \mathrm{sec}$. and a principal $\alpha$-energy of $9.06 \pm 0.04 \mathrm{MeV}$ to previously known ${ }_{104}^{259} \mathrm{Rf}$ which in turn was 
shown to decay to the known nuclide ${ }_{102}^{255} \mathrm{No}$. Thus the atomic numter of the new nuclide was firmly established by a genetic link to its daughters. Os,anessian, Y. P. Tretyakov, A. S. Iljinov, A. G. Demin, A. S. Pleve, S. P. Tretyakova, V. M. Plotko, M. P. Ivanov, N. A. Danilov, Y. S. Korotkin, and G. N. Flerov (41) (Figure 20) reported the observation of ${ }^{2}$ spontaneous fission activity with a half-life of 4-10 ms, produced by bombarding ${ }_{82}^{207} \mathrm{~Pb}$ with ${ }_{24}^{54} \mathrm{Cr}$, which they assigned to ${ }^{259} 106$ on the basis of reaction systematics. We now know this assignment was erroneous in that the observed spontaneous fission activities were primarily due to the daughters of element 106, i.e., 256,255104, and not element 106 (42). The isotope 260106 (which may have been produced also in the Oganessian et al. work) is now known to have a half-life of $\sim 4 \mathrm{~ms}$ with a partial half-life for spontaneous fission of $\sim 7 \mathrm{~ms}$. Neither group has suggested a name for element 106.

\section{Element 107}

In 1976. Oganessian and co-workers (43) reported the production of a spontaneous fission activity with a half-life of $\sim 2 \mathrm{~ms}$ from the reaction of ${ }_{83}^{209} \mathrm{Bi}$ with ${ }_{24}^{54} \mathrm{Cr}$ which they attributed to 261107 . In 1981 G. Münzenberg, S. Hofmann, F. P. Hessberger, W. Reisdorf, K. H. Schmidt, J. R. H. Schneider, W. F. W. Schneider, P. Armbruster, C. C. Sahm, and B. Thuma (44) working at the Gesellschaft fur Schwerionenforschung (GSI) at Darmstadt, West Germany, identified the nuclide 262107 produced in the "cold fusion" reaction

$$
{ }_{83}^{209} \mathrm{Bi}+{ }_{24}^{54} \mathrm{Cr} \rightarrow 262107+{ }_{0}^{1} \mathrm{n}
$$

The recoiling product nuclei from the nuclear reaction were passed through a velocity separator (called SHIP) which guaranteed that they had the characteristic velocity of the product of complete fusion of projectile and target ruclei. The mass number of the velocity-separated product nuclei was roughly determined using a timeof-flight spectrometer and the atomic number and mass number were determined by observing the time correlated $\alpha$-decay of 262107 to its decay products (see Figure 21). One sequence of correlated decays ended in the known nucleus $I s(254,103) \mathrm{Lr}$, one ended in ${ }_{98}^{246} \mathrm{Cf}$, two ended in ${ }_{100}^{250} \mathrm{Fm}$ decay, and one ended in ${ }_{101}^{250} \mathrm{Md}$. Five decays of 262107 were observed with $\mathrm{E} \alpha=10.4 \mathrm{MeV}$ and $\mathrm{t}_{1 / 2} \sim 5 \mathrm{~ms}$. The cross section for producing these nuclei was $\sim 2 \times 10^{-34} \mathrm{~cm}^{2}$ (approximately $1 / 5,000,000$ of the production cross section assumed in the first one-atom-at-a-time experiments with Md!) It is a remarkable tribute to the quality of this experiment that the results of this sxperiment have found rapid, universal acceptance despite the exceedingly low production rate involved. By 1988 a total of 38 atoms had been obsepved. Subsequent experiments (45) identified three 107 species, $261107\left(t_{1 / 2}=11.8+5.3 \mathrm{~ms}, E_{\alpha} \sim 10.2 \mathrm{MeV}\right), 262107$ $\left(t_{1 / 2}=102 \pm 26 \mathrm{~ms} ; E_{\alpha} \sim 9.9 \mathrm{MeV}\right)$ and $262 \mathrm{~m} 107\left(\mathrm{t}_{1 / 2} \approx 8.0 \pm 2.1 \mathrm{~ms}_{;} E_{\alpha} \sim 10.3 \mathrm{MeV}\right)$. Contrary to the initial observations of the Dubna group, no spontaneous fission activities with $t_{1 / 2}=1-2 \mathrm{~ms}$ were observed. No name has been suggested for element 107. 


\section{Element 108}

In 1984 two reports of the successful synthesis of element 108 appeared. The Darmstadt group (G. Münzenberg, P. Armbruster, H. Folger, F. P. Hessberger, S. Hofmann, J. Keller, K. Poppensieker, W. Reisdorf, K. H. Schmidt, H.-J. Schott, M. E. Leino, and R. Hingmann, Figure 22) used the velocity separator SHIP to identify 3 atoms of element $108(46)$. The nuclear reaction used was ${ }^{208} \mathrm{~Pb}(58 \mathrm{Fe}, \mathrm{n}){ }^{265108}$ at a $58 \mathrm{Fe}$ energy of $5.02 \mathrm{MoV} /$ nucleon which should lead to an excitation energy of $18 \pm 2$ $\mathrm{MeV}$ for the compound system. The cross section for production of these nuclei was $1 / 10$ that observed for the production of element 107 (o (108) $\sim 2 \times 10^{-35} \mathrm{~cm}^{2}$ ). Three time-correlated alpha-decay chains that clearly led to known nuclei 261106 and 257104 were observed (Figure 23). The observed species 265108 appears to have a $t_{1 / 2} \sim 1.8$ $\mathrm{ms}$ and decays by the emission of a $10.36 \mathrm{MeV} \alpha$-particle. In a second experiment (47), one atom of the even-even nuclide 264108 ( $t_{1 / 2} \sim 80 \mu s$ ) was produced in the $207 \mathrm{~Pb}$ $\left({ }^{58} \mathrm{Fe}, n\right)$ reaction. The observation of $\alpha$-decay by element 108 is taken as a sign that spontaneous fission lifetimes are unexpectedly long for these nuclei, possibly portending the synthesis of still heavier nuclei.

At approximately the same time as the Münzenberg et al. report, Oganessian et al. (48) (Y. T. Oganessian, A. G. Demin, M. Hussonnois, S. P. Tretyakova, Y. P. Kharitonov, V. K. Utyonkov, I. V. Shirokovsky, O. Constantinescu, H. Bruchertseifer, and 1. Korotkin) reported the observation of the possible decay of $263,264,265108$ produced in the reactions of $5.5 \mathrm{MeV} /$ nucleon $55 \mathrm{Mn}+209 \mathrm{Bi}(\rightarrow 263108)$ and $58 \mathrm{Fe}+207,208 \mathrm{~Pb}(\rightarrow$ $264,265108)$. The production cross sections reported by this Dubna group were $1 / 10$ $1 / 4$ those observed by the Darmstadt group. None of the $\alpha$-particle decays of these nuclei were observed directly. In the case of 264108, a $8 \mathrm{~ms}$ and a $6 \mathrm{~ms}$ fission activity were observed and attributed to the granddaughter of 264108, 256104, a known $9 \mathrm{~ms}$ spontaneous fission activity. Similarly 263108 was identified on the observation of a $1.1 \mathrm{~s}$ spontaneous fission activity attributed to its granddaughter, 255104, a known 2s spontaneous fission activity. The nuclide 265108 was said to have been detected because of the observation of $\alpha$-emitting $253 \mathrm{Es}$, a possible great-great-greatgranddaughter of 265108 . Interesting as the observations of the Dubna group are, they are not sufficient by themselves to be a claim for the discovery of element 108 or to be a confirmation of the work of the Darmstadt group. No name has been suggested for element 108.

\section{Element 109}

In 1982 G. Münzenberg, P. Armbruster, F. P. Hessberger, S. Hofmann, K. Poppensieker, W. Reisdorf, K. Schneider, K. H. Schmidt, C. Sahm, and D. Vermeulen reported the observation (49), after about 2 weeks of bombardment, of one unusual time-correlated decay sequence that occurred for a reaction product that had been 
velocity-separated by SHIP from the ${ }_{83}^{209} \mathrm{Bi}+{ }_{25}^{58} \mathrm{Fe}$ reaction. After implantation of the complete fusion reaction product in a detector, an $11.1 \mathrm{MeV} \alpha$-particle decay was detected, followed $22 \mathrm{~ms}$ later by a detected alpha-particle of $1.14 \mathrm{MeV}$ energy, followed $13 \mathrm{~s}$ later by a spontaneous fission. A possible sequence for this decay is shown in Figure 24. The 1.14 MeV alpha-particle is assumed to result from a decay in which only part of the alpha-particle energy was deposited in the detector. Such a yield corresponds to a formation cross section of $\approx 10^{-35} \mathrm{~cm}^{2}$. In a second experiment in 1988 two more time-correlated decay sequences similar to the first event were found (50). The combined results of both experiments give a value of the half-life of $3.4_{-1.3}^{+6.1}$ $\mathrm{ms}$ for 266109 and a production cross section of $10_{-6}^{+10}$ picobarns. No name has been suggested for element 109.

\section{Element 110}

Y. T. Oganessian et al. (51) in 1987 reported the production in the reaction of ${ }_{20}^{44} \mathrm{Ca}$ with $232 \mathrm{Th}$, with a cross section of 8 picobarns, of a $9 \mathrm{~ms}$ spontaneous fission activity, which they assigned to an isotope of element 110 (possibly 272110). A similar activity was also produced, and so assigned, in the reaction of ${ }_{18}^{40} \mathrm{Ar}$ with ${ }_{92}^{235-236} \mathrm{U}$. The evidence is not sufficient to assign an atomic number. An attempt (52) by a GSI team to observe this activity from the reaction of ${ }^{40} \mathrm{Ar}$ with $235 \mathrm{U}$, using SHIP, led to negative results. Additional exhaustive attempts (52) by a GSI team to produce and identify element 110 by the reaction ${ }_{82}^{208} \mathrm{~Pb}+{ }_{58}^{64} \mathrm{Ni} \rightarrow 271110+1 \mathrm{n}$ have also led to disappcintment. A. Ghiorso (53) is attempting another approach through the reaction ${ }_{83} \mathrm{Bi}+{ }_{27} \mathrm{Co} \rightarrow 267110+1 \mathrm{n}$, using a rebuilt version of SASSY (Small Angle Separating System) (54), a gas-filled on-line recoil separator, to separate and identify the expected product. An electrostatic separator device, called "VASILISA," has been built at Dubna (55) for the separation of heavy-ion beams from reaction products of complete nuclear fusion reactions.

\section{Heavier elements?}

Considerations by theoretical physicists, beginning more than 20 years ago, led to the prediction that there should be an "Island of Stability" in a region of spherical nuclei at or near atomic number 114 (eka-lead) and neutron number 184, which hopefully might be reached by bombardment of neavy target nuclei by heavy ions. There have been more than 25 publications describing futile efforts to reach this region of "Superheavy Elements" $(56,57)$. The efforts, by both the Dubna group (58) and the collaborative work of the GSI-Berkeley-Los Alamos-Mainz-Bern-Göttingen groups (59) have used the promising approach of bombarding ${ }_{96}^{248} \mathrm{Cm}$ with ${ }_{20}^{48} \mathrm{Ca}$ projectiles to produce a product such as $294116(N=178)$, but these comprehensive experiments have also yielded negative results. 
However, the product of even this reaction is some half dozen neutrons short of the objective of $N=184$ (although P. Möller et al. (60) suggest that this spherical shell is pushed down to $N=178$ ). A closer approach to $N=184$ might be achieved by using ${ }_{99}^{254}$ Es as a target, but this is hampered because it is presently available in very limited (microgram) quantities. An interlaboratory group in the United States (BerkeleyLivermore-Los Alamos-Oak Ridge) is proposing that this nuclide be produced in larger amounts $(40 \mu \mathrm{g})$ for this purpose (61).

More recent calculations $(\underline{60}, 62)$ suggest that there should be stabilizing, deformed nuclear shells (or subshells) at lower neutron numbers, such as $N=162$. Some of the above described attempts to synthesize element 110 were designed to reach a neutron number near such a subshell. However, an attempt by Hulet et al. (63) to detect the alpha-decay of $272108(N=164)$ as the electron capture daughter of $272109(N=163)$, produced in the reaction ${ }_{99}^{254} \mathrm{Es}\left({ }_{10}^{22} \mathrm{Ne}, 4 n\right)$ was unsuccessful, leading to the conclusion that the stability is less than anticipated. Similarly, M. Schädel et al. (64) failed to detect $266107(N=159)$ in the reaction ${ }^{254} \mathrm{Es}\left({ }^{16} \mathrm{O}, 4 \mathrm{n}\right)$.

The effects of a rather distinct deformed shell at $N=152$ were clearly seen (65) as early as 1954, in the alpha-decay energies of isotopes of californium, einsteinium, and fermium. In fact, a number of authors (66) have suggested that the entire transuranium region is stabilized by shell effects with an influence that increases markedly with atomic number. Thus, the effects of shell structure lead to an increase in spontaneous fission half-lives of up to about 15 orders of magnitude for the heavy transuranium elements, the heaviest of which would otherwise have half-lives of the order of that for a compound nucleus (10.14 s or less) and not of milliseconds or longer, as found experimentally. This gives hope for the synthesis and identification of several elements beyond the present heaviest (element 109) and suggests (66) that the peninsula of nuclei with measurable half-lives may extend up to the "Island of Stability" at $Z=114$ and $N=184$ (or $N=178$ ).

\section{Reflections}

Serious research on the transcurium elements is, with some exceptions, performed by scientists working at, or with connections to, large laboratories with extensive facilities--in the United States, the national laboratories (Argonne Nationai Laboratory, Lawrence Berkeley Laboratory, Lawrence Livermore National Laboratory, Los Alamos National Laboratory, Oak Ridge National Laboratory); in Europe, the Gesellschaft für Schwerionenforschung (GSI) in the Federal Republic of Germany, and the international laboratories, the Joint Institute for Nuclear Research, Dubna, USSR, and the European Institute for Transuranium Elements, Karlsruhe, FRG. (There are, of course, other laboratories that are making important contributions.) However, the potential of the transuranium field is so large that there is a need for even more specialized facilities. It is the author's dream that in the future--perhaps the distant 
future--additional laboratories or institutes will be created for exclusive research on the transuranium elements.

There are almost unlimited possibilities for research on these elements, which already constitute nearly $20 \%$ of the total of all known chemical elements. When thinking in terms of the distant future, the tendency is to underestimate potential contributions.

As indicated earlier, estimates suggest that 500 transuranium nuclides would have half-lives sufficiently long to be detectable experimentally (longer than a microsecond). The synthesis and identification of another half dozen or so elements seems likely; this would include the discovery of Superheavy Elements and the extension of the present peninsula of elements to connect with the Island of Stability. Longer-lived isotopes than those now known will probably be found in the transactinide region especially among the early transactinide elements. (The recently discovered long-lived isotopes of lawrencium (261 Lr and ${ }^{262} \mathrm{Lr}$ ) will make possible the detalled study of the chemical properties of this element. [67].) As a result, it should be possible to study the chemical properties of elements beyond hahnium (Element 105) and certainly of Element 106 (already possibly using the 0.9 s 263106 ).

Much more research on the macroscopic properties of einsteinium will be possible with the availability of ${ }^{254} \mathrm{Es}$. It will surely be possible to study the macroscopic properties of ferrnium and not out of the question that this will be done for mendelvium. The art of one-atom-at-a-time chemistry will advance far beyond what can be imagined today to make it possible to study the chemistry of heavier and heavier elements. All of this will result in the delineation of relativistic effects on the chemical properties of these very heavy elements, which might thus be substantially different than those expected by simple extrapislation from their lighter homologs in the Periodic Table (an advanced form of which is shown in Figure 25).

And in the course of preparation of this broad range of nuclides by heavy ion reactions and the study of their decay properties much will be learned about the dynamics of nuclear matter, the exact location of shell structure, and the energy levels and spectroscopic states of heavy nuclei. This will give the theorists information to further increase the understanding of nuclear forces and structure.

Such a research program will require, for success, the availability of apparatus and equipment of increasing complexity, versatility, and power. Central will be the need for higher neutron flux reactors, for sustained operation as a research tool and to produce large quantities of transplutonium nuclides for use in the research and as target materials as a source of the presently known and expected nuclides. (Higher neutron fluxes will be especially valuable for the production of the heaviest nuclides, ${ }^{254} \mathrm{Es}$ and $257 \mathrm{Fm}$, springboards to the region beyond.) Higher intensity heavy lon accelerators 
must be built and means of coping with their beams at the target must be developed in order to overcome limitations due to small nuclear reaction cross sections. Increase in orders of magnitude in heavy ion intensity should make possible nuclear synthesis reactions with secondary (radioactive) beams of neutron-excessive projectiles, which might greatly increase the yields of sought-after new nuclides. Improved methods for handling safely and efficiently and making chemical measurements on increasing quantities of the highly radioactive transcurium nuclides must be developed.

Improved apparatus of all kinds for the determination of the chemical structure, energy levels and their electronic structure, thermodynamic data, etc., improved laser beams, and the use of new apparatus, such as the Advanced Light Source (AL.S) being bullt at the Lawrence Berkeley Laboratory, will place new power in the hands of the chemist. The ultimate achievement will be the perfection of means of performing single atom chemistry. 


\section{FGURES}

1. Perlodic Table of the 1930s. Atomic numbers of undiscovered elements are shown in parentheses.

(XBL 769-10601- ElX)

2 a. The discoverers of neptunium: Edwin M. McMillan.

(XBL 761-72.56 - H44)

2. b. P. H. Abelson.

(XBB 766-5887 - H47)

3 a. The discoverers of plutonium: Joseph W. Kennedy. (XBP 892-809 - H 990)

3 b. Arthur C. Wahl and Glenn T. Seaborg. Seaborg and Wahl are shown with the sample of $239 \mathrm{Pu}$ on which fission was demonstrated in 1941. (The clgar box belonged to Gilbert N. Lewis.) (XBB.769-8637 - H-51)

4. Emillio Segrè, Berkeley, 1947. (XBB 888.7963 - H-967)

5. University of California at Berkeley, in 1940: 1. LeConte Hall, 2. Gilman Hall, 3. Chemistry Building, 4. Chemistry Annex, 5. Freshman Chemical Laboratory, 6. Radiation Laboratory, 7. Crocker Laboratory, 8, East Hall, 9. Drake's Restaurant \& Smorgasbord, 10. Varsity Candy Shop, and 11. Alta Vista Building.

(XBB 907-5883 - HS-100)

6. Louis B. Werner and Burris B. Cunningham in Room 407 of the Jones Laboratory at the University of Chicago, August 20, 1942. (XBB 768-7456 - H-4)

7. First weighed sample of plutonium (as an oxide), University of Chicago, Metallurgical Laboratory, September 10, 1942. (Chem 2011 - F-28x)

8. Periodic table published by the author in 1945, showing the heaviest elements as members of an actinide series. (XBL 769-10603 - E-3)

9 a. Discoverers of americium and curium: Leon O. Morgan (1944), (ХBB 769-8633 - HS-123)

9 b. Ralph A. James (1945), (XBB $761-7430 \cdot \mathrm{H}-169$ ) 
9 c. Albert Ghiorso (in Met Lab counting room, January 1946) (XBB 769.8628 - H.177a)

10. Quiz Kids Shella Conlan and Robert Burke with the author when he informally announced discovery of elements 95 and 96 on a radlo show in 1945.

(XBB 764-3297 - H-61)

11. The co-discoverers of berkelium and californium in Seaborg's office, Lawrence Berkeley Laboratory, January 20, 1975 (25th anniversary of discovery): Kenneth Street, Jr., Stanley G. Thompson, Seaborg, Albert Ghiorso.

(XBB 751-855 - H.969)

12. Production of uranlum isotopes in the November 1952 "Mike" thermonuclear device, and their decay to beta-stable nuclel. (XBL 907-2539 - HS-125)

13. Co-discoverers of elements einsteinlum and fermium at symposium commemorating the 25th anniversary of their discovery held at Lawrence Berkeley Laboratory, January 23, 1978: (front row) Louise Smith, Sherman Fried, Gary Higgins; (back row) Al Ghlorso, Rod Spence, Seaborg, Paul Fields and John Huizenga. (XBC 781-876-H-955)

14. The sequence of nuclides produced in a high-flux reactor neutron irradiation of a $239 \mathrm{Pu}$ target. The horizontal arrows represent neutron capture, vertical arrows up represent $B$ decay, and vertical arrows down represent electron capture decay. (XBL 843-10225 - HS-102)

15. Co-discoverers of mendelevium at the Lawrence Berkeley Laboratory on March 28, 1980 (25th anniversary of discovery): Gregory R. Choppin, Seaborg, Bernard G. Harvey, Albert Ghiorso. (CBB 888-8770 - HS-101)

16. The co-discoverers of nobellum, HILAC Building, Lawrence Berkeley Laboratory, 1958: Albert Ghiorso, Torbjorn Sikkeland, and John R. Walton (Seaborg absent). (Morgue 1958-17(P-1) - F-149)

17. The co-discoverers of lawrencium, HILAC Building, Lawrence Berkeley Laboratory, 1961: Torbjorn Sikkeland, Albert Ghiorso, Almon E. Larsh, Robert M. Latimer. (HIA 265 - F-143) 
18. The co-discoverers of rutherfordium and hahnlum with Seaborg, HILAC Bullding, Lawrence Berkeley Laboratory, 1970: Mattl Nurmla, James Harris, Karl Eskola, Seaborg, Pirkko Eskola, Albert Ghlorso. (XBB 769-8641 - HS-3)

19. The co-discoverers of Element 106, HILAC Bullding, Lawrence Berkeley Laboratory, 1974: Matti Nurmla, Jose R. Alonso, Albert Ghlorso, E. Kenneth Hulet, Carol T. Alonso, Ronald W. Lougheed, Seaborg, Joachim M. Nitschke.

(XBC 749.6476 - (9.164X)

20. At Laboratory of Nuclear Reactions, Dubna, USSR, September 23, 1975: V. A. Druin, Seaborg, Albert Ghlorso, Georgly N. Flerov, Yuri T. Oganesslan, and Ivo Zvara.

(CBB 769.8644 - HS.5)

21. Sequence of time-correlated decay chain observed by Munzenberg et al. to identify the product of the ${ }^{209} \mathrm{Bl}\left({ }^{54} \mathrm{Cr}, n\right) 262107$ reaction. (XBL 907-2510 - G-350A)

22. Co-discoverers of Element 108, QSI Laboratory, 1984: Sigurd Hofmann, Karl Heinz Schmidt, Peter Armbruster, Will Reisdorf, H. J. Schött, and Gottfried Münzenberg. (CBB 8810.9477 - HS.4)

23. The three observed decay sequences associated with Element 108. The nucleus 266108 is assumed to have been the compound nucleus which emitted 1 neutron to form 265108. (XBL. 907-2382 - HS-103)

24. A possible decay sequence of an event attributed to the reaction ${ }^{109} \mathrm{Bi}(58 \mathrm{Fe}, \mathrm{n}) 266109$.

(XBL 843-10226 - HS-126)

25. Modern Periodic Table. Atomic numbers of undiscovered elements appear in parentheses. (XBL 751-2036A - E21C) 

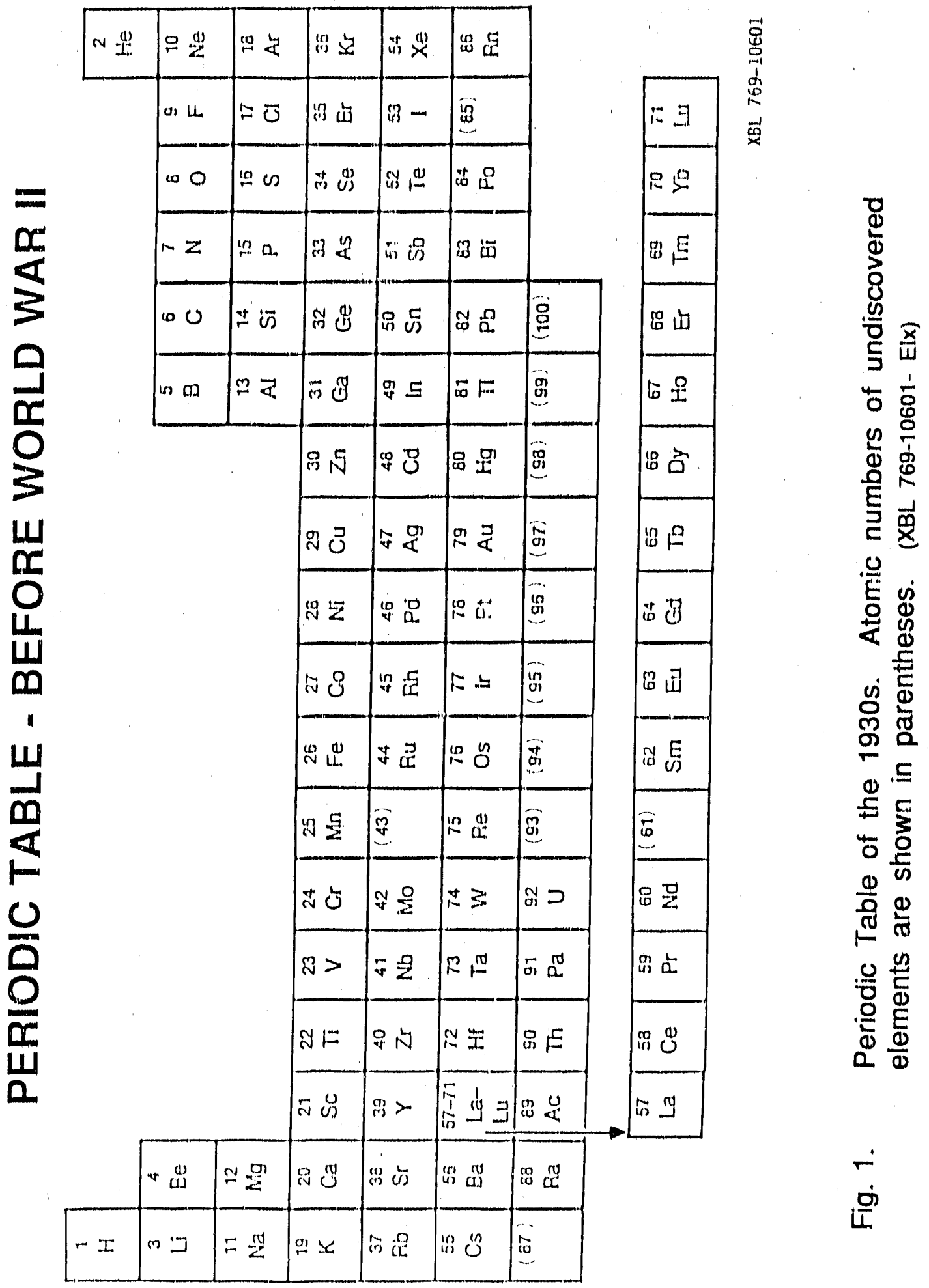


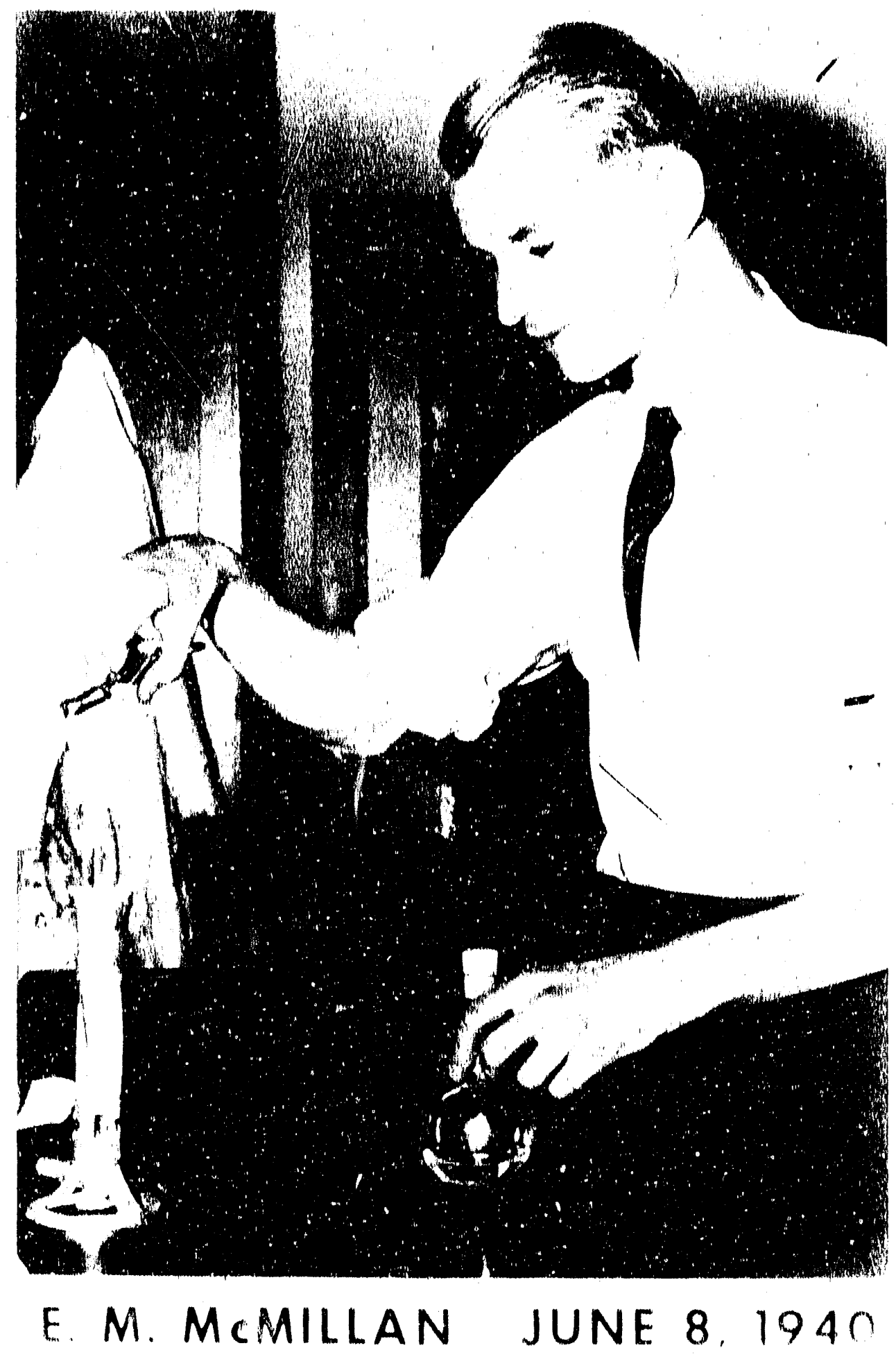

Fig. 2 a. The discoverers of neptunium: Edwin M. McMillan. (XBL. 761-7256 H44) 


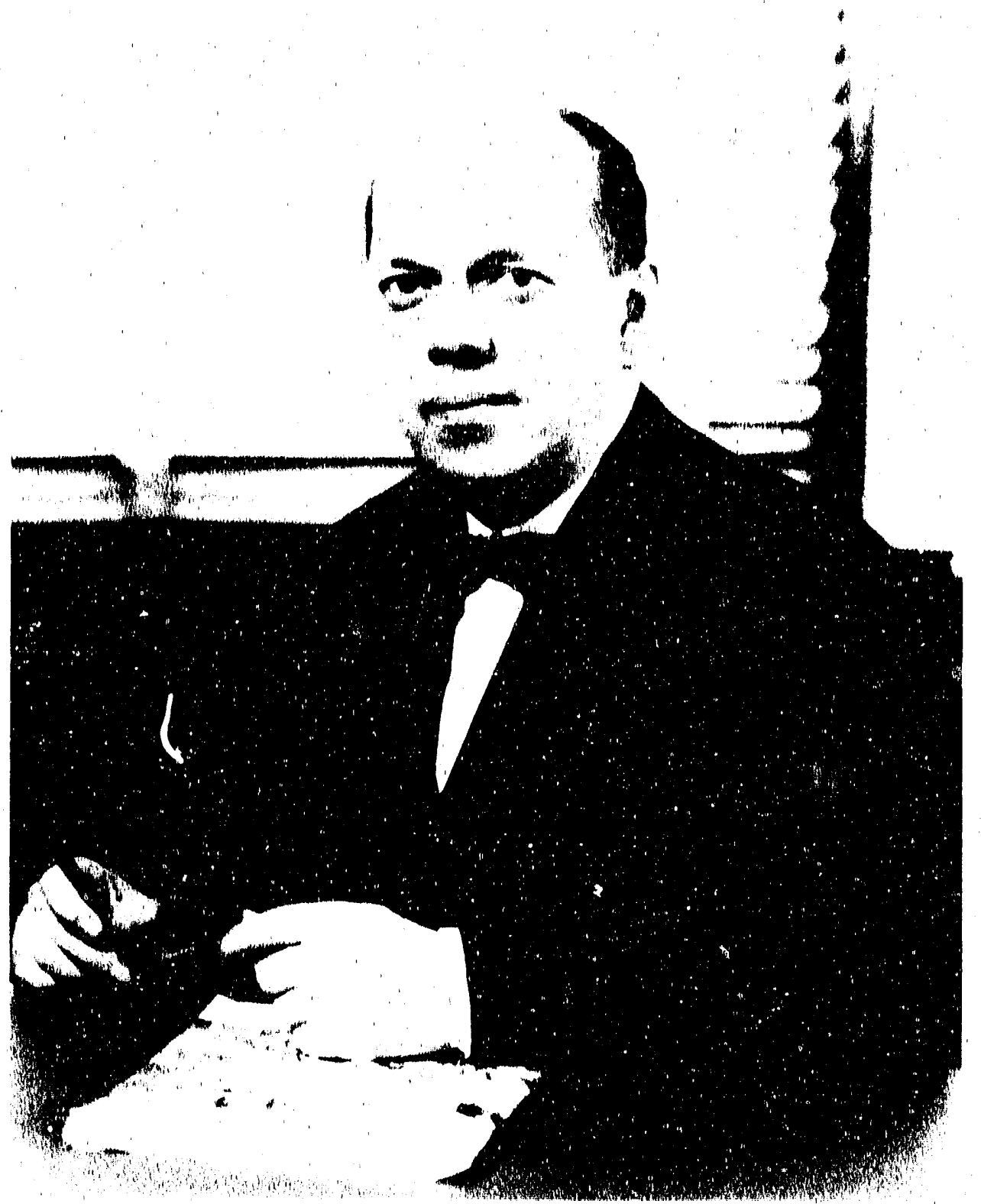

PHILIP H. ABELSON

Fig. 2 b. 


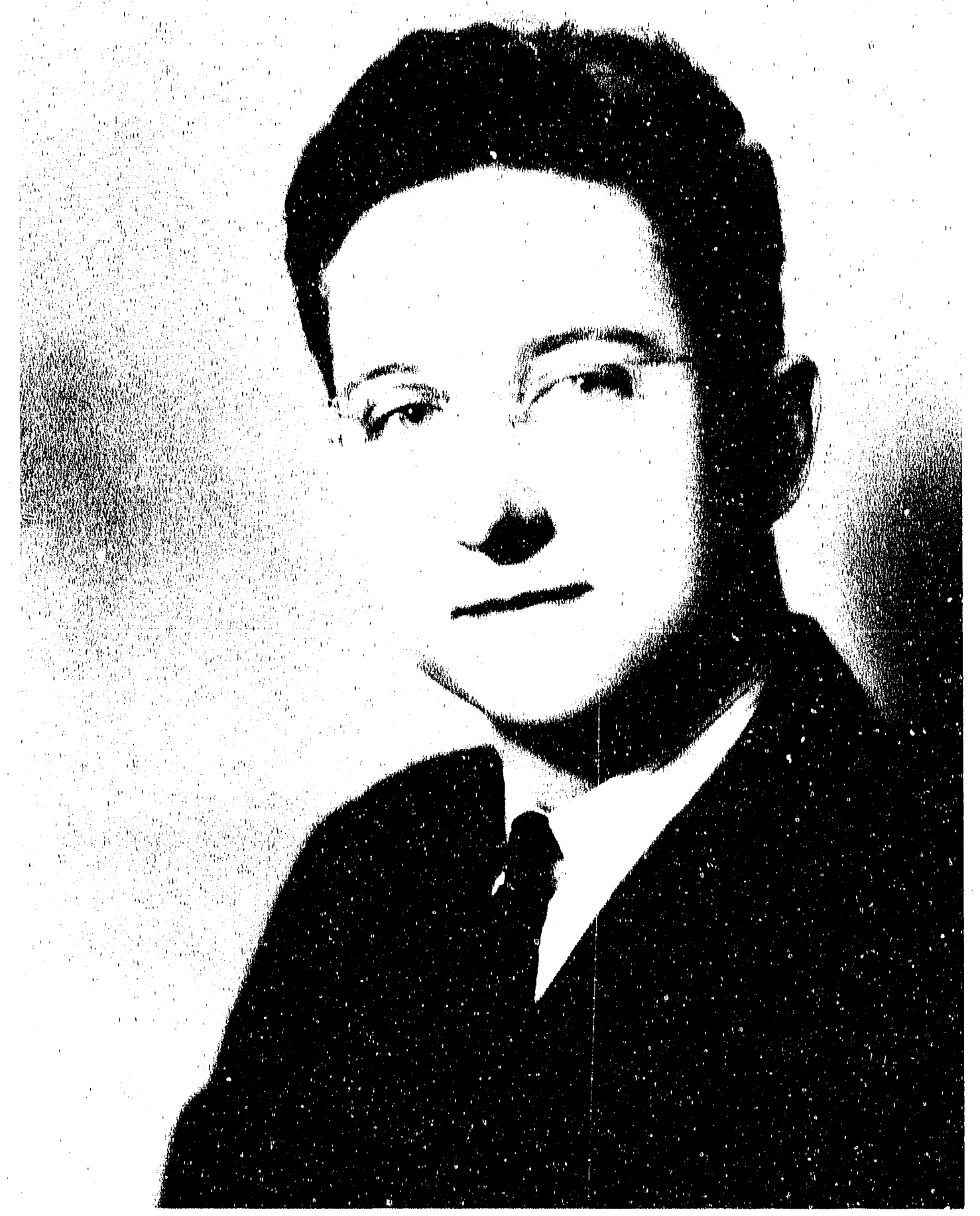

Fig. 3 a. The discoverers of plutonium: Joseph W. Kennedy (XBP 892.809. H 990) 


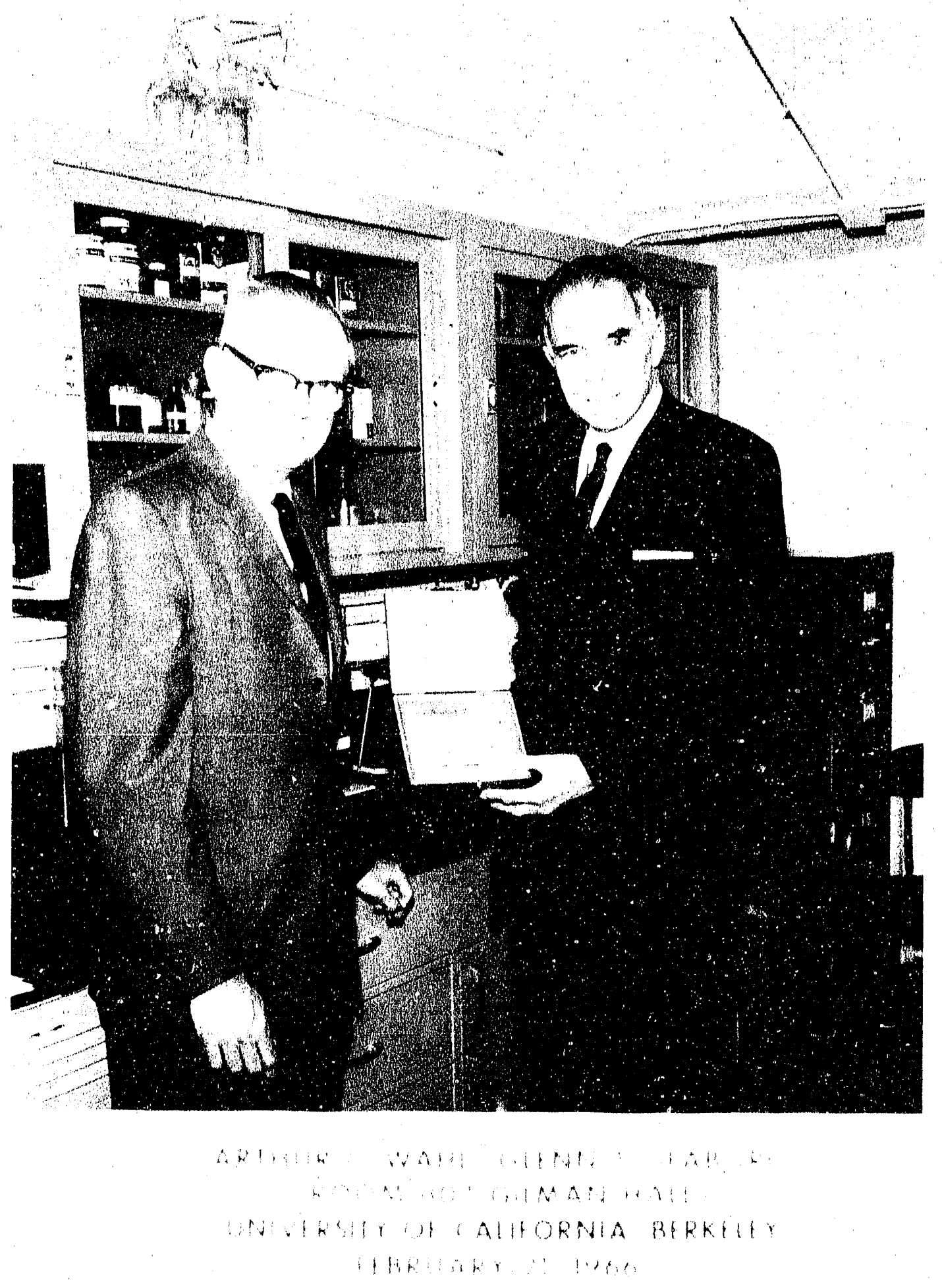

Fig. $3 b$. 


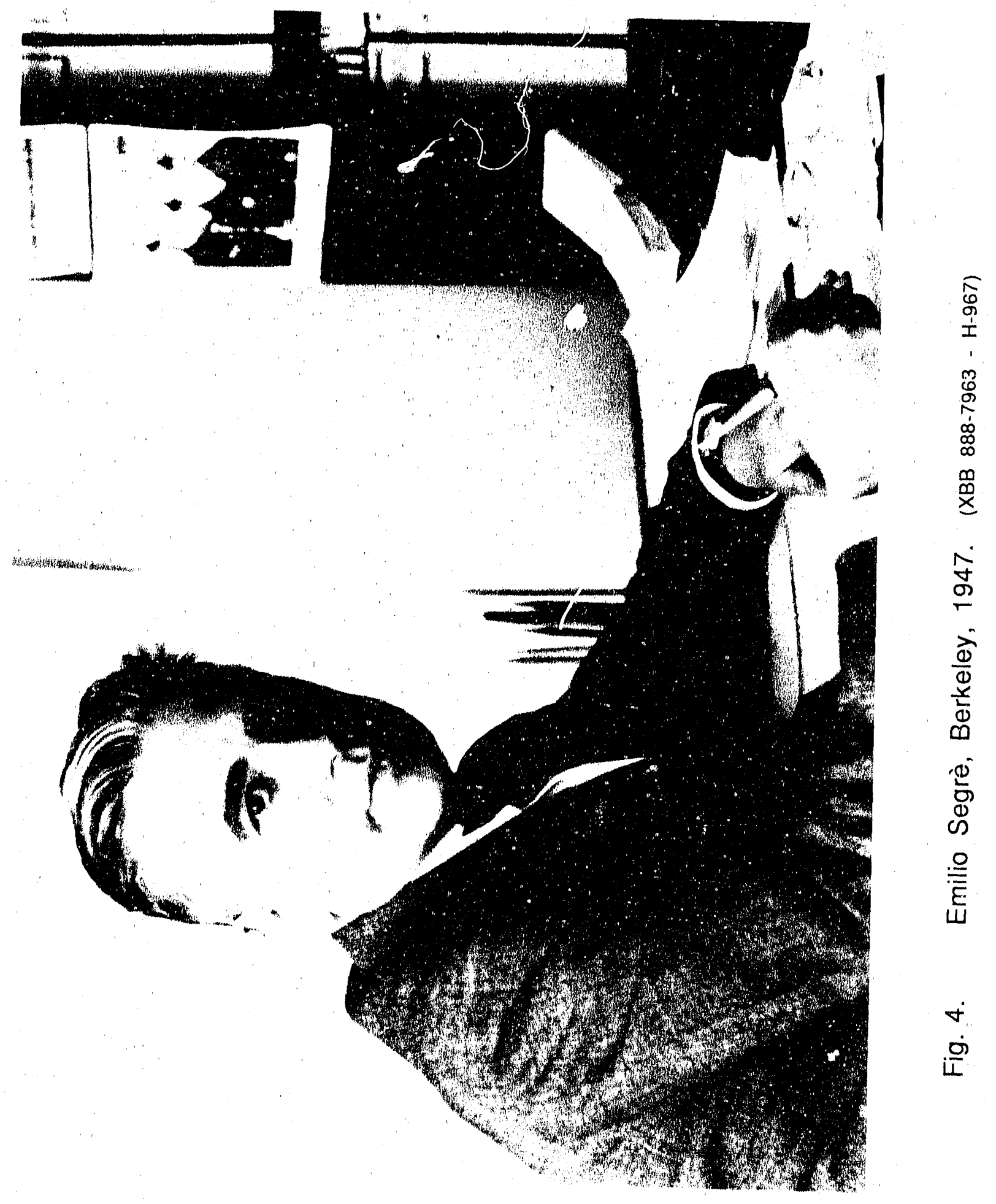






llaversity of califonni, Berkolny, 1940

\begin{tabular}{|c|c|c|}
\hline 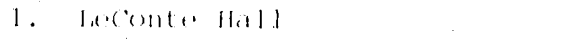 & 7. & crocker laboratory \\
\hline (:ilman Ha!l & ti. & Fiast Batl \\
\hline Chemistry kuidaling & 9 & Orakes Restaurant s smorgasbord \\
\hline chemistry Anmex & 10. & Varsity candy shop \\
\hline $\begin{array}{l}\text { Froshman chemical laboratory } \\
\text { Radiation haboratory }\end{array}$ & 11 & Alta Vista Building \\
\hline
\end{tabular}

Fig. 5 . 


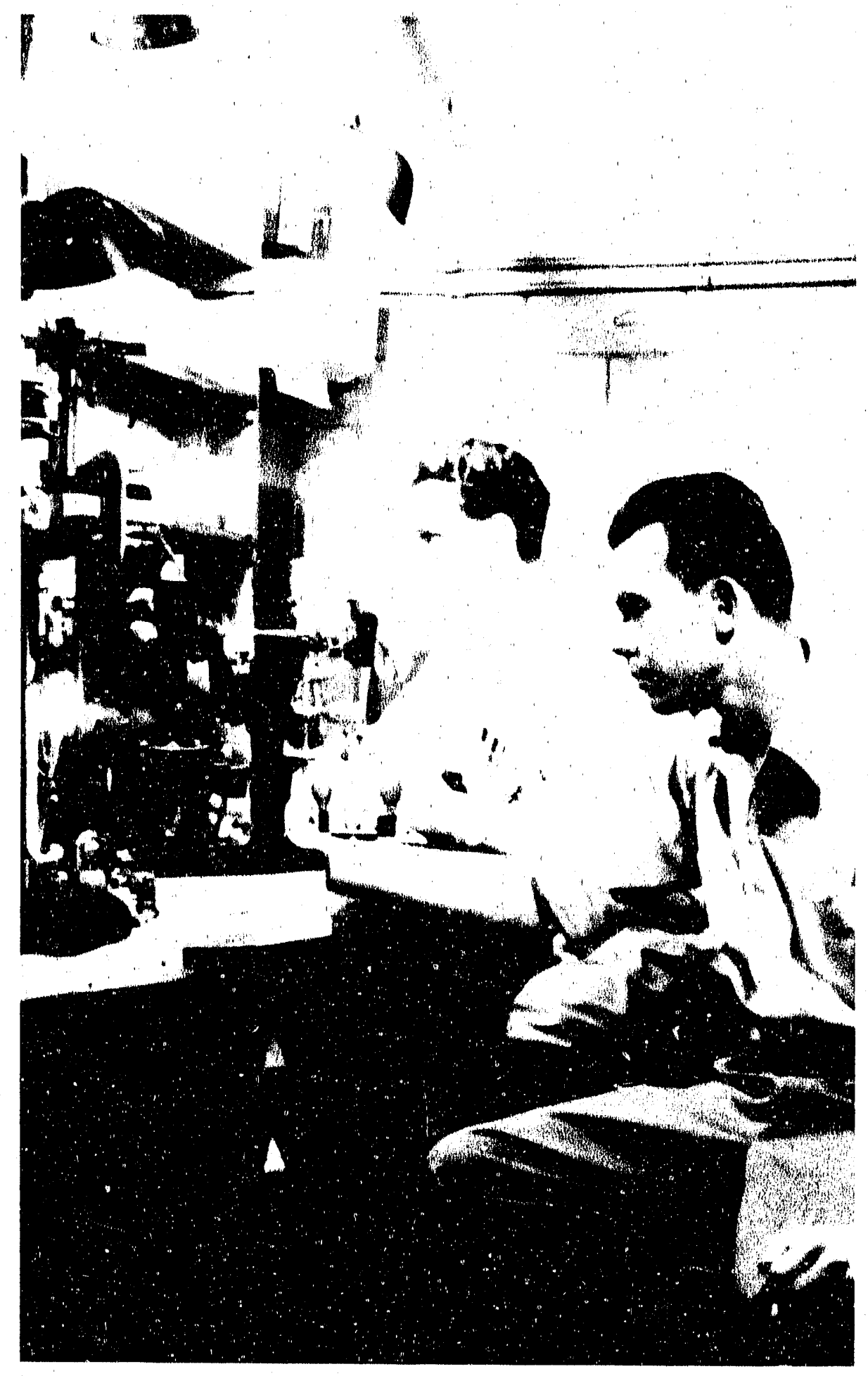

Fig. 6. Louis B. Werner and Burris B. Cunningham in Room 407 of the Jones Laboratory at the University of Chicago, August 20, 1942. (XBB 768-7456 - H-4) 


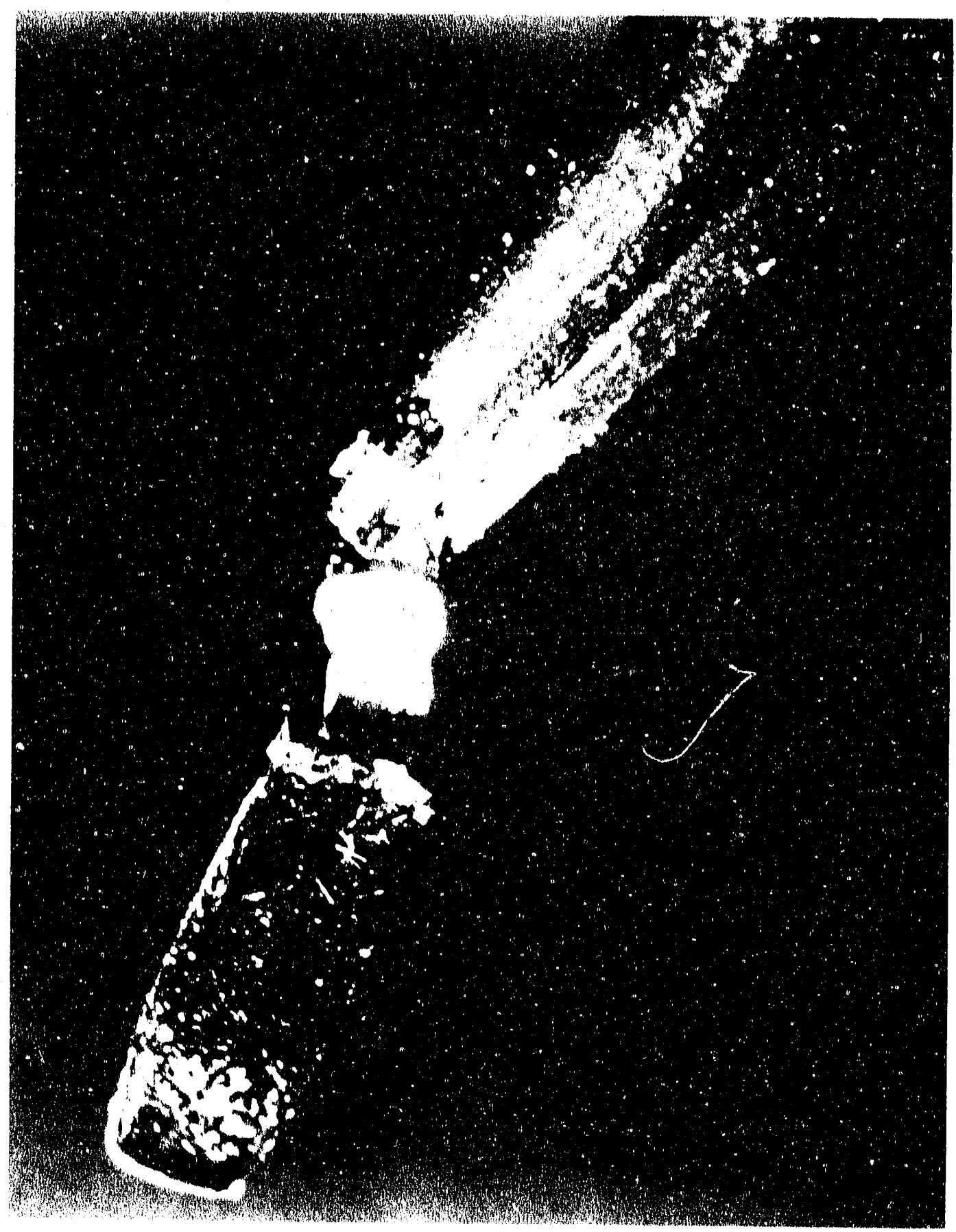

Fig. 7. First weighed sample of plutonium (as an oxide), University of Chicago, Metallurgical Laboratory, September 10, 1942. (Chem 2011 - F-28x) 

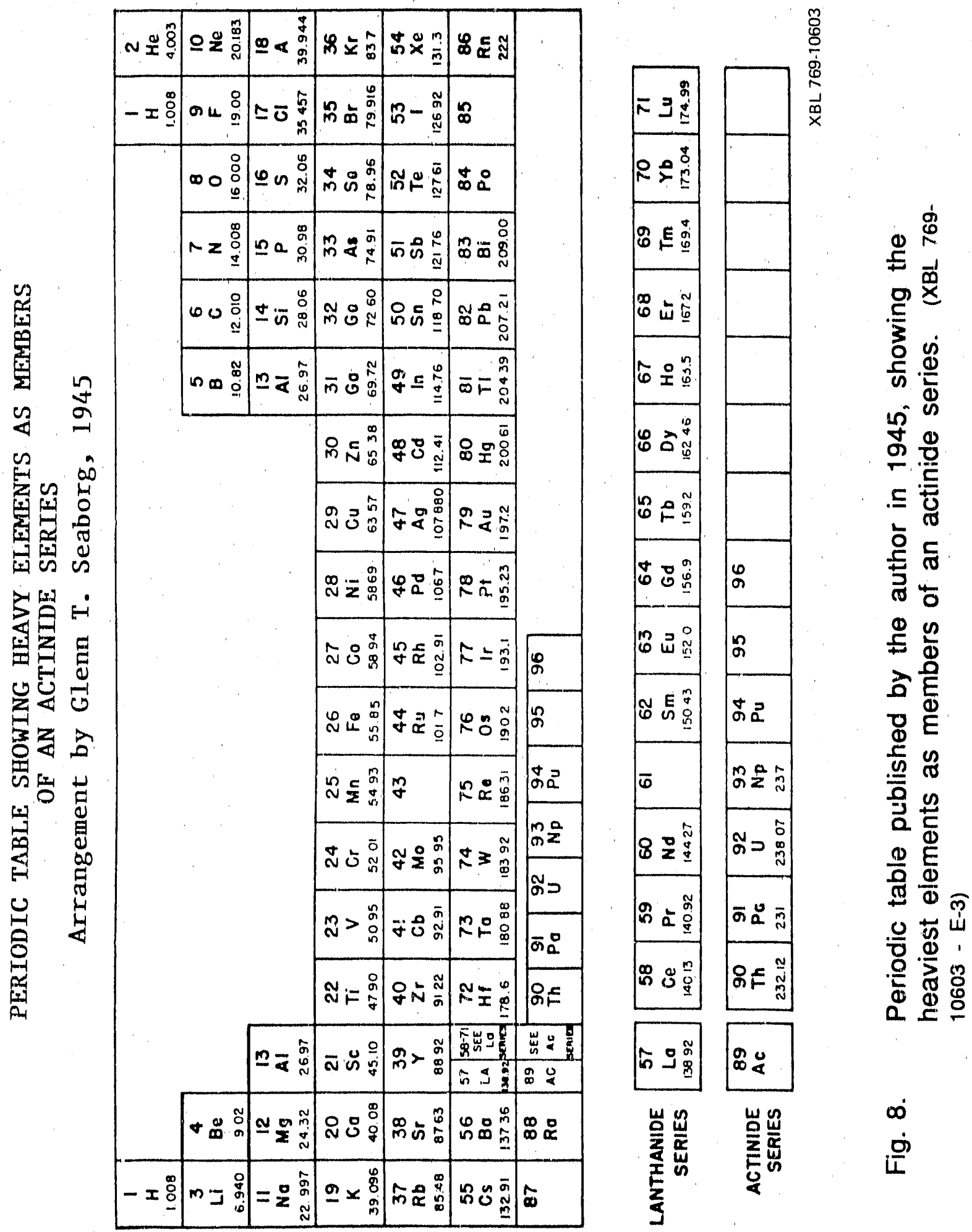


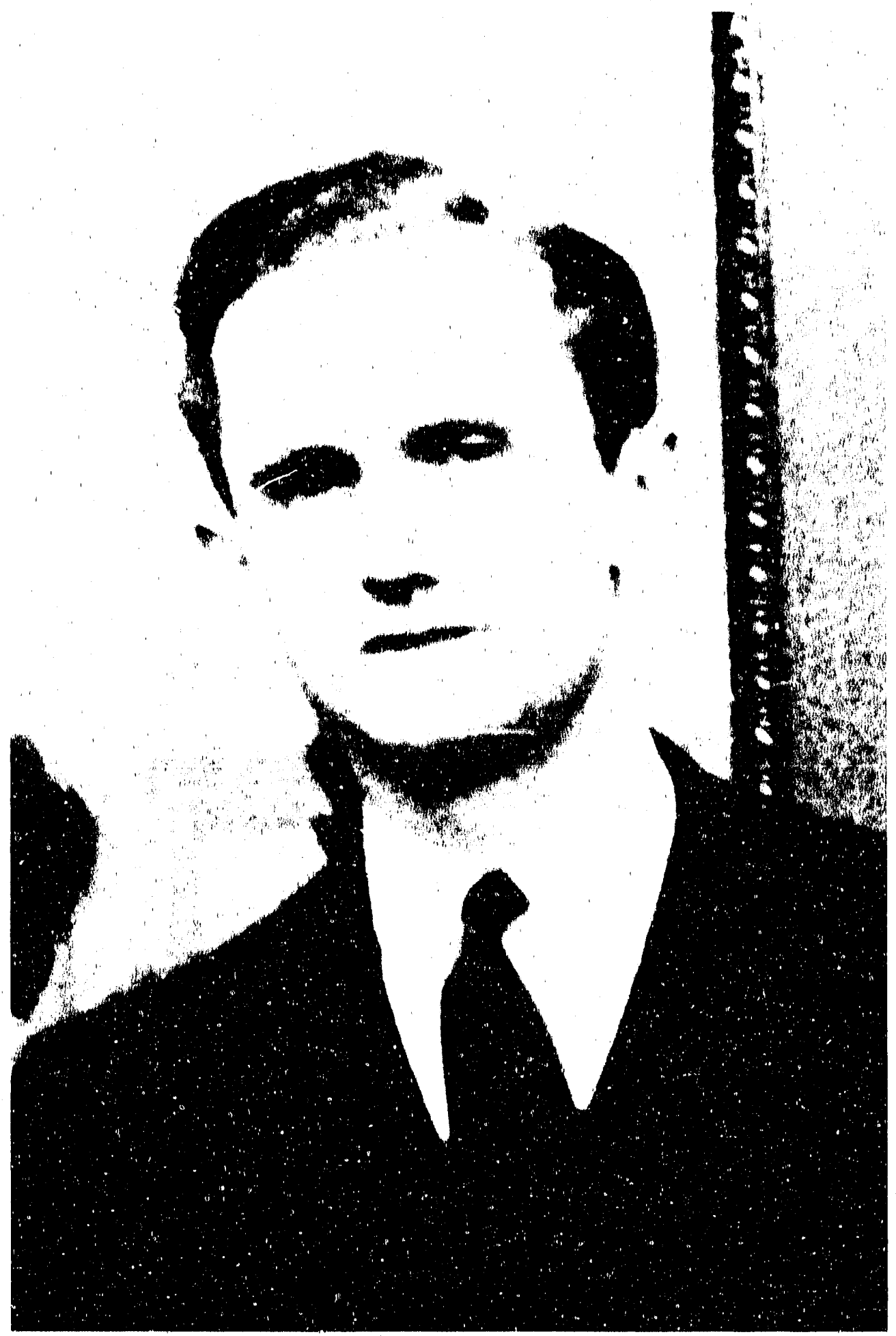

Fig. 9 a. Discoverers of americium and curium: Leon O. Morgan (1944), (XBE 769.8633 - HS-123) 


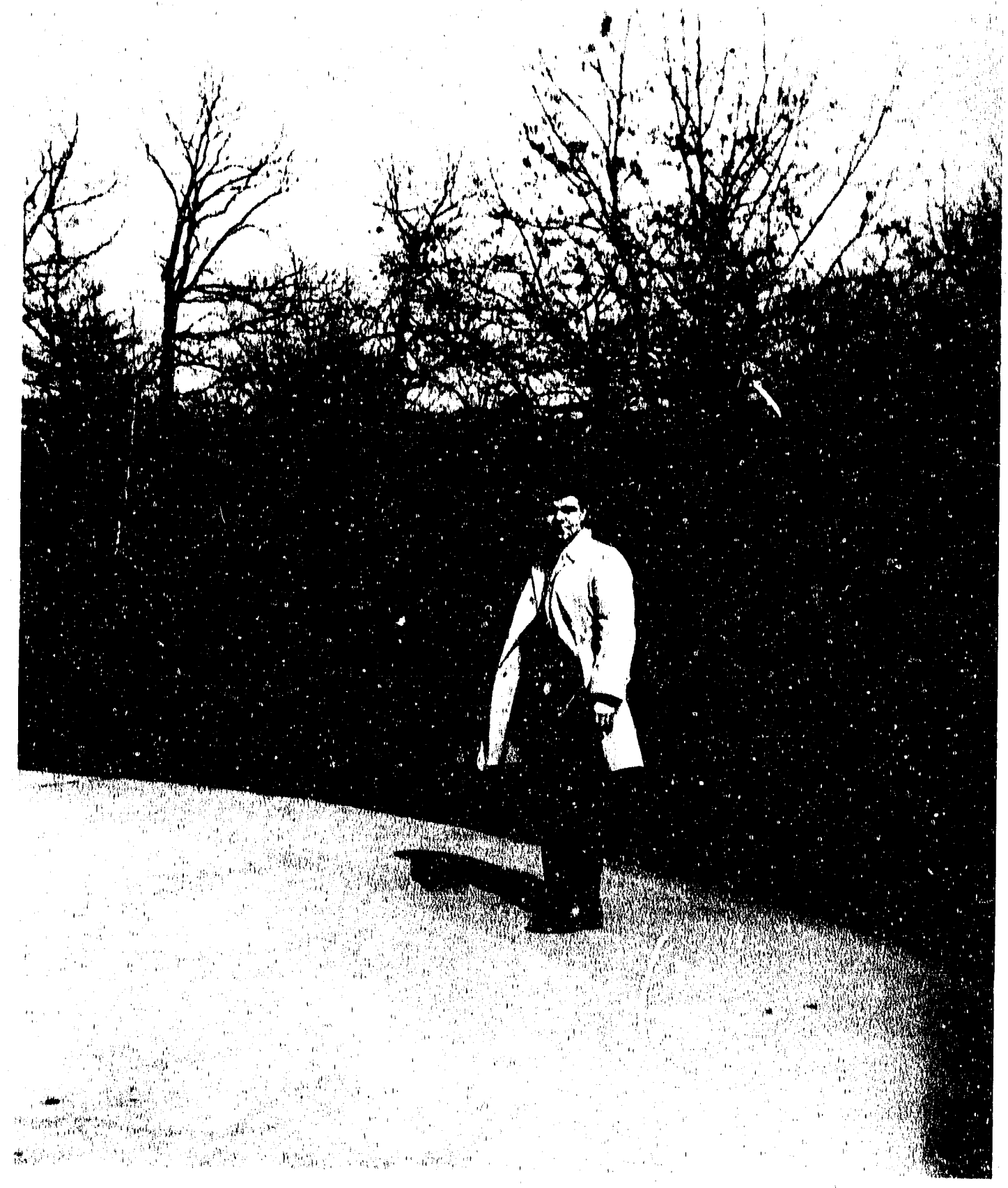

Fig. 9 b. Ralph A. James (1945). (XBB 761-7430-H-169) 


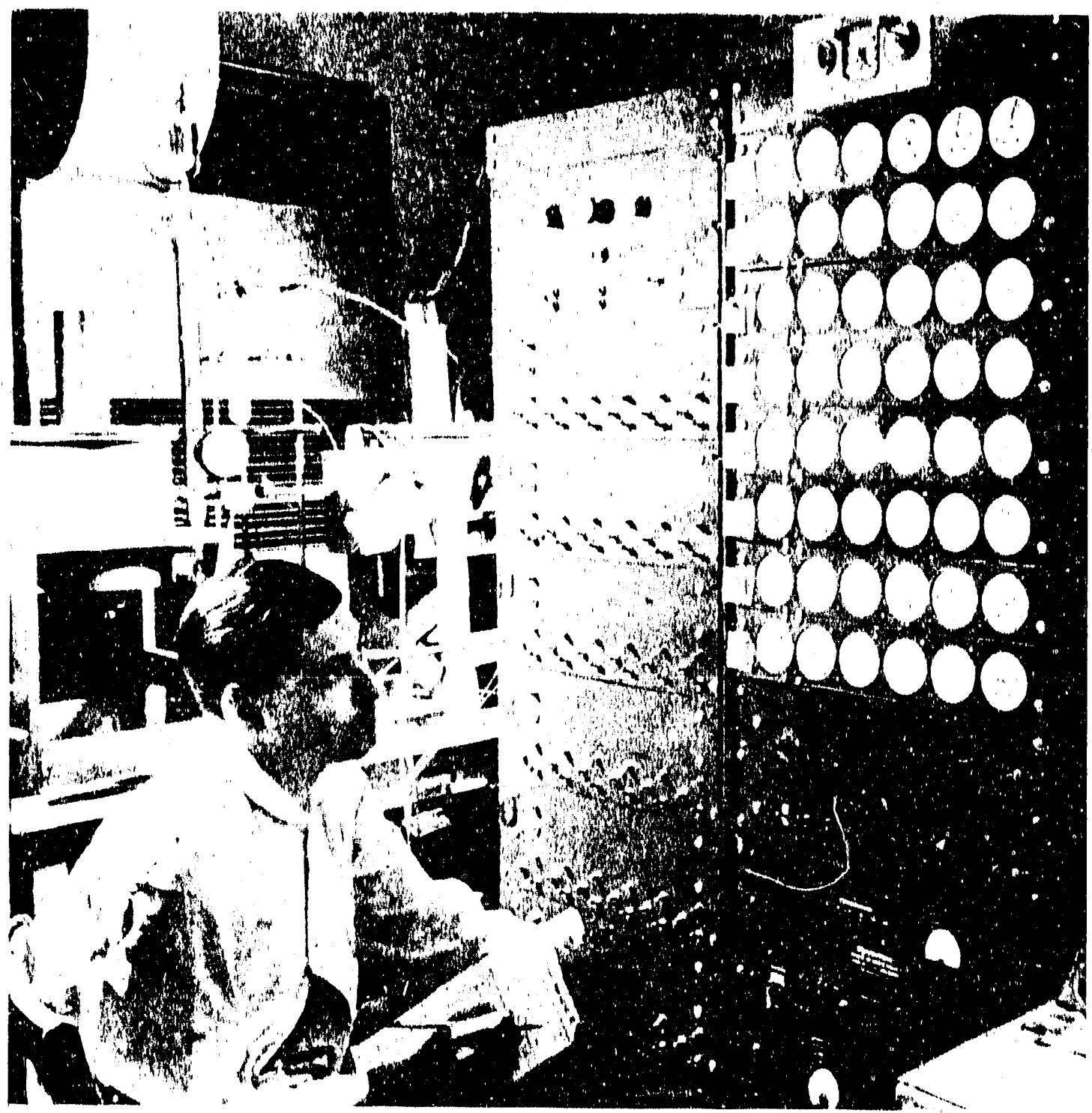

Fig. 9 c. Albert Ghiorso (in Met Lab counting room, January 1946). (XBB $769.8628 \cdot H \cdot 177 a)$ 


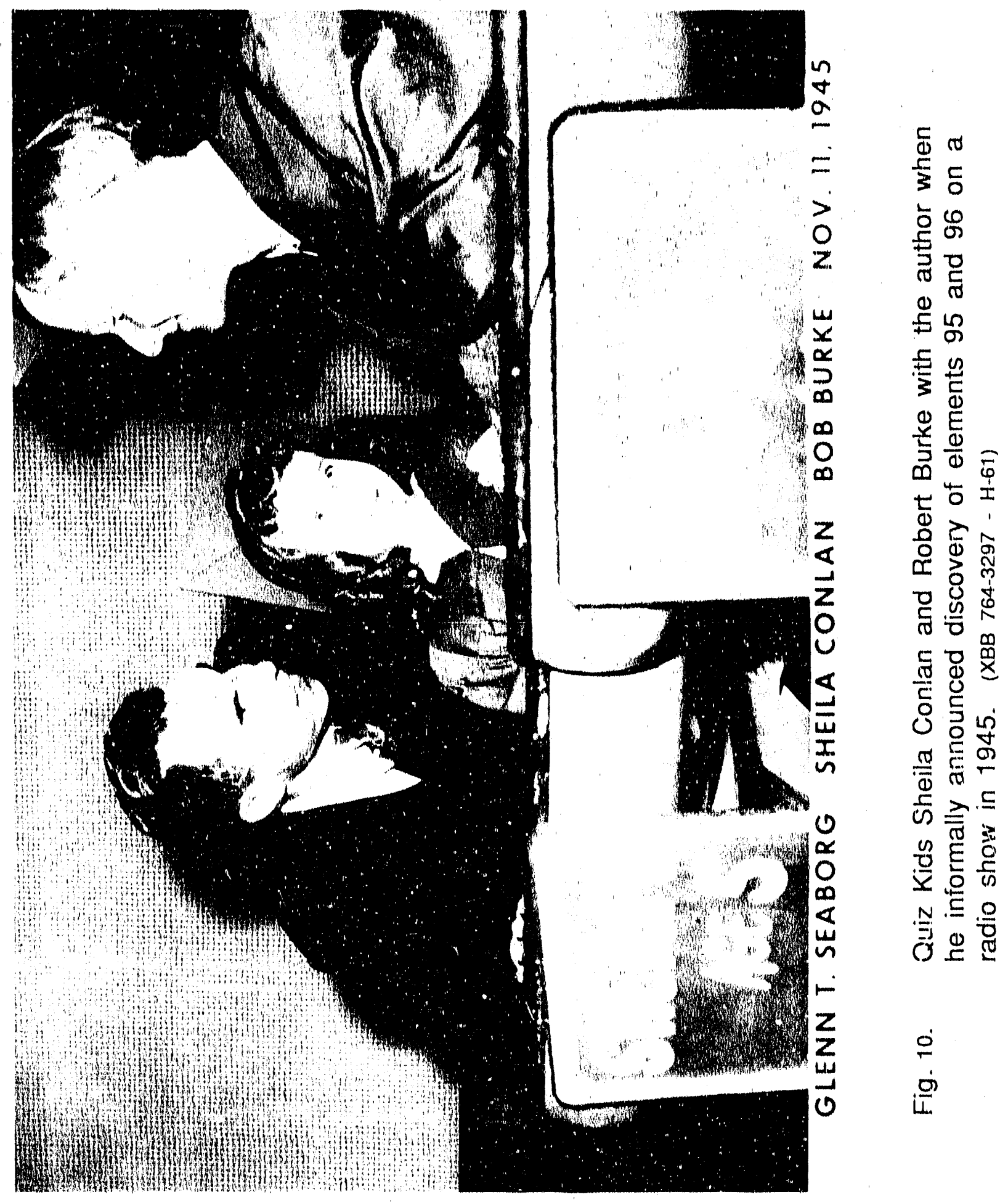




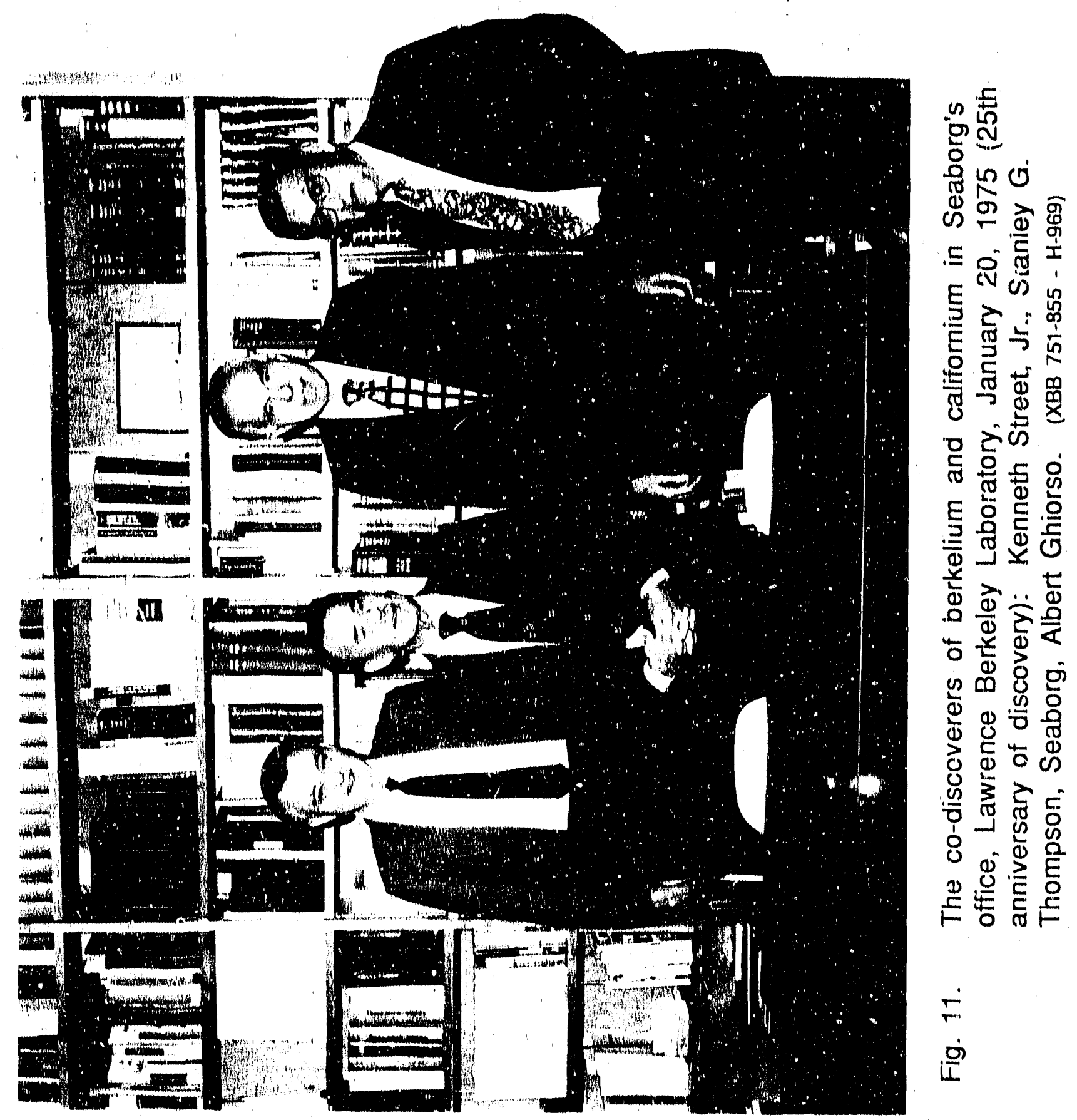




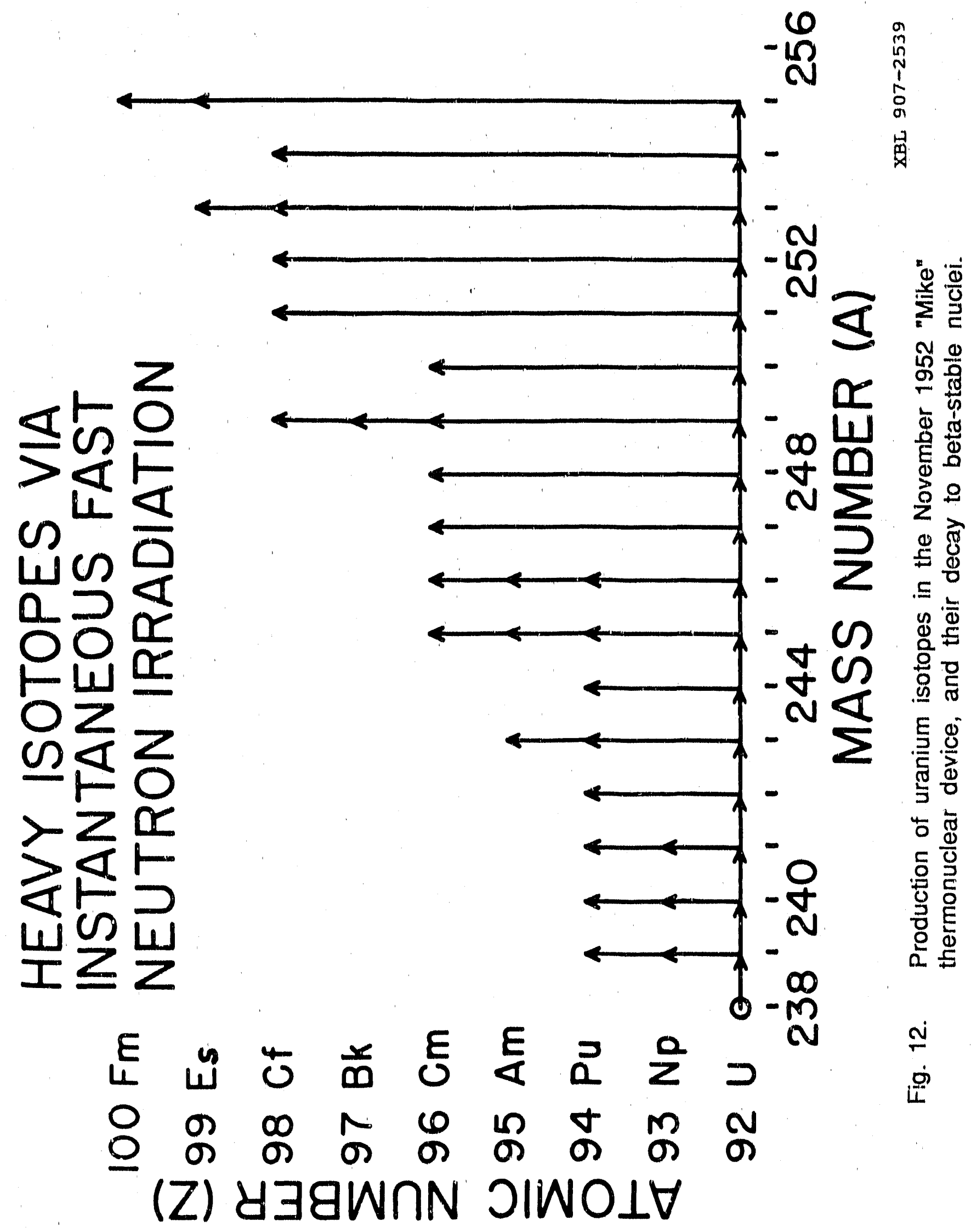




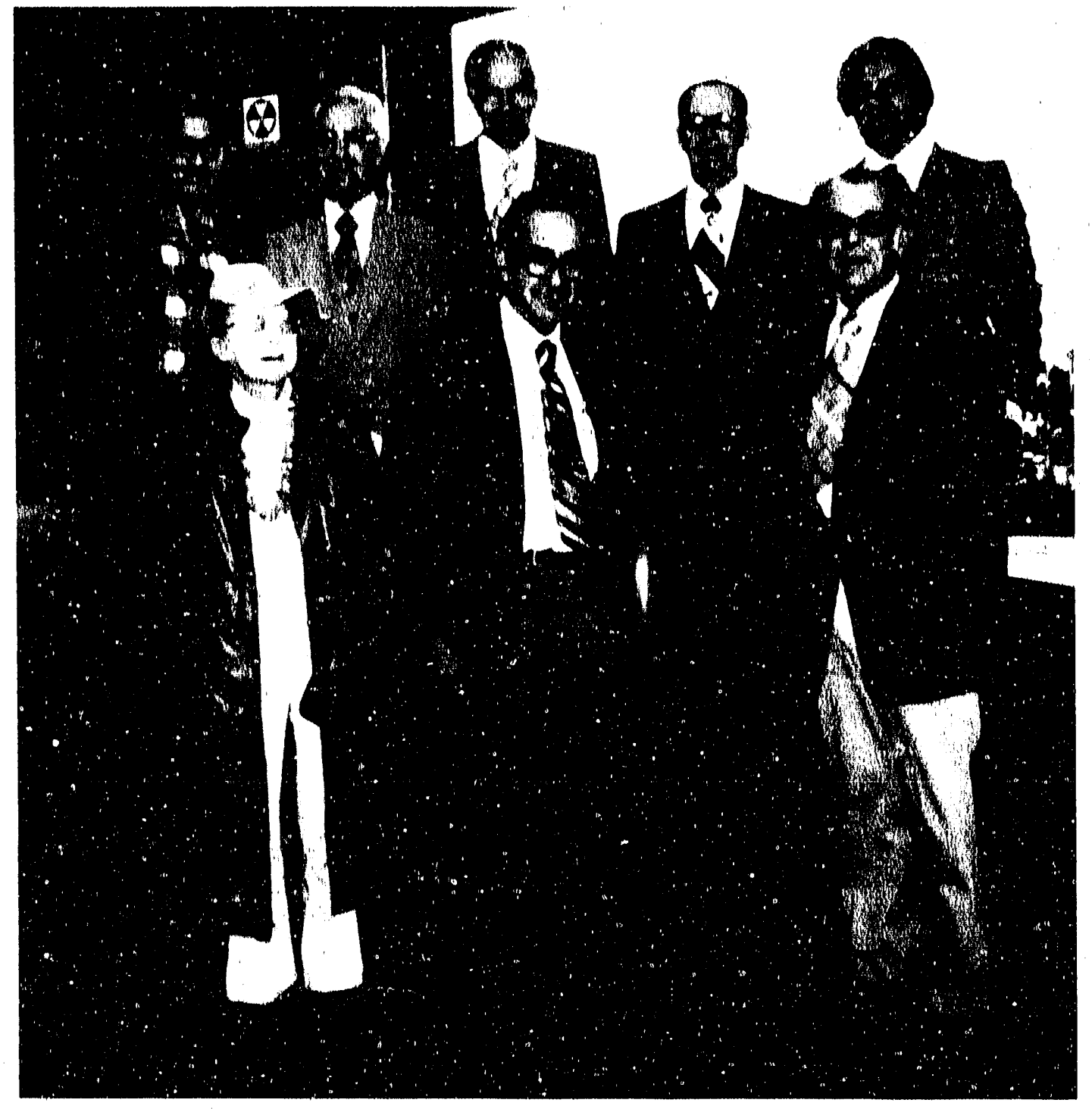

(.i)-discoverers of elements 99 and 100 at sympos ium commemoral iml the 25th anmiversary of their discovery held at L.amence liorkeley laboratory, damary 23,1978 . Front row: lontes smith, Sherman lried, Ciary lliggins. Back row: Al Cihiorso, Rod Spenco, cilem Seabory, Paul rields and form Huizangal.

Fig. 13. 


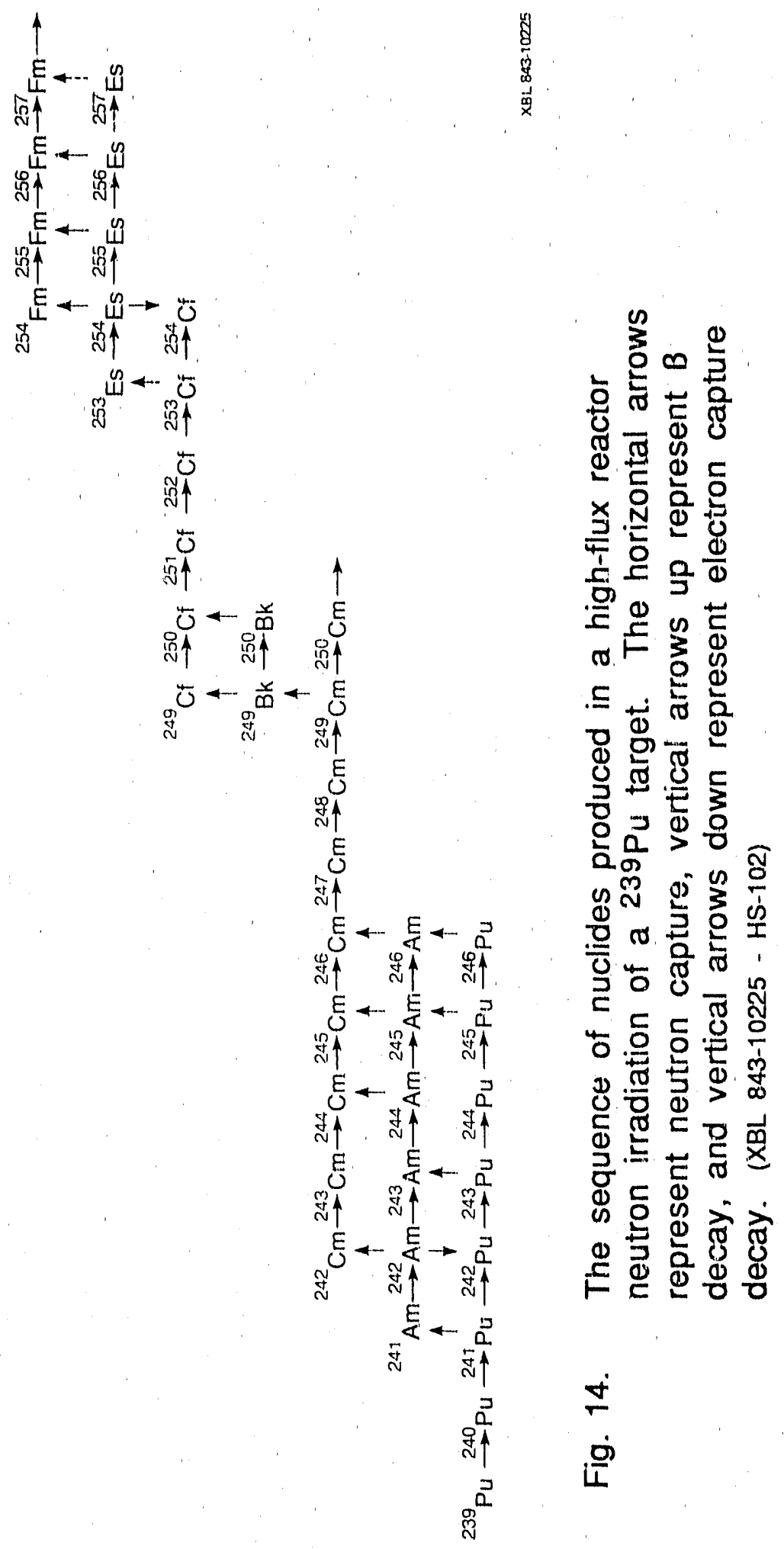




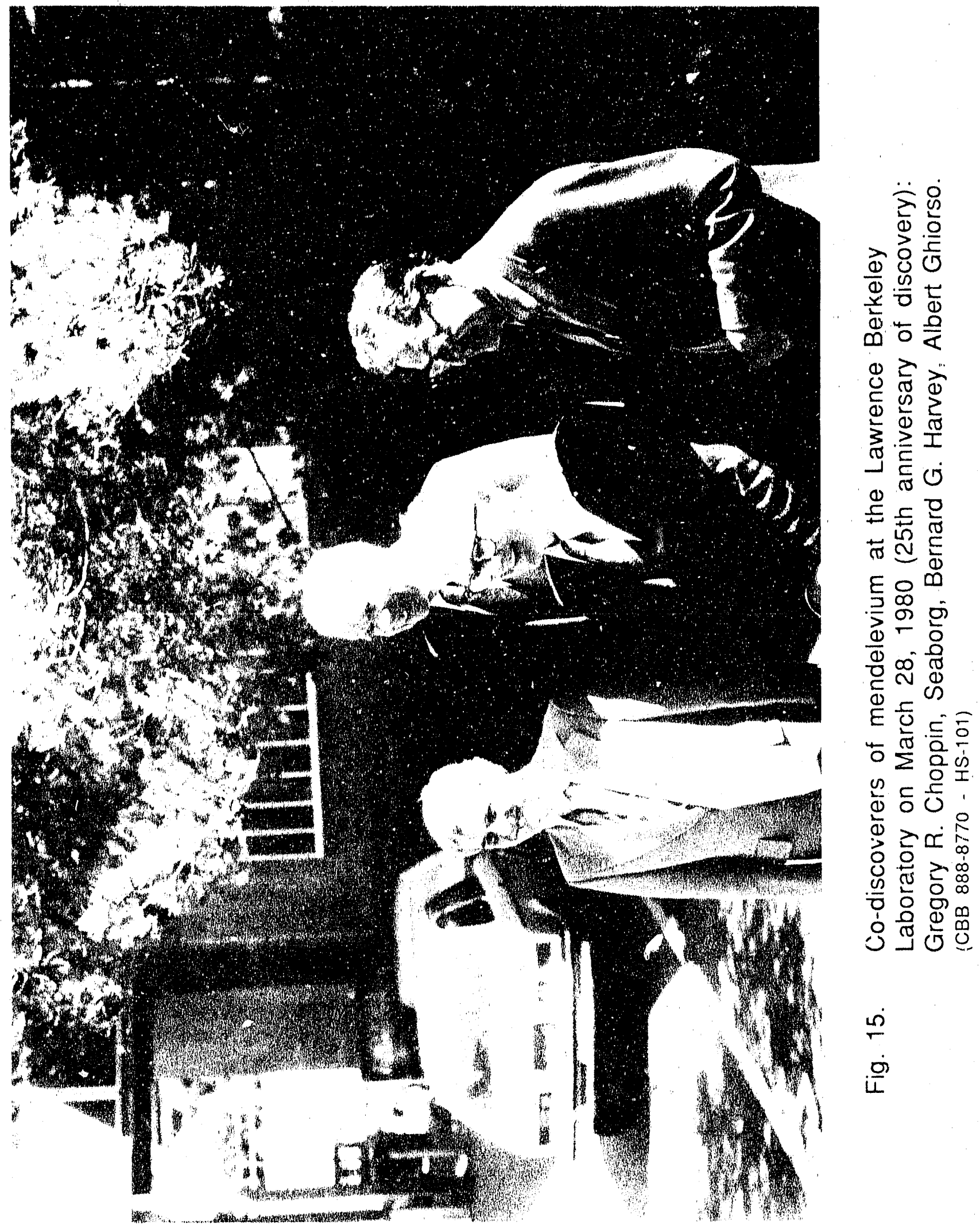






Fig. 16. The co-discoverers of nobelium, HILAC Building, Lawrence Berkeley Laboratory, 1958: Albert Ghiorso, Torbjorn Sikkeland, and John R. Walton (Seaborg absent). 


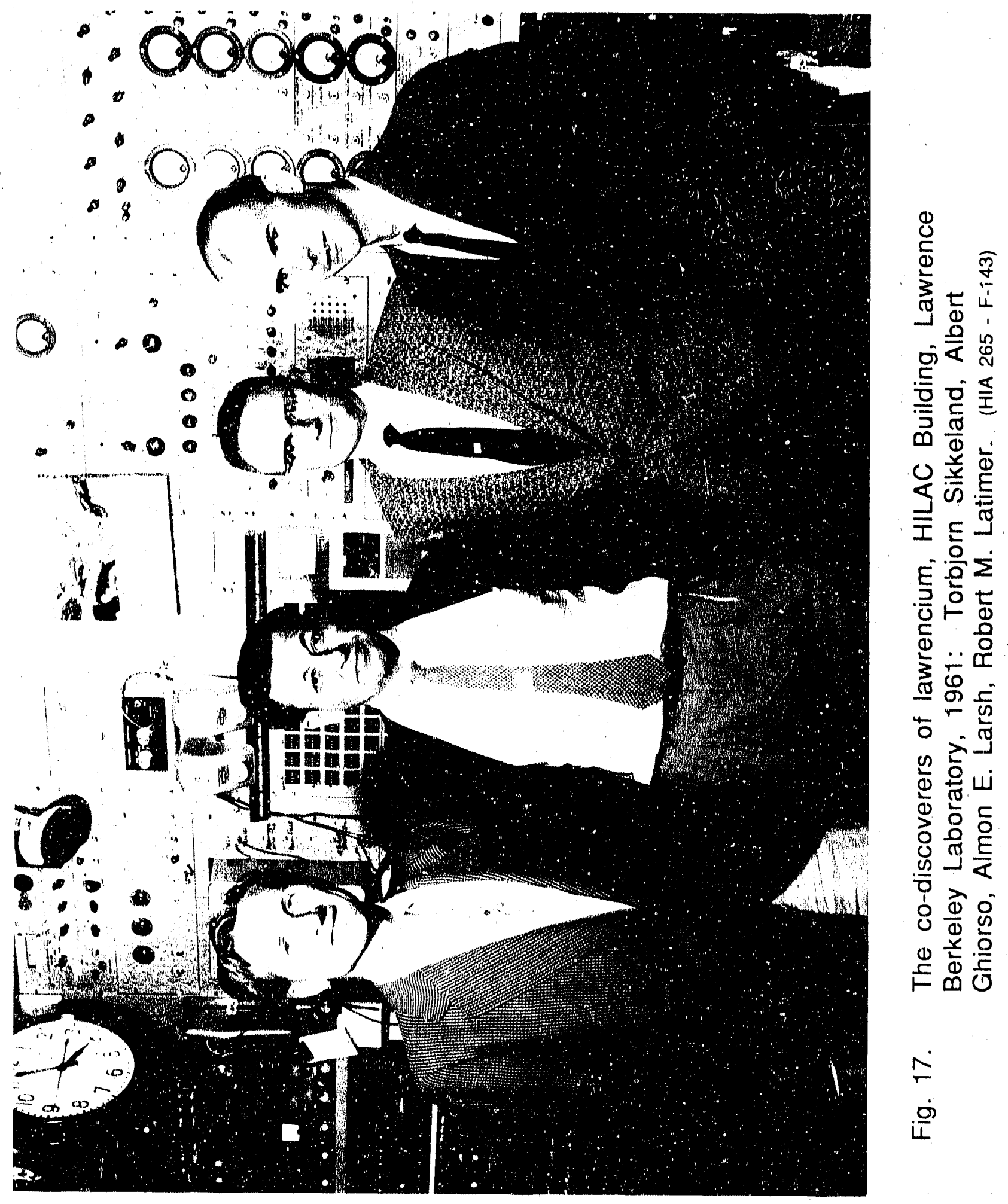




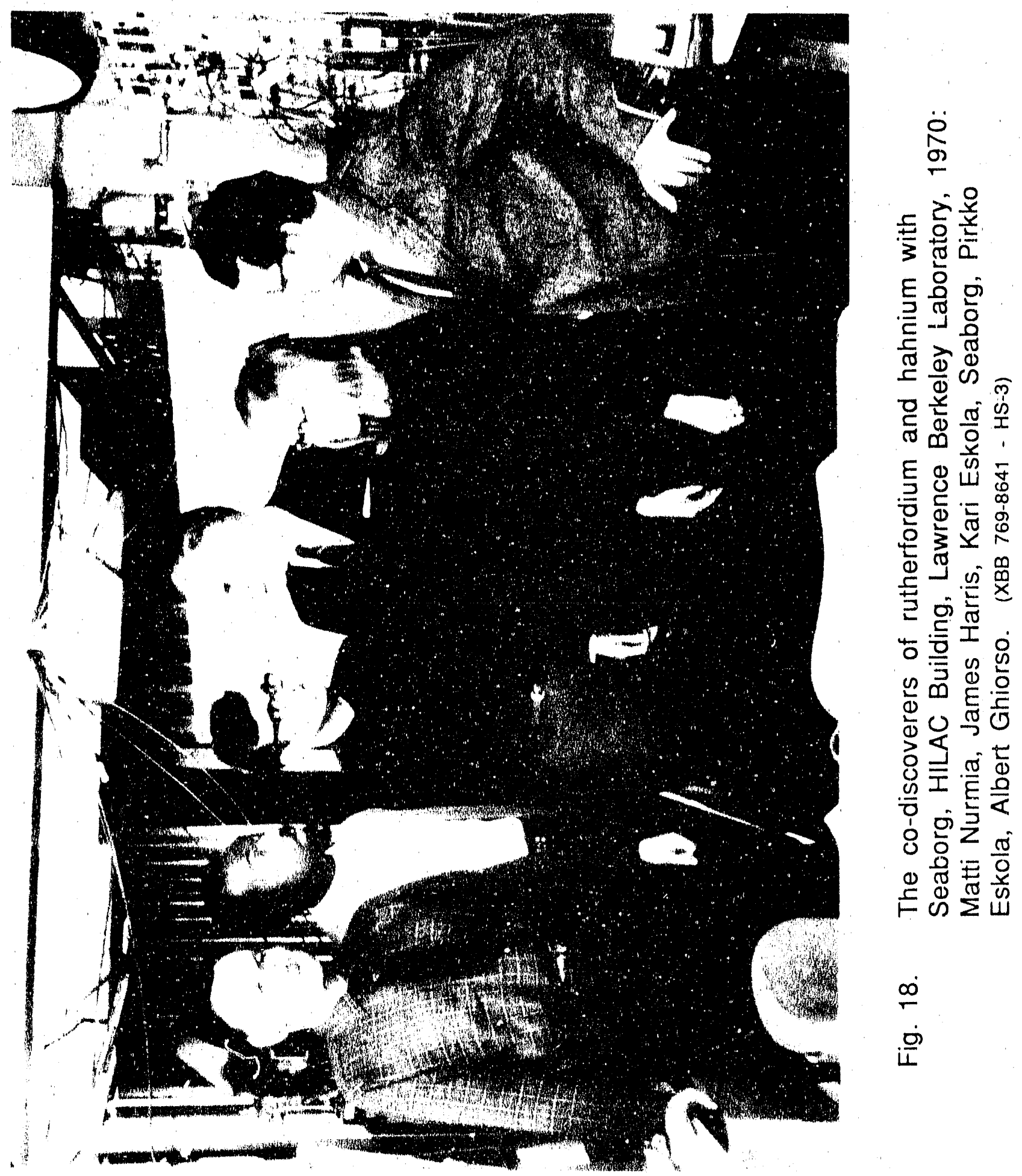




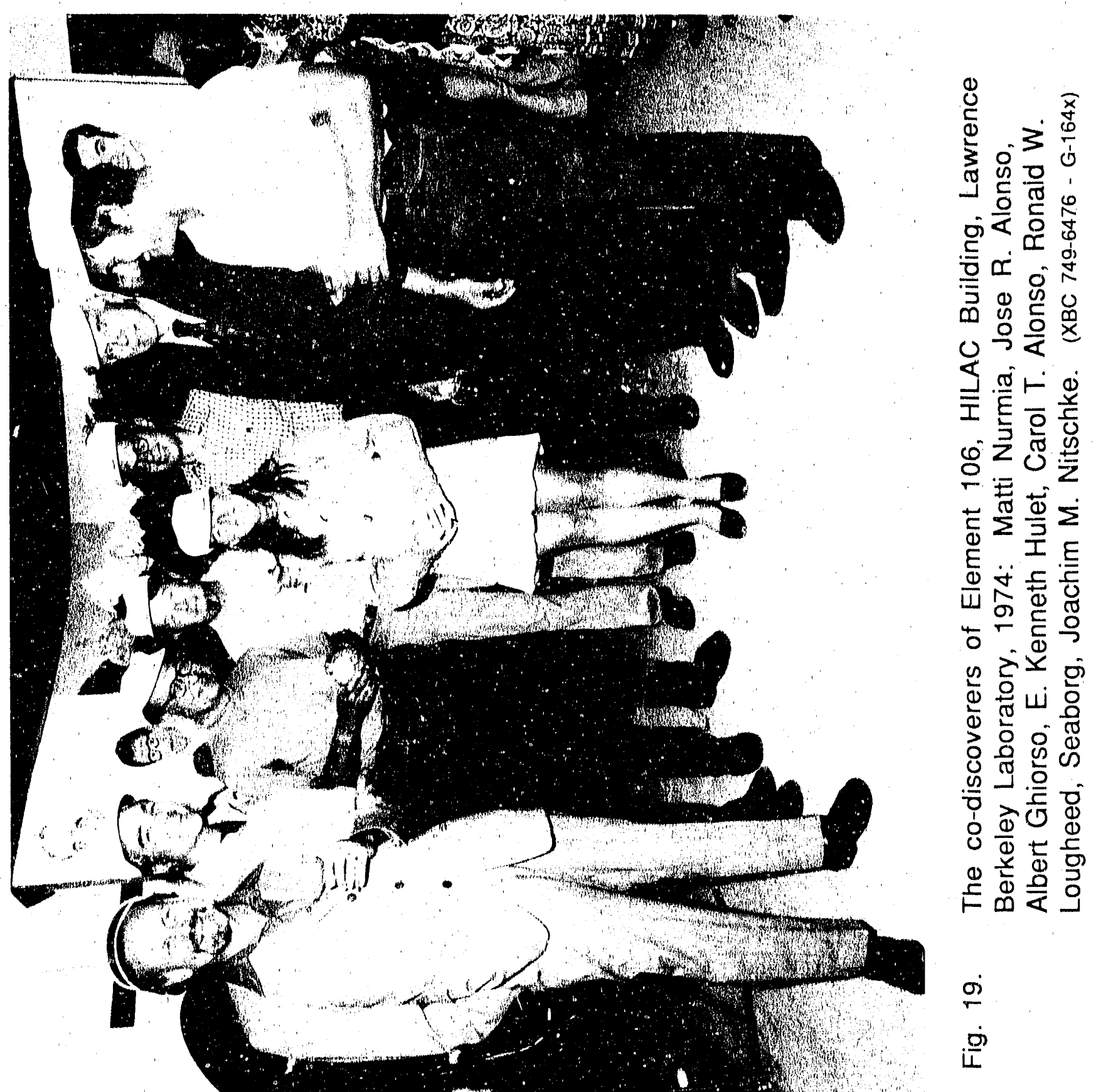




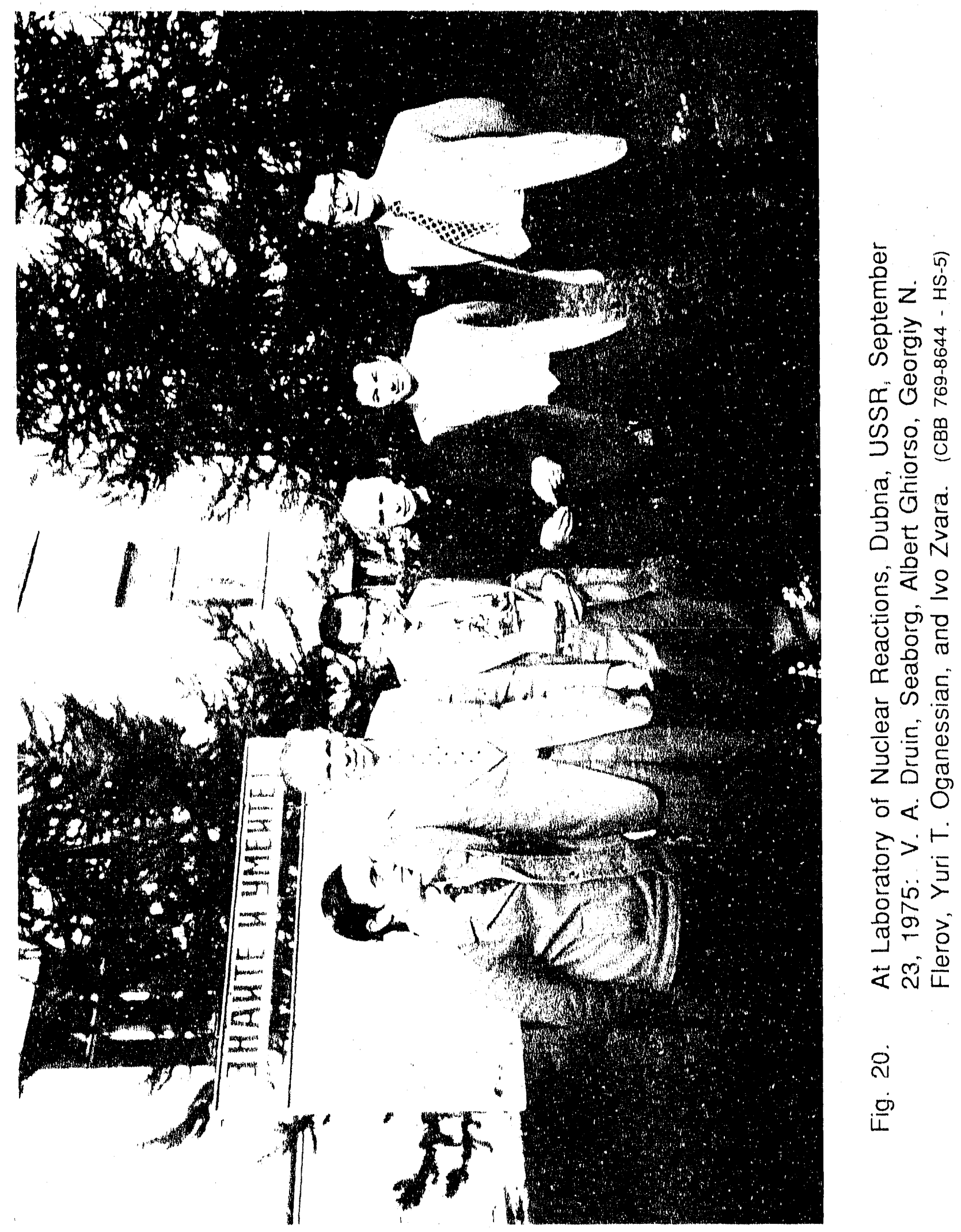



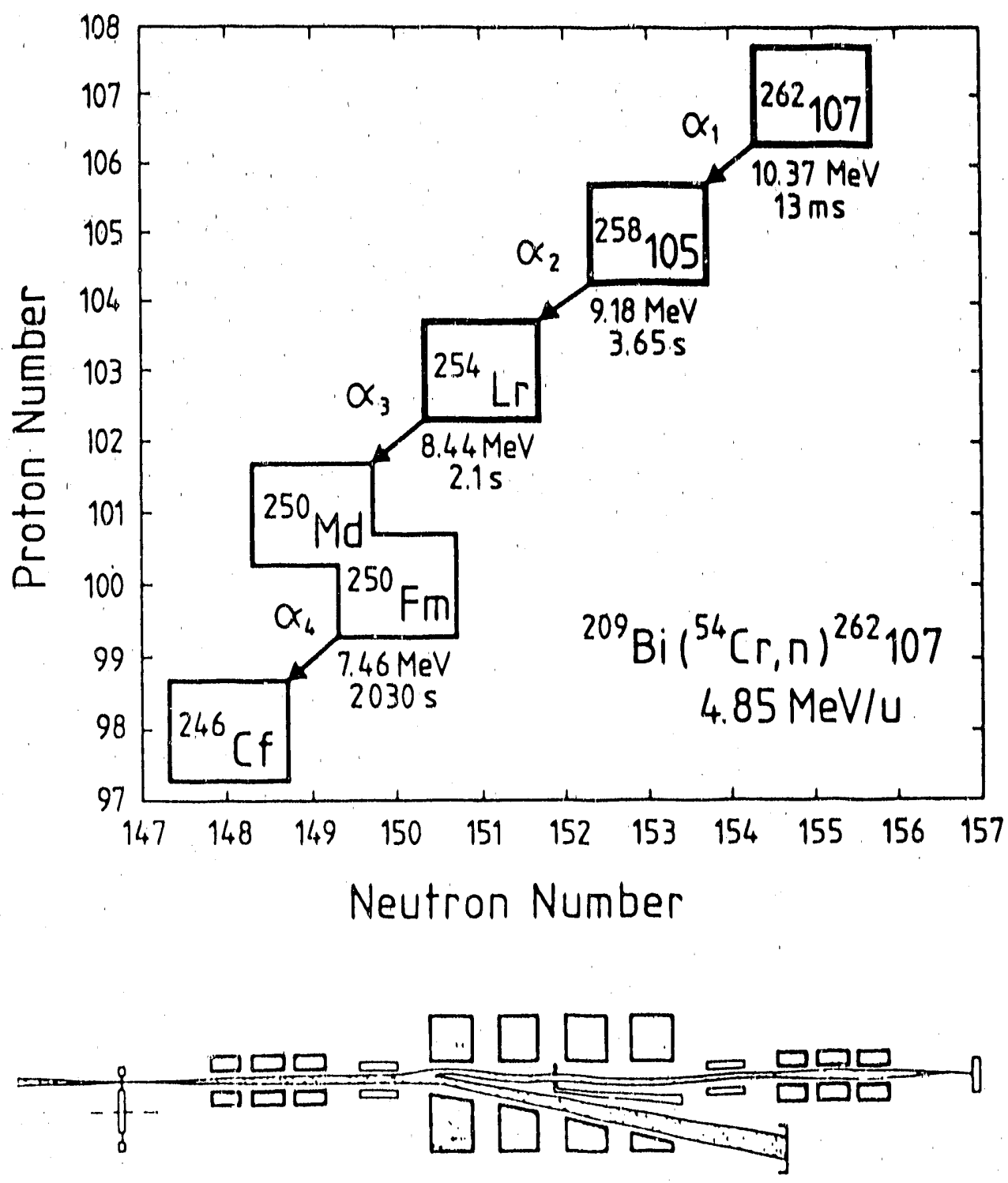

Rotating

Target - Wheel

$$
\begin{gathered}
\text { Velocity-Filler } \\
\text { SHIP }
\end{gathered}
$$

Detector-Array $x-t$ Correlation

Fig. 21. Sequence of time-correlated decay chain observed by
Munzenberg et al. to identify the product of the $209 \mathrm{Bi}$
262107 reaction. (XBL $907-2510$. G-350A)

Fig. 21. Sequence of time-correlated decay chain observed by
Munzenberg et al. to identify the product of the $209 \mathrm{Bi}(54 \mathrm{Cr}, \mathrm{n})$
262107 reaction. (XBL $907-2510$ - G-350A)

Fig. 21. Sequence of time-correlated decay chain
Munzenberg et al. to identify the product
262107 reaction. (XBL 907-2510 - G-350A)

$$
\text { XBL 907-2510 }
$$




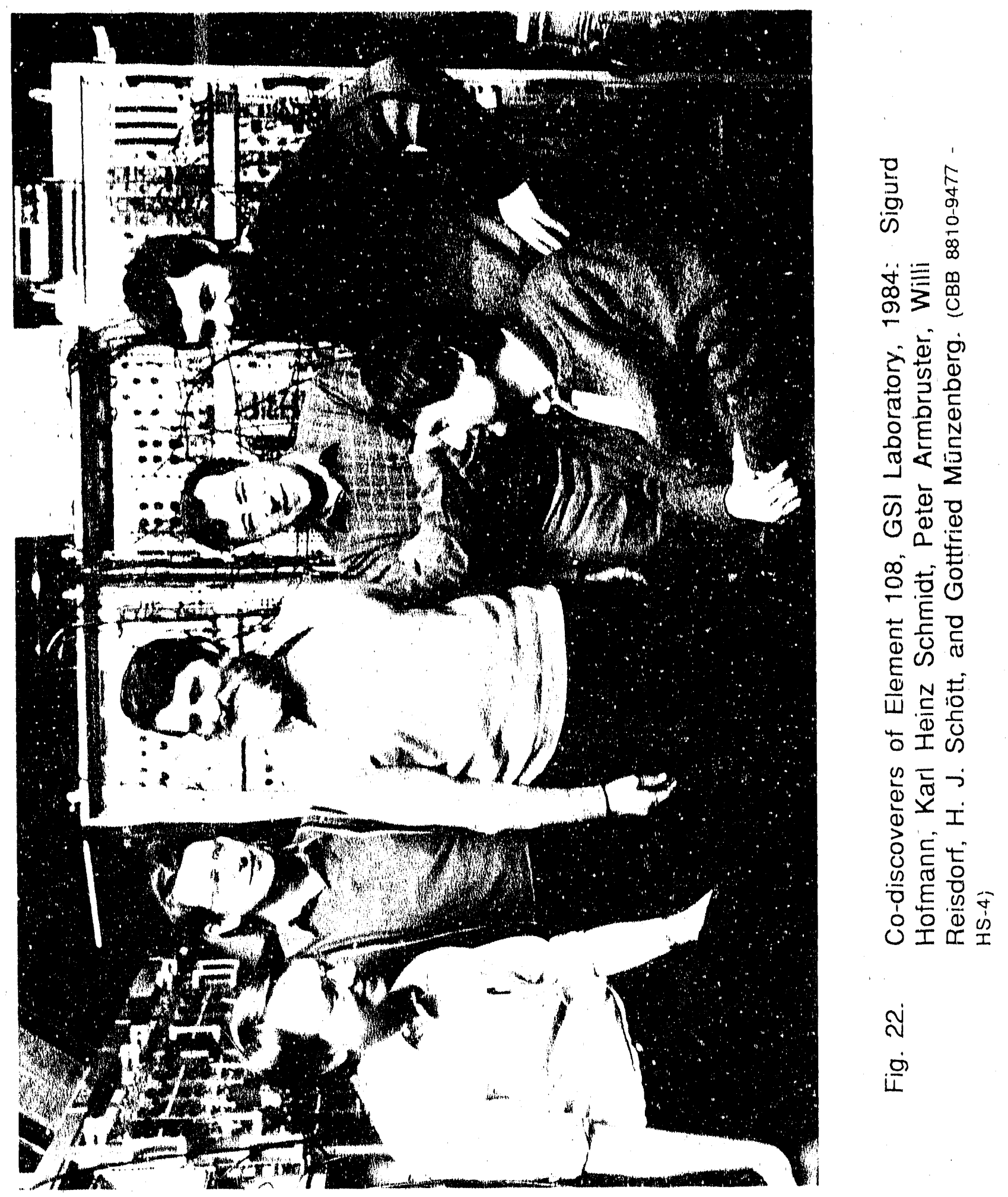




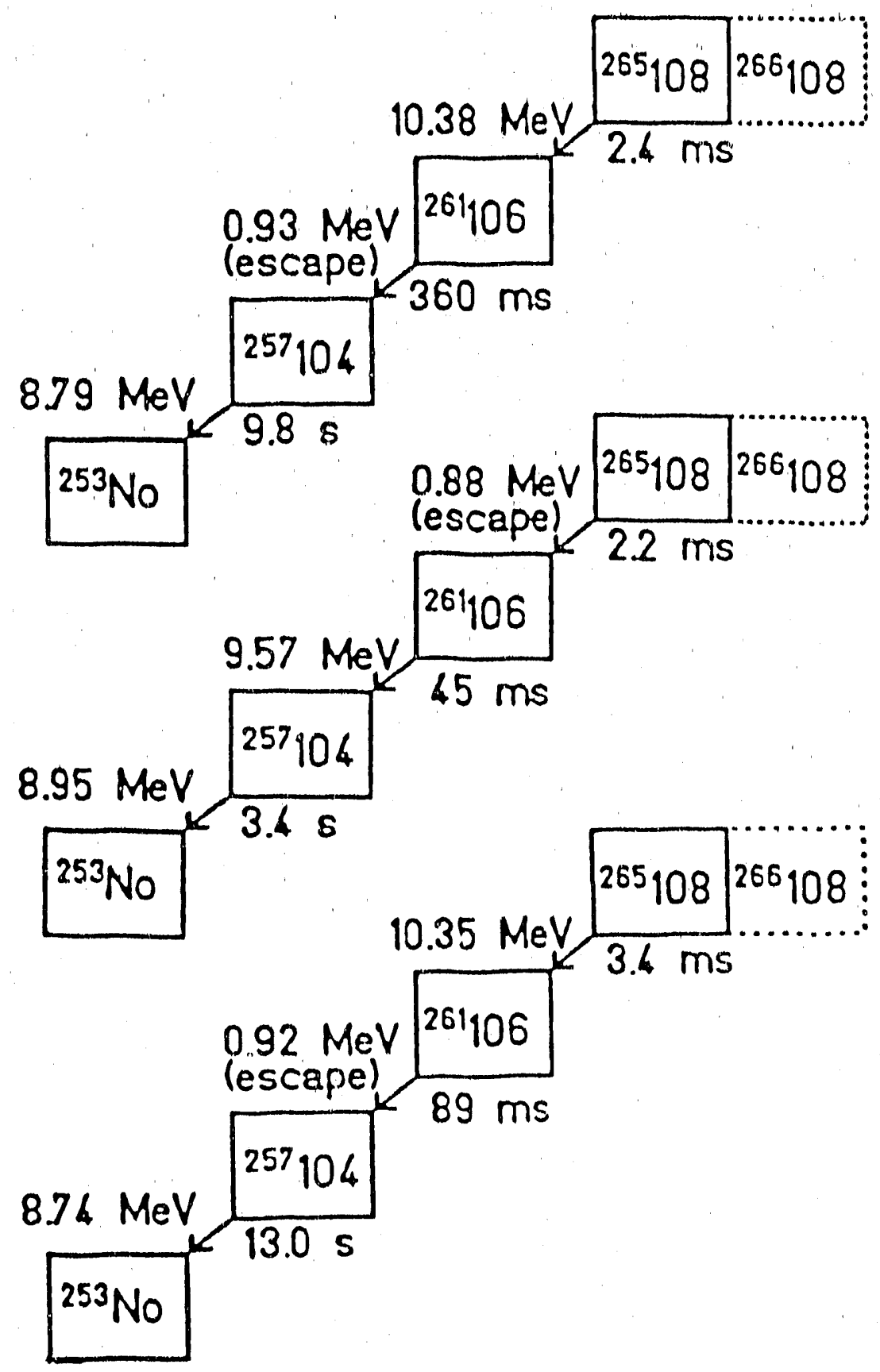

XBI $907-2382$

Fig. 23. The three observed decay sequences associated with Element 108. The nucleus 266108 is assumed to have been the compound nucleus which emitted 1 neutron to form 265108. 


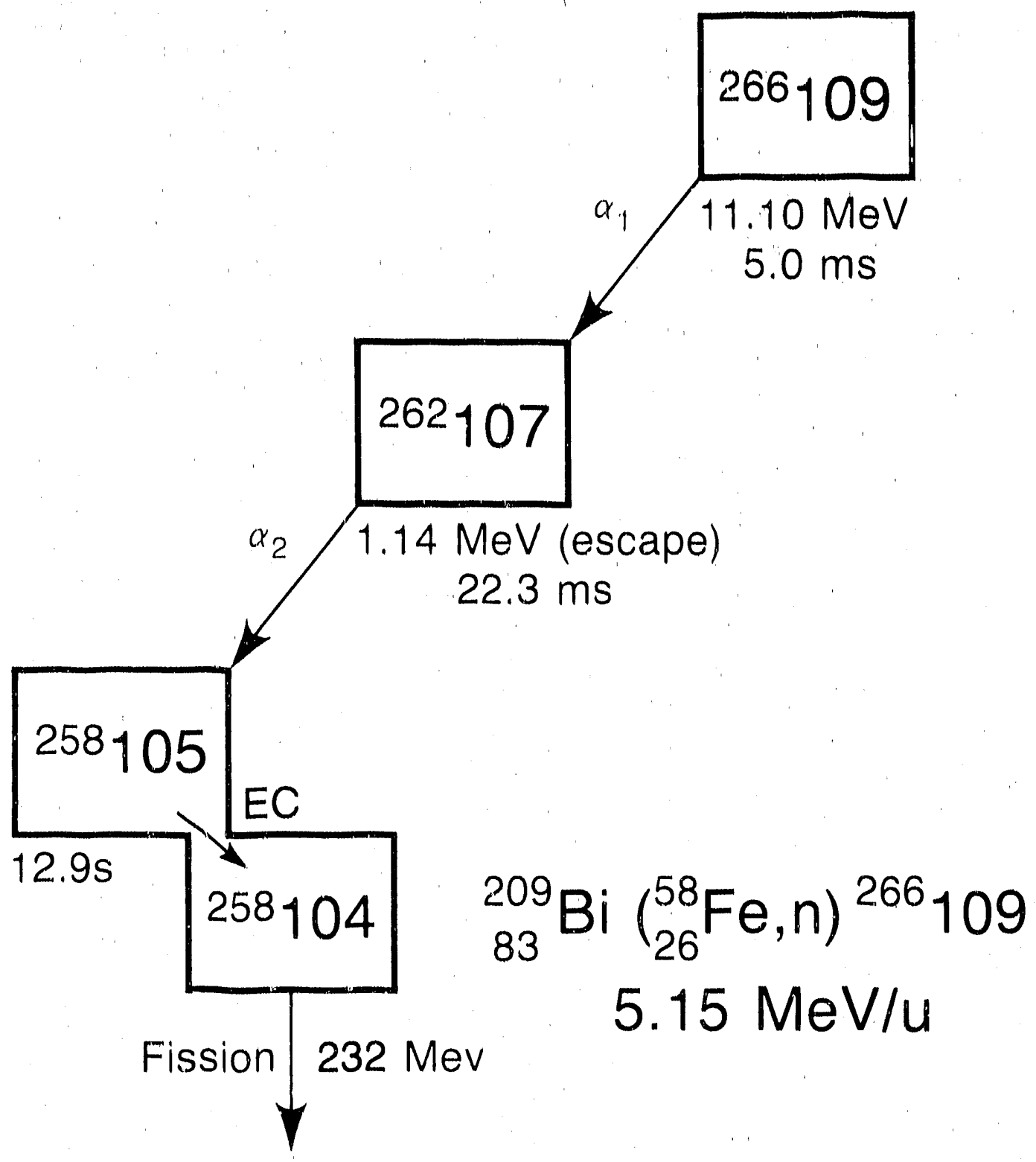

XBL 843.10226

Fig. 24. A possible decay sequence of an event attributed to the reaction, ${ }^{109} \mathrm{Bl}\left({ }^{58} \mathrm{Fe}, \mathrm{n}\right) 266109$. 


\begin{tabular}{|c|c|c|c|c|c|c|c|}
\hline$\sim \stackrel{\Phi}{I}$ & $O \stackrel{d}{Z}$ & $\infty \frac{\swarrow}{4}$ & $\stackrel{x}{ }$ & in $\ddot{x}$ & $₫ 5$ & $\stackrel{\infty}{\equiv}$. & $\begin{array}{l}\infty \\
\stackrel{\infty}{0}\end{array}$ \\
\hline & or & $=\overline{0}$ & 品 & in - & 出走 & $\equiv$ & $\cong$ \\
\hline & $\infty 0$ & $\Phi(s)$ & 屾 & $\tilde{\text { in }} \stackrel{\varphi}{ }$ & \pm 0 & $\stackrel{\varrho}{\varrho}$ & $\overline{0}$ \\
\hline & $-z$ & $\simeq 0$ & $m \frac{n}{4}$ & in $\frac{a}{n}$ & $m \bar{\infty}$ & & \\
\hline & $\infty u$ & $\nabla \bar{n}$ & జు & ம் & $\approx \frac{0}{\square}$ & & \\
\hline & $\pi \infty$ & $9 \overrightarrow{<}$ & $\bar{m}$ & \&5 & $\bar{\infty} \bar{F}$ & & \\
\hline & & & 品 & $\approx 0$ & $\therefore$ 임. & & \\
\hline & & & $\stackrel{\sim}{\mathcal{U}}$ & $\approx \frac{\pi}{4}$ & $\therefore 2$ & & \\
\hline & & & 泣 & 足 & $\sim a^{+}$ & ఏ & \\
\hline & & & $\approx 8$ & $\& \frac{5}{\alpha x}$ & $\tilde{N}$ & g & \\
\hline & & & 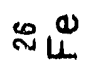 & $\because \vec{x}$ & $\stackrel{0}{\sim}$ & $\stackrel{\infty}{0}$ & \\
\hline & & & $\sim \Sigma$ & $\approx 0$ & $\stackrel{\mathscr{q}}{\mathscr{\alpha}}$ & 흐 & \\
\hline & & & $\lesssim J$ & $\approx \frac{0}{\Sigma}$ & 23 & : & \\
\hline & & & $\approx>$ & $\bar{\sigma} \frac{0}{z}$ & $\approx 0$ & 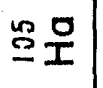 & \\
\hline & & & $\approx F$ & $8 N$ & $\approx \pm$ & $\stackrel{4}{\underline{a}}$ & \\
\hline & & & $\bar{N}$ & s & is & \& U & \\
\hline & $\sigma \stackrel{\Delta}{\infty}$ & $\cong \frac{\pi}{\Sigma}$ & 이 & $\stackrel{m}{n}$ & 䑻 & $\infty_{\infty}^{\infty} \mathbb{x}$ & \\
\hline$-I$ & In & $=\frac{0}{z}$ & ax & 两足 & מై & 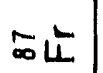 & \\
\hline
\end{tabular}

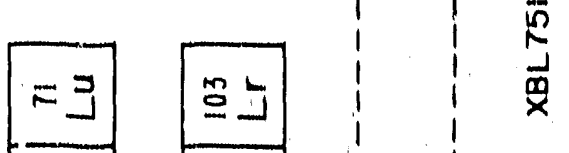


1. McMillan, E. M.; Abelson, P. H. Phys. Rev. 19.40, 57, 1185-1186.

2. Forml, E. Nat. 1934, 133, 888-898.

3. Hahn, O.; Meitner, L.; Strassmann, F. Elemente jenseits Uran. Ber. 1936, $69,905-919$.

4. Noddack, I. Angew Chem. 1934, 47,653.

5. Hahn, O.; Strassmann, F. Naturw. 1939, 27,11.15.

6. MoMillan, E. M. Phys. Rov. 1939, 55, 510.

7. Seaborg, G. T.; McMillan, E. M.; Kennedy, J. W.; Wahl, A. C. Phys. Rev. 1946, 69, 366-367.

8. Seaborg, G. T.; Wahl, A. C.; Kennedy, J. W. Phys. Rev. 1946, 69, 367.

9. Seaborg, G. T.; Wahl, A. C. J. Am. Chem. Soc. 1948, 70, 1128-1134.

10. Kennedy, J. W.; Seaborg, G. T.; Segrè, E.; Wahl, A. C. Phys. Rev. 1946, $70,555-556$

11. Cunningham, B. B.; Werner, L. B. J. Am. Chem. Soc. 1949, 71, 15211528.

12. Seaborg, G. T. Chem. Eng. News 1945, 23, 2190.

13. Ghiorso, A.; James, R. A.; Morgan, L. O.; Seaborg, G. T. Phys. Rev. 1950 , $78,472$.

14. Thompson, S. G.; Ghiorso, A.; Seaborg, G. T. Phys. Rov. 1950, 77, 838.

15. Thompson, S. G.; Street, K., Jr.; Ghlorso, A.; Seaborg, G. T. Phys. Rev. $1950,78,298$.

16. Ghiorso, A. et al. Phys. Rev. 1955, 99, 1048.

17. Ghlorso, A.; Harvey, B. G.; Choppln, G. R.; Thompson, S. G.; Seaborg, G. T. Phys. Rev. 1955, 98, 1518.

18. Fields, P. R.; Friedman, A. M.; Milsted, J.; Atterling, H.; Forsling, W.; Holm, L. W.; Áström, B. Phys, Rev. 1957, 107, 1460.

19. Ghiorso, A.; Sikkeland, T.; Walton, J. R.; Seaborg, G. T. Phys. Rev. Lett. $1958,1,17$.

20. Flerov, G. N. et al. Sov. Phys. 1958, Doklady 3, 546. 
21. Ghlorso, A.; Sikkeland, T.; Walton, J. R.; Seaborg, G. T. Phys. Rev. Lett. $1958,1,18$.

22. Flerov, G. N. P/2299, Proceedings of the Second United Nations International Conference on the Peaceful Uses of Atomic Energy, Geneva, 1958, Vol. 14, pp 151.157.

23. Donets, E. D.; Schegolev, V. A.; Ermakov, V. A. Atomnaya Energiya 1964, 16, 195; Engllsh translation, Soviet Journal Atomic Energy 1964, $16,233$.

24. Ghlorso, A.; Slkkeland, T.; Larsh, A. E.; Latimer, R. M. Phys. Rov. Lett. $1961,6,473$.

25. Donets, E. D.; Schegolev, V. A.; Ermakov, V. A. Aiomnaya Energiya 1965, 19, 109; Engllsh translation, Soviet Journal Atomic Energy 1965, $19,995$.

26. Silva, R. S.; Slkkeland, T.; Nurmla, M.; Ghlorso, A. Inorg. Nucl. Chem. Lett. 1970, 6, 733.

27. Flerov, G. N.; Oganessian, Y. T.; Lobanov, Y. V.; Kuznetsov, V. I.; Druln, V. A.; Perelygin, V. P.; Gavrilov, K. A.; Tretyakova, S. P.; Plotko, V. M. Phys. Rev. Lett. 1964, 13, 73.

28. Zvara, 1.; Chuburkov, Y. T.; Tsaletka, R.; Zvarova, T. S.; Shalayevsky, M. R.; Shllov, B. V. Soviet Journal Atomic Energy 1966, 21, 709.

29. Hyde, E. K.; Hoffman, D. C.; Keller, O. L. Radiochimica Acta 1987, 42, 57.

30. Ghlorso, A.; Nurmia, M.; Harris, J.; Eskola, K.; Eskola, P. Phys. Rev. Lett. $1969,22,1317$.

31. Bemls, C. E., Jr.; Silva, R.J.; Hensley, D. C.; Keller, O. L., Jr.; Tarrant, J. R.; Hunt, L. D.; Dlther, P. F.; Hahn, R. L.; Goodman, C. D. Phys. Rev. Lett. $1973,31,647$.

32. Silva, R.; Harrls, J.; Nurmia, M.; Eskola, K.; Ghlorso, A. Inorg. Nud. Chem. Lett. 1970, 6, 871.

33. Flerov, G. N.; Druin, V. A.; Demin, A. G.; Lobanov, Y. V.; Skokelev, N. K.; Akap'ev, G. N.; Fefilov, B. V.; Kolesov, I. V.; Gavrilov, K. A.; Kharitonov, Y. P.; Chelnokov, L. P. Preprint JINR P7-3808, Dubna, 1968.

34. Ghiorso, A.; Nurmia, M.; Eskola, K.; Harris, J.; Eskola, P. Phys. Rev. Lett. $1970,24,1498$.

35. Bemis, C. E., Jr.; Dither, P. F.; Silva, R. J.; Hahn, R. L.; Tarrant, J. R.; Hunt, L. D.; Hensley, D. C. Phys. Rov. 1977, C16, 1146. 
36. Flerov, G. N.; Oganesslan, Y. T.; Lobanov, Y. V.; LasareV, Y. A.; Tretyakova, S. P.; Kolesov, I. V.; Plotko, V. M. Nucl. Phys. 1971, A160, 181.

37. Zvara, I.; Belev, V. Z.; Korotkin, Yu. S.; Shalayevsky, M. R.; Schegolev, V. A.; Hussonnols, M.; Zager, B. A. Preprint P12-5120, Joint Institute for Nuclear Studies, Dubna, May 15, 1970.

38. Gregorich, K. E.; Henderson, R. A.; Le日, D. M.; Nurmia, M. J.; Chasteler, R. M.; Hall, H. L.; Bennett, D. A.; Gannett, C. M.; Chiadwick, R. B.; Leyba, J. D.; Hoffman, D. C.; Herrmann, G. Radiochimica Acta 1988, 43, 223.

39. Kratz, J. V.; Zimmerman, H. P.; Scherer, U. W.; Schädel, M.; Brüchle, W.; Gregorich, K. E.; Gannett, C. M.; Hall, H. L.; Henderson, R. A.; Le日, D. M.; Leyba, J. D.; Nurmia, M. J.; Gäggeler, H.; Jost, D.; Baltensperger, U.; NalQl, Ya; Türler, A.; Llenert, Ch. Radiochimica Acta 1989, 48, 121-133.

40. Ghlorso, A.; Nitschke, J. M.; Alonso, J. R.; Alonso, C. T.; Nurmla, M.; Seaborg, G. T.; Hulet, E. K.; Lougheed, R. W. Phys. Rev. Lett. 1974, 33, 1490.

41. Oganessian, Y. T.; Tret'yakov, Y. P.; Ilijnov, A. S.; Demin, A. G.; Pleve, A. A.; Tretyakova, S. P.; Plotko, V. M.; Ivanov, M. P.; Danllov, N. A.; Korotkin, Y. S.; Flerov, G. N. JETP Lett. 1974, 20, 265.

42. Demin, A. G.; Tretyakova, S. P.; Utyonkov, V. K.; Shirokovsky, I. V. Z. Fhys, 1894, A315, 197.

43. Oganessian, Y. T.; Demin, A. G.; Danilov, N. A.; Ivanov, M. P.; Illinov, A. S.; Kolesnikov, N. N.; Markov, B. N.; Plotko, V. M.; Tretyakova, S. P.; Flerov, G. N. JETP Lett. 1976, 23, 277; Oganessian, Y. T. et al. Nucl. Phys. 1976, A273, 505.

44. Münzenberg, G. et al. Z. Phys. 1981, A300, 107.

45. Münzenberg, G. et al. Z. Phys. 1989, A333, 163.

46. Münzenberg, G. ế al. Z. Phys. 1984, A317, 235; see also Münzenberg, G. et al. Z. Phys. 1987, A328, 49.

47. Münzenberg, G. et al. Z. Phys. 1986, A324, 489.

48. Oganessian, Y. T. et al. Z. Phys. 1984, A319, 215.

49. Münzenberg, G. et al. Z. Phys. 1982, A309, 89; see also Münzenberg, G. et al. Z. Phys. 1984, A315, 145.

50. Münzenberg, G. et al. Z. Phys. 1989, A330, 435. 
51. Oganessian, Y. T.; Lobanov, Y. V.; Hussonnois, M.; Kharitonov, Y. P.; Gorski, B.; Constantinescu, O.; Popeko, A. G.; Bruchertseifer, H.; Sagaidak, R. N.; Tretyakova, S. P.; Buklanov, G. V.; Rykhlyuk, A. V.; Gulbekyan, G. G.; Pleve, A. A.; Ivanov, G. N.; Plotko, V. M. Preprint D7: 87-392, Dubna, June 1987; Flerov, G. N.; Ter-Akopian, G. M. In progress in Particle and Nuclear Physics; Fässler, A., Ed.; Pergamon Press: Oxford, 1987; Vol. 19, pp 197-239.

52. Münzenberg, G.; Armbruster, P.; Berthes, G.; Folger, H.; Hessberger, F. P.; Hoffman, S.; Poppensieker, K.; Quint, B.; Reisdorf, W.; Schmidt, K. H.; Schött, H. J.; Sümmerer, K.; Zychor, I.; Leino, M. GSI Scientific Report 1986, GSI 87-1, p 14; Münzenberg, G.; Hessberger, F. P.; Armbruster, P.; Hofmann, S.; Schmidt, K. H.; Berthes, G.; Folger, H.; Geissel, H.; Keller, J. G.; Lemmertz, P.; Montoya, M.; Poppensieker, K.; Quint, B.; Schött, H. J.; Zychor, I.; Leino, M. E.; Gollerthän, U. GSI Scientific Report 1985, GSI 86-1, p 29.

53. Ghiorso, A. Private Communication, 1990.

54. Ghiorso, A.; Yashita, S.; Leino, M. E.; Frank, L.; Kalnins, J.; Armbruster, P.; Dufour, J. P.; Lemmertz, P. K. Nucl. Instr, and Meth. 1988, A269, 192.

55. Ezemin, A. V.; Tarabrin, V. A.; Stepantsov, S. V.; Okukhov, Y. L.; TerAkopian, G. M. Dubna Report 1985, P15-85-786.

56. Flerov, G. N.; Ter-Akopian, G. M. In Treatise on Heavy-Ion Science; Bromley, D. A., Ed.; Plenum Press: New York and London, 1985; Vol. 4, p 333; Rep. Prog. Phys. 1983, 46, 817.

57. Herrmann, G. Nature 1979, 280, 543; Seaborg, G. T.; Loveland, W.; Morrissey, D. J. Science 1979, 203, 711 .

58. Oganessian, Y. T.; Bruchertseifer, H.; Buklanov, G. V.; Chepigin, V. I.; Val Sek, C.; Eichler, B.; Gavrilov, K. A.; Gäggeler, H.; Korotkin, Y. S.; Orlova, O. A.; Reetz, T.; Seidel, W.; Ter-Akopian, G. M.; Tretyakova, S. P.; Zvara, I. Nucl. Phys. 1978, A294, 213

59. Armbruster, P.; Agarwal, Y. K.; Brüchle, W.; Brügger, M.; Dufour, J. P.; Gäggeler, H.; Hessberger, F. P.; Hofmann, S.; Lemmertz, P.; Münzenberg, G.; Poppensieker, K.; Reisdorf, W.; Schädel, M.; Schmidt, K. H.; Schneider, J. H. R.; Schneider, W. F. W.; Sümmerer, K.; Vermeulen, D.; Wirth, G.; Ghiorso, A.; Gregorich, K. E.; Lee, D. J.; Leino, M.; Moody, K. J.; Seaborg, G. T.; Welch, R. B.; Wilmarth, P.; Yashita, S.; Frink, C.; Greulich, N.; Herrmann, G.; Hickmann, U.; Hildebrand, N.; Kratz, J. V.; Trautmann, N.; Fowler, M. M.; Hoffman, D. C.; Daniels, W. R.; von Gunten, H. R.; Dornhöfer, H. Phys. Rev. Lett. 1985, 54, 406. 
60. Möller, P.; Leander, G. A.; Nix, J. R. Z. Phys. 1986, A323, 41; Bengtsson, R.; Möller, P.; Nix, J. R.; Zhang, J.Y. Phys. Scripta 1984, 29, 402.

61. Ghiorso, A.; Hoffman, D. C.; Hulet, E. K.; Keller, O. L.; Seaborg, G. T. LEAP-Proposal, Lawrence Berkeley Laboratory Report PUB-5188, 1985.

62. Cwiok, S.; Pashkevich, V. V.; Dudek, J.; Nazarewicz, W. Nucl. Phys. 1983, A410, 254.

63. Hulet, E. K.; Moody, K. J.; Lougheed, R. W.; Wild, J. F.; Dougan, R. J.; Bethune; G. R. FY'87 Annual Report, Lawrence Livermore National Laboratory, Nuclear Chemistry Division, pp 4-9.

64. Schädel, M.; Brüchle, W.; Jäger, E.; Sümmerer, K.; Hulet, E. K.; Wild, J. F.; Lougheed, R. W.; Dougan, R. J.; Moody, K. J. GSI Scientific Report 1987, GSI 88-1, P 14.

65. Ghiorso, A.; Thompson, S. G.; Higgins, G. H.; Harvey, B. G.; Seaborg, G. T. Phys. Rev. 1954, 95, 293.

66. See, e.g., Böning, K.; Patyk, Z.; Sobiczewski, A.; Cwiok, S. Z. Phys. 1986, A325, 479; Sobiczewski, A.; Patyk, Z.; Cwiok, S. Phys. Lett. 1987, B186, 6.

67. Lougheed, R. W.; Moody, K. J.; Dougan, R. J.; Wild, J. F.; Hulet, E. K.; Dupzyk, R. J.; Henderson, C. M.; Gannett, C. M.; Henderson, R. A.; Hoffman, D. C.; Lee, D. M.; Sümmerer, K.; Hahn, R. L. FY'87 Annual Report, Lawrence Livermore National Laboratory, Nuclear Chemistry Division, pp 4.2-4.5. 

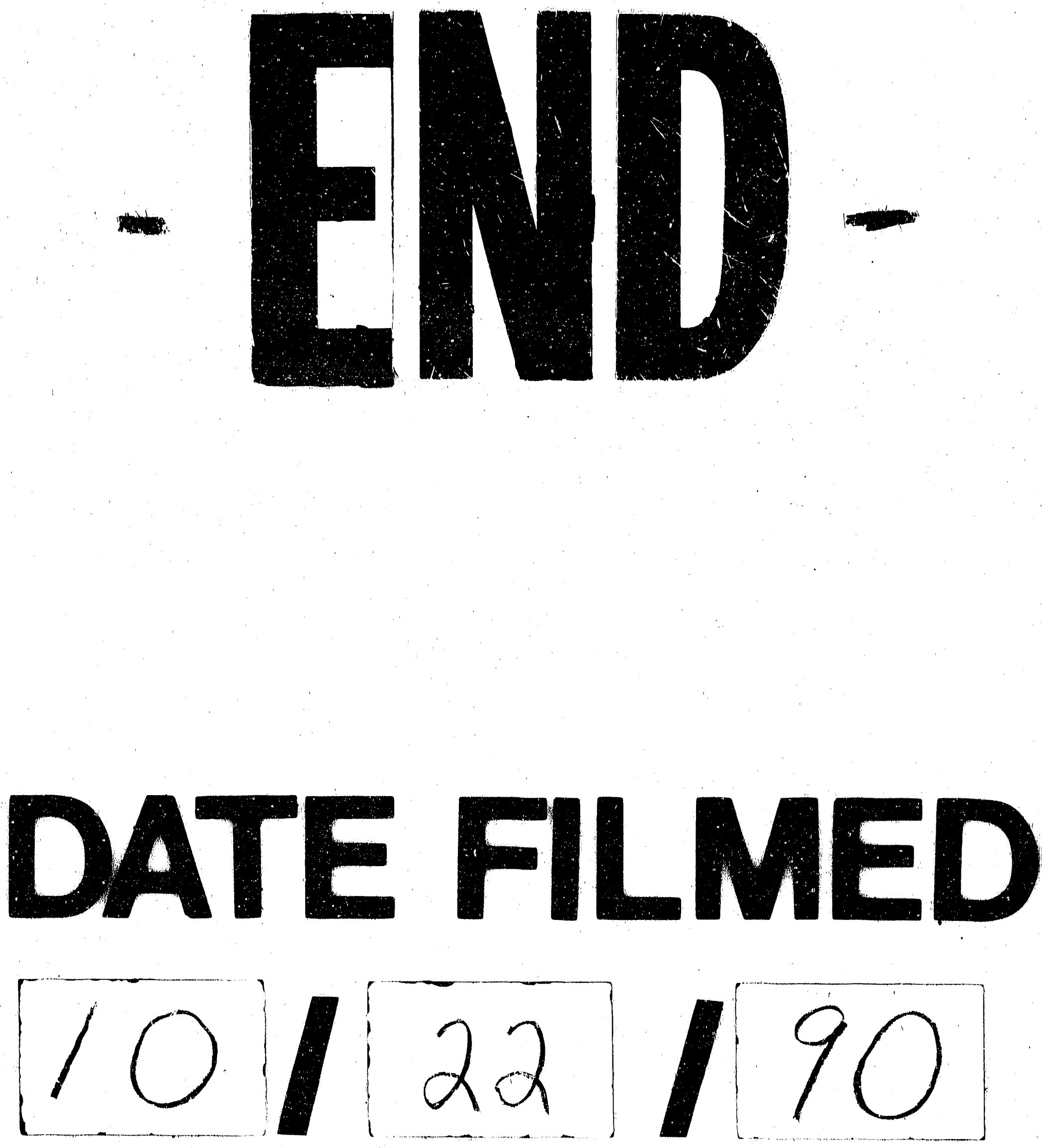
